\title{
Dos inscripciones sobre la fundación de Lara y una sobre sus siete infantes, con un análisis evolutivo de su iglesia parroquial
}

\author{
Esteras, José Ángel; Lorenzo, Josemi; Montaner, Alberto \\ Arquitecto de patrimonio de La Chaux-de-Fonds (Suiza) / \\ Investigador independiente / Universidad de Zaragoza \\ joseangel.esteras@ne.ch; http://orcid.org/oooo-OooI-6385-7798 \\ josemi2o@hotmail.com; http://orcid.org/oooO-OOO2-94I2-85OI \\ amonta@unizar.es; http://orcid.org/oooo-00O2-49o6-4246 \\ Received 25/o5/20I6; accepted o3/o8/20I6 \\ DOI I0.7203/MCLM.3.8254
}

Two inscriptions on the founding of the town of Lara and another one on its seven Infantes with an evolutionary analysis of its parish church

Abstract

This paper studies the controversial topic of the origin of Castile in three epigraphic inscriptions from Lara de los Infantes, from a perspective both philological and historical. The making of the oldest inscription, found in the hermitage of San Julián (and preserved at the Museum of Burgos since the early 2oth century) must date back to the mid-I2th century. It was written with the monastery of San Pedro de Arlanza (Burgos) in mind, since it highlights the preeminence of the former because of its links to count Fernán González. It was also possibly based on a local tradition from Lara now lost to us and of spurious provenance. In the humanistic period, prior to I6oo, a copy of this inscription was made, to which a new one was added, from an unknown source; and both were placed in the western gable of Lara's parish church in the event of a structural alteration to enlarge the temple, thus counteracting the aims of the monasteries of San Millan (La Rioja), Santo Domingo de Silos (Burgos) and the neighboring town of Salas de los Infantes to appropriate the memory of Fernán González and the seven Infantes. The parish inscriptions, then, are also of use to outline a proposal of periods in the structural evolution of this Romanesque church..

KEYWORDS

Epigraphy; Romanesque; forgeries; medieval copywriting; Fernán González; counts of Castile; origins of Castile, Ausina.

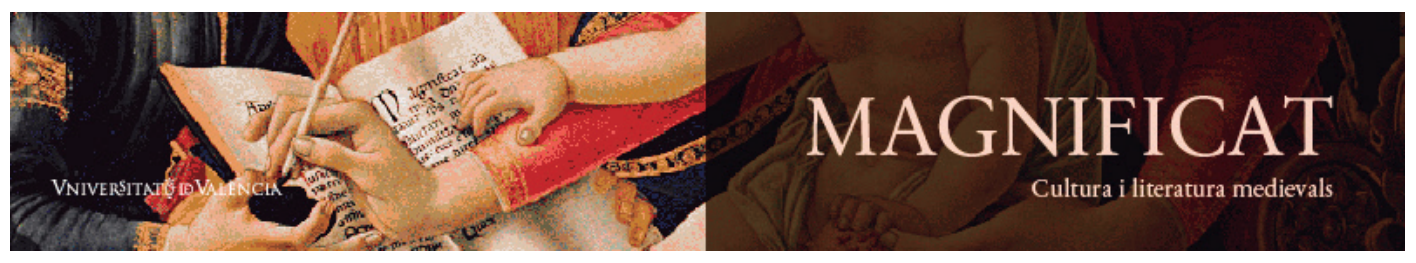

Magnificat Cultura i Literatura Medievals 3, 20I6, 95-16о. http://ojs.uv.es/index.php/MCLM

ISSN $2386-8295$ 
RESUMEN

Se someten a crítica filológica e histórica tres inscripciones epigráficas procedentes de Lara de los Infantes que abordan el discutido tema del origen de Castilla. La factura de la más antigua, encontrada en la ermita de San Julián (en el Museo de Burgos desde principios del siglo XX) se debió de redactar a mediados del siglo XII, en sintonía con el monasterio burgalés de San Pedro de Arlanza, pues resalta la preeminencia de este centro en su vínculo con Fernán González. Posiblemente se basó también en una tradición local lareña hoy perdida y, en todo caso, partiendo de noticias espurias. En época humanística, antes del año I600, se realizó una copia de esta inscripción a la que se añadió otra, procedente de una fuente desconocida, y se colocaron en el hastial occidental de la iglesia parroquial de Lara al tiempo de una reforma estructural para agrandar el templo. Así se contrarrestaban las intenciones de apropiarse de la memoria de Fernán González y de los siete infantes por parte tanto de los monasterios de San Millán de la Cogolla (La Rioja) y Santo Domingo de Silos (Burgos) como de la vecina localidad de Salas de los Infantes. Las inscripciones parroquiales, de este modo, sirven también para esbozar una propuesta secuencial de la evolución constructiva de este templo de origen románico.

Epigrafía; Románico; falsificaciones; escritura publicitaria; Fernán González; condes de Castilla; origen de Castilla; Ausina.

Esteras, José Ángel; Lorenzo, Josemi; Montaner, Alberto. 20I6. ‘Dos inscripciones sobre la fundación de Lara y una sobre sus siete infantes, con un análisis evolutivo de su iglesia parroquial', Magnificat Cultura i Literatura Medievals, 3: 95-160

\section{TABLA DE CONTENIDOS}

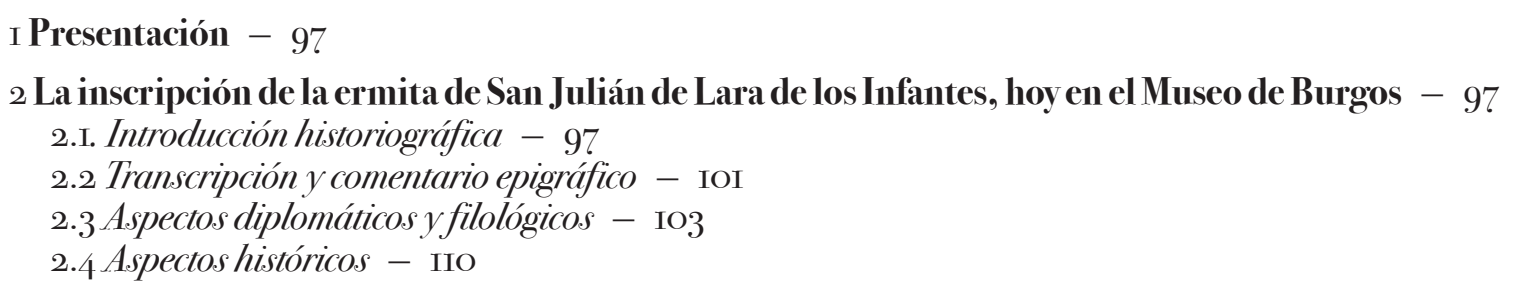

3. La parroquia de la Natividad de Nuestra Señora de Lara de los Infantes. Análisis arquitectónicoevolutivo - II 4

3.I. Periodo románico - II5

3.2. Evolución del templo entre los siglos XIV y XVII - II7

$3 \cdot 3$ Últimas transformaciones importantes en su fábrica: siglos XVIII Y XIX - I22

3.4 Continuidad decorativa: el Románico repintado - I23

4 Las inscripciones de la galería de la iglesia parroquial de la Natividad de Nuestra Señora de Lara de los Infantes - I24

4.I. Introducción historiográfica - I26

4.2 El primer epígrafe, la fundación de Lara - 130

4.3 El segundo epigrafe, los siete infantes - I34

5 Propuesta de explicación - I37

6 Conclusiones - I44

${ }_{7}$ Apéndice. Elementos románicos en la iglesia parroquial de Lara de los Infantes - ${ }_{4} 6$

8 Obras citadas - I 49 


\section{ə*⿻}

\section{Presentación}

En el transcurso del I Congreso Internacional "Los siete infantes de Lara, la historia frente a la leyenda", ${ }^{\mathrm{I}}$ y durante la presentación que acompañaba a la exposición oral de la comunicación de José Ángel Esteras y Josemi Lorenzo titulada "Siete arcos, siete infantes: leyendas en torno al origen de las galerías porticadas románicas” (Esteras-Lorenzo 20I4), proyectamos una imagen que mostraba las dos inscripciones insertas en la parroquia de la Natividad de Nuestra Señora de Lara de los Infantes, de interés colateral al tema que tratábamos, con una sucinta descripción. Alberto Montaner Frutos, ponente en dicho congreso, se interesó en ellas y siguió un rico intercambio por correo electrónico cuyo resultado es este artículo, fruto de la colaboración entre tres investigadores que entreveran varias disciplinas: filología, arquitectura, historia e historia del arte.

Versan, pues, estas páginas sobre tres inscripciones alusivas a Lara y a los siete infantes, procedentes de la ermita y parroquia de Lara de los Infantes, y se amplía la investigación con una reflexión sobre las vicisitudes sufridas por la parroquial de esta localidad desde un punto de vista arquitectónico-evolutivo. La antigüedad del lugar ha hecho que se haya prestado atención a otros testimonios epigráficos de la zona, principalmente romanos, de los que hay una amplia tradición bibliográfica desde finales del siglo XIX. ${ }^{2}$ Estas inscripciones medievales o medievalizantes, por el contrario, han atraído solo ocasionalmente el interés de los investigadores, y de ellas se presentan nuevas lecturas. No es de extrañar la presencia de estos epígrafes en Lara de los Infantes porque la adscripción de los mismos a la localidad de Salas o a la de Lara fue un tema ya controvertido al menos desde la Baja Edad Media. Precisamente en el contexto de la apropiación de la memoria y genealogía de los míticos personajes, tanto entre localidades de la región como en disputa con centros de poder más lejanos, hemos de entender estas reivindicaciones epigráficas.

\section{La inscripción de la ermita de San Julián de Lara de los Infantes, hoy en el Museo de Burgos}

\section{I. Introducción historiográfica}

En el Museo de Burgos se conserva, con número de inventario 348, una inscripción en piedra caliza de dimensiones son $845 \times 400$ (parte central) $\times 120 \mathrm{~mm}$, actualmente expuesta en la sala dedicada al prerrománico (Castillo I977: 33). Su transcripción cuasi-facsimilar, en la que resaltamos en negrita los restos de enlucido claramente presentes en el interior del bisel de distintas letras, es la

I. Salas de los Infantes, I3-I5 de julio de 2OII. Organizado por el Excmo. Ayuntamiento de Salas de los Infantes, dirigió el Congreso Raúl Fernández González, y transcurrieron las sesiones en el Palacio Municipal de Cultura. Después de varias vicisitudes, las actas se publicaron en Les sept infants de Lara: l'histoire face à la légende (Justel ed. 2OI3-I4).

2. Fita (I894), Abásolo (i974: I977 y 2005), Albertos (1980), Mangas-Cortina (i98I), Blázquez (i995), Escalona (I995: 657-728), Núñez-Curchin (2005: 497-500). Geolocalización de Lara de los Infantes: < $\underline{\text { http://tinyurl.com/ }}$ jid25659>. 
siguiente: ${ }^{3}$

\section{$\because I N \bar{N} E$ DN̄I GVNDESAL BVS ET RVDERICVS FECERVNT ISTAM CITTEM SUB REGE DN̄O ADEFONSO IN ERA dсcсc}

I. Transcripción cuasi-facsimilar de la inscripción de la ermita de San Julián de Lara de los Infantes

(c) BY Br Esteras, Lorenzo \& Montaner

La inscripción procede de la desaparecida ermita de San Julián, en Lara de los Infantes ${ }^{4}$ cuyas ruinas protegió en I93I el Gobierno Provisional de la II República, junto a otros cientos de monumentos en toda España. ${ }^{5}$ La Comisión Provincial de Monumentos de Burgos (1926-29: 365) afirmó, en la segunda década del siglo Xx, que la inscripción "se encontraba hasta hace poco tiempo en el plano del altar de la ermita, en que por haber hecho quiebra el edificio se sacó de allí y ahora se conserva en el atrio de la iglesia parroquial" ${ }^{6}$ y reproduce dos fotografías (la ermita, de ciclópeos sillares, y la inscripción), instantáneas tomadas por Photo Club. ${ }^{\text {? }}$ Ya ruinosa cuando se le otorgó protección, hoy tan solo los vecinos recuerdan el lugar donde se asentó secularmente el templo.

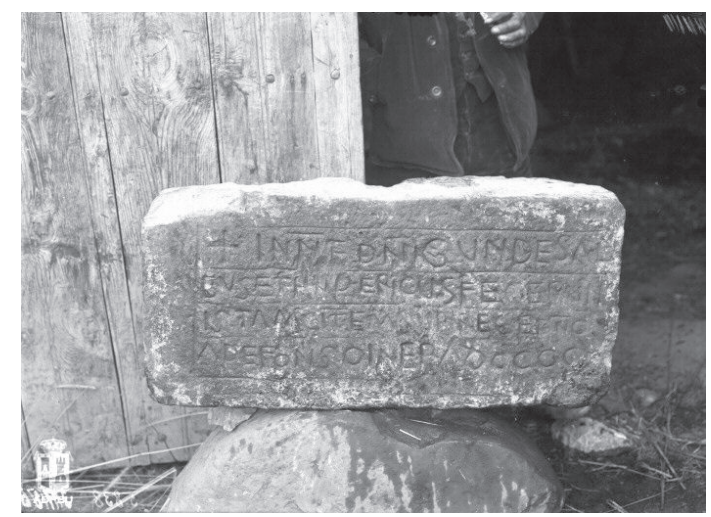

2. La inscripción de la ermita de San Julián hacia I925 @ Photo Club de Burgos, ADPBU-PH-O5838

No obstante, se poseen noticias muy anteriores sobre esta inscripción. El primer historiógrafo en

3. Todas las ilustraciones, salvo indicación en contrario, han sido realizadas o preparadas por los autores.

4. Según consta en el artículo, publicado anónimo, “La ermita de San Julián” (i995). En ella se reproduce facsimilarmente la descripción y planimetría del templo cuando todavía estaba en pie, aunque ya arruinado, publicada en su día por la Comisión Provincial de Monumentos de Burgos (I926-29: 365-67). Debemos esta referencia y una copia de la misma a la amabilidad de Elías Rubio y Ricardo Mazagatos, burgaleses de pro. La descripción más completa de la ermita la ofrece Huidobro (I928), cumpliendo con presteza la promesa de investigar el epígrafe de la ermita, realizado en la misma publicación un año antes: “la lápida hallada en la iglesia de San Julián de Lara, recientemente destruida y hoy conservada en la iglesia principal, de la cual nos ocuparemos algún día” (Huidobro 1927: 24I).

5. "Se declaran Monumentos histórico-artísticos pertenecientes al Tesoro Artístico Nacional los siguientes: [...] Ruinas de San Julián, de Lara”, por Decreto de 3 de junio de I93I, Gaceta de Madrid, .55, de 4 junio (Ministerio de Instrucción Pública y Bellas Artes I93г: II82).

6. Lo mismo se afirma en la Guía ilustrada de la provincia de Burgos, itinerario no. 4 "Burgos-San Pedro de Cardeña.-Los Ausines.-Revilla del Campo-Paules de Lara-Lara de los Infantes-Burgos” (Diputación Provincial I930: s. p.).

7. Actualmente custodiadas en el Archivo de la Diputación Provincial de Burgos: ADPBU-PH-O5836 (ermita); ADPBU-PH-o5838 (inscripción), de las que reproducimos a continuación la segunda, reproducida también por Huibobro (1928) como imagen no. 5, junto a una vista del interior de la ermita, ya arruinada, también realizada por Photo Club. 
dar noticia de la misma fue Prudencio de Sandoval, que, sin embargo, transmitió el texto de la copia que se hizo en un muro de la parroquial de Lara (de la que nos ocuparemos luego), la cual, según se verá, no reproduce fielmente el epígrafe de la ermita de San Julián:

En el año $762[\ldots]$ reedificaron, y poblaron la ciudad de Ausina dos Caualleros, que se dezian Gonçalo, y Frenderico, por mandado del Rey don Alonso de Asturias. Dezia esto vna piedra, que estaua en la hermita de San Iulian, que cae debaxo de la Iglesia parrochial de Lara, al Setentrion, y dizen fue Monesterio: en la qual estauan muchas sepulturas nobles y antiguas, y se hallaron en la peana del altar, donde el Sacerdote pone los pies, quando dize Missa vnas reliquias, que agora están en la parrochia. Las letras de la piedra eran Goticas [= 'visigóticas'], y renouaronse con letras Romanas [= ‘humanísticas'] en otra piedra que se asentó en la pared de la puerta principal de la parrochia ha pocos años, dizen assi.

In nomine Domini, Gundisaluus, \& Findericus fecerunt istam ciuitatem sub Rege Domino Adefonso in Era DCcC. Olim Ausina, modo Lara. ${ }^{8}$

Como puede apreciarse, el cronista regio era perfectamente consciente de la diferencia entre ambas piezas; simplemente, sus fuentes de información no eran suficientemente precisas y creyó que eran idénticas. Su texto fue retomado por numerosos autores, como se verá al tratar de las inscripciones de la parroquial de Lara. Una transcripción independiente, según consigna Emil Hübner (I87ı: IOO, no. 62*), fue incluida en un inédito Memorial de San Pedro de Arlanza preparado por Ambrosio de Morales y del que hizo un extracto el humanista y naturalista ilustrado José Cornide (I734-I803), ${ }^{9}$ de quien lo tomó el propio epigrafista germano para su sylloge, donde lo incluyó entre las inscripciones falsae et suspectae. El texto que ofrece Hübner es básicamente correcto, salvo por la errada transcripción del segundo antropónimo (1. 2), donde lee "federi | cus", forma más semejante a la que trae la lápida de la iglesia parroquial (lo que puede tener su importancia, como veremos luego) y que además incluye una divisoria de líneas inexistente. En general, la división de líneas que marca dicho autor no se corresponde ni con la lápida de San Julián ni con la copia inscrita en la parroquia. Otros detalles son nomine y civitatem sin abreviar, y "gunde | salvus" por GVNDESAL | BvS. Finalmente, señala como variante de Sandoval únicamente la de la fecha, DCCG, en lugar de DCCCC de la inscripción más antigua. Posteriormente, Luciano Serrano tuvo por primera vez acceso al epígrafe, cuando ya estaba en el Museo de Burgos, pero se dejó llevar por la tradición previa, de modo que transcribe "Gundisalvus et Frendericus" y solo abrevia domno. A cambio, ofrece la era correcta, marcando lo que considera ausencia de los últimos numerales de la data "DCCCC...”, y añade (sin percatarse de la existencia de dos epígrafes diferentes) que "Los autores antiguos y modernos añadieron a la misma olim Ausina, modo Lara que no

8. Sandoval (I6I5: 27I [= 283]-84). En la p. 355 repite en parte esta información, pero el final y la transcripción varían un poco: "estaba vna piedra con letras Goticas: las quales se pusieron en vna piedra de la Parroquia, cerca de la puerta al Mediodia, abriéndolas de nueuo dizen assi, como queda dicho. In nominè Domini $\uparrow$ Gundisaluus \& Fendericus, | Fecerunt istam ciuitatem, sub Rege dono Adefonso. | In Era DCcC. olim Mausina modo Lara". Adviértase la diferente lectura del segundo antropónimo y del primer topónimo. En la traducción que acompaña a la primera transcripción adopta también esta última forma: "En el nombre del Señor, Gonzalo, y Finderico hizieron esta ciudad Reynando don Alonso año 762 . Llamose antiguamente Mausina, y agora se llama Lara” (p. 284). Finalmente, no se comprende bien la descripción del emplazamiento "cerca de la puerta al Mediodia", si, como parece, se trata de la ubicación actual, en el hastial oeste del espacio que en su día fuera galería porticada, como se verá después.

9. Hübner remite a “Cornide ms. acad. Matrit. I8, 38”. Se trata del legajo 9-39i8 (olim 9-18-3-38) de la Biblioteca de la Real Academia de la Historia, que incluye, como sección 6a, unas Inscripciones sacadas de un manuscrito existente en la Biblioteca de los Estudios de San Isidoro de Madrid el qual tiene por titulo Memorial de cosas antiguas de Romanos y de San Pedro de Arlanza y de otros: Estos apuntamientos fueron del célebre Ambrosio de Morales (vid. Rodríguez Vila 2005: [93]; Abascal-Cebrián 2005: 359). 
están en el original” (Serrano r935: I, 89, n. I). Sorprendentemente dice lo mismo Pérez de Urbel (I945: I, 249), quien considera auténtica la lápida. Por su parte, el propio benedictino confunde ambas inscripciones, aumentando con su testimonio las imprecisiones, y proporciona un relato del presunto hallazgo del epígrafe de la ermita en un pajar, sin ofrecer fuente alguna:

Esta lápida es un monumento de una autenticidad innegable. Ya Sandoval hizo alusión a ella, y más tarde Flórez, de quienes la sacaron otros historiadores, no sin sospechar de ella; pero ni uno ni otro debieron conocer la inscripción primitiva, puesto que añaden una cláusula que no se encuentra en ella: "Olim Auxina, nunc Lara". La que nosotros reproducimos fué encontrada hace cosa de quince años en un pajar del pueblo de San Millán de Lara, y hoy se conserva en el Museo Provincial de Burgos. Desgraciadamente, está desportillada en la extremidad, donde se lee la fecha. Falta, indudablemente, alguna cifra, pues en la era 900, año 862, no reinaba todavía Alfonso III. Entre las varias lecturas posibles: DCCCCX (año 872), DCCCCXX (882) y DCCCCXL (9O2), prefiero esta última, porque además de explicarse mejor en el espacio desaparecido, se armoniza perfectamente con las circunstancias históricas del momento [...] La ermita de San Julián de Lara, con restos que se remontan a la época condal, se asienta a corta distancia del pueblo de Lara, en dirección nordeste. Es allí, en el plano del altar, donde, según Luciano Huidobro, se encontró la lápida de Gundisalvus y Fendericus, como lee este sagaz investigador de las cosas burgalesas. ${ }^{10}$

La propia información que consta en el Museo mantiene el error en la transcripción del segundo antropónimo, pues, según se indica en su Guía, el epígrafe "hace referencia a la refundación de la ciudad en la Era DCCCCV (año 867), por los Condes Gonzalo y Federico" (Castillo 1997: 33). "Los datos que obran en la ficha catalográfica del Museo, gentilmente cedidos por su conservadora, doña Belén Castillo, difieren de la información antedicha facilitada al público visitante, de nuevo con variantes en el segundo antropónimo y en la fecha. La transcribimos tal cual (las cursivas son suyas):

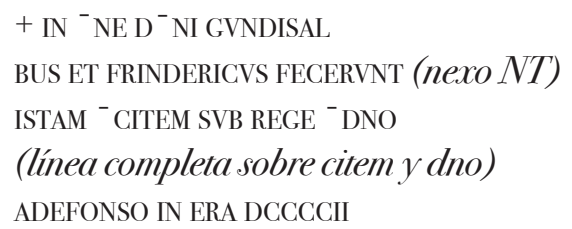

Posteriormente, se ha ocupado de este epígrafe Julio Escalona (1995: $\left.565^{-567}\right),{ }^{12}$ quien, además de un interesante comentario sobre el que volveremos luego, ofrece por vez primera una transcripción correcta, aunque marca con un innecesario interrogante la resolución de la abreviatura $\mathrm{Cl}^{-} \mathrm{T}^{-} \mathrm{EM}=$ CIvitaTEM, mera variante de la conocida abreviatura epigráfica CT. $=\mathrm{CIViTAS}^{13}$, la cual proporciona el único término que cuadra al contexto. Sin conocer este fundamental trabajo, ha ofrecido dos nuevas ediciones Alejandro García Morilla (2ОI2: 22I, Ap. I, y 2OI3: 252-54, no. 5 , y 564, lám. III.2), que, por desgracia, suponen un salto atrás, tanto en la transcripción (FRINDERICVS o FRIDERICVS por el incontestable RVDERICVS, FECERVN $<\mathrm{T}>$ supliendo una $\mathrm{T}$ escrita al extremo del

Io. Pérez de Urbel (i945: I, 249-5o: n. 25). Estas imprecisiones las señaló en su momento Escalona (I995: 565, n. $820)$.

II. Esta información coincide con la expuesta en sala. En consecuencia, la errada datación de la repoblación de Lara en 867 es aceptada por García González et al. (20IO: I50).

I2. Este investigador alude también a ella en Escalona (2000: I6I, n. IO9), pero de modo incidental, pues se centra en la inscripción de la parroquia.

I3. Vid. Cappelli (I979: 445). Se documenta también cītas = ci(vi)tas en el ámbito paleográfico (ibid., 53), aunque es más tardía. En los Anales Castellanos I o Annales Legionenses, § I2, se emplea ĉem por c(ivitat)em: "In era DCCCCLVIII. sic fregerunt cortobesses c\{iuitat\}em Burgus” (Martín ed. 2009: 208). 
renglón), como en la interpretación.

\subsection{Transcripción y comentario epigráfico}

Asentada la lectura, después de la pertinente comprobación in situ, la transcripción puede fijarse así:

IN NOMinE DOMINI GVNDESAL

BVS ET RVDERICVS FECERVNT

ISTAM CIVitaTEM SVB REGE DOmiNO

ADEFONSO IN ERA DCCCC

Su traducción es: "En nombre del Señor. Gonzalo y Rodrigo hicieron [o mandaron hacer] esta

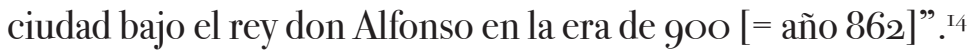

El epígrafe está inscrito en un pautado inciso, formado por cuatro líneas de justificación que delimitan la caja de escritura y cuatro líneas rectrices que determinan otros tantos renglones, quedando en blanco el espacio entre la cuarta línea rectriz y la línea marginal inferior. En el lateral izquierdo, según se mira la parte inscrita, aparecen las únicas marcas de labra formando un listel en su borde superior. La escritura es visigótica epigráfica versal, con predominio del ductus angular en el caso de letras con alógrafos curvos y rectos (A, E, F, N). Constituye una excepción la fecha,

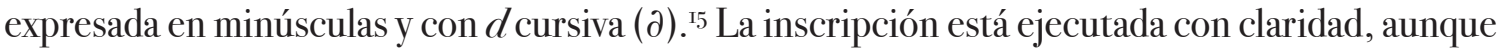
con un trazado irregular, debido a que la altura de los caracteres no se ajusta a la del renglón (situación normal cuando no hay líneas rectrices dobles que determinen la interlínea, $c f$. Favreau I999: 69), resultando un módulo variable y una alineación solo aproximada, que la adscribe al grupo de las que García Lobo (I982: 2I-22) denomina "inscripciones cursivizadas", de las que también es propia la $V$ de influencia uncial, cuyo primer astil tiende a ser curvo y el segundo es recto (vid. García Lobo 1982: cuadro 2). La invocación gráfica responde al usual modelo de cruz griega ${ }^{16} \mathrm{en}$ este caso con remates triangulares (como en la inscripción de Aratorés comentada a continuación). Se utilizan abreviaturas usuales, por contracción, recurriendo como signo abreviativo a la tilde suprarrayada horizontal: $\mathrm{N}^{-} \mathrm{E}=\operatorname{NominE}(1 . \mathrm{I}),{ }^{17} \mathrm{DN}^{-} \mathrm{I}=$ DomiNI (1. I), $\mathrm{CI}^{-} \mathrm{T}^{-} \mathrm{EM}=$ CIvitaTEM (1. 3), $\mathrm{DN}^{-} \mathrm{O}$ $=$ Domino (1. 3). Pese a que es un rasgo muy frecuente de la epigrafía en escritura visigótica, no presenta ni nexos ni letras enclavadas. Carece de signos de puntuación e interpunción, y hay partición de palabras, sin marca alguna, en 1l. I-2: GVNDESAL | BVS.

Los caracteres gráficos de la inscripción son totalmente compatibles con la fecha en ella consignada. Pueden sorprender quizá los numerales, que no adoptan esa disposición cursiva

I4. Sobre el sentido efectivo o yusivo de facere (en el segundo caso, equivalente a fieri iubere ofieri facere), véase abajo la nota $3^{2}$.

I5. Sobre este tipo de numeral, es importante la observación de Santiago (2008: 302): "Se trata de un caso similar al de la D con valor de 50o, utilizada con gran frecuencia en la data de las inscripciones (fig. 7). Comúnmente ha sido considerada una D uncial, pero en realidad no es más que una D capital con tratamiento cursivo y, de hecho, ya es utilizada en papiros desde el siglo I d.C. Mallon atribuye la presencia de estas curiosas formas al empleo de un sistema numeral que se distinguía de las grafías ordinarias, basado y procedente de la vieja cursiva romana" (la figura aludida es la fotografía de una "D capital cursiva con valor numeral" y se reproduce en la p. 303).

I6. Así aparece en una inscripción hallada en el cerro de San Cristóbal (Santo Domingo de Silos), situado a apenas treinta kilómetros de Lara de los Infantes, con data imprecisa entre los siglos VI y VII (Pérez de Urbel r925: 88-89). Sobre su empleo en inscripciones en letra visigótica, vid. Hübner (I87I: XI-XII, y I9OO:I57) y García Lobo (I982: 33); $c f$ además Favreau (i999: 68).

I7. Esta opción, en lugar del más frecuente $\mathrm{NM}^{-} \mathrm{E}$, es típica de la escritura visigótica, según señala Cappelli (I979: 233); cf. además Hübner (1900: 152 ). 
minúscula en la mayor parte de la epigrafía castellano-leonesa. Sí aparecen de modo semejante en una inscripción conmemorativa de la parroquial de San Juan Bautista de Aratorés (lugar del municipio de Castiello de Jaca, Huesca), cuya data aparece como "ERA ḋ́ċéxxxv1111" ${ }^{18}{ }^{8}$ Se trata, no obstante, de una inscripción que, dejando aparte lo problemático de su contenido, presenta una clara influencia carolina ( $a$ minúscula de copete, formas unciales de $\mathrm{D}, \mathrm{M}, \mathrm{R}$ y $\mathrm{U}$, nexo $\mathrm{O}_{2}=o r$, signo especial de abreviatura $z_{4}=$ rum), lo que se compadece mejor con su situación nororiental, pese a lo cual arroja dudas sobre su cronología. ${ }^{19}$ Esto podría sugerir que la fecha de ejecución de la inscripción de Lara se ha de retrasar a un momento en que pudiera dejarse sentir en tierras burgalesas ese influjo carolino, lo que en epigrafía no parece darse antes del siglo XII. ${ }^{20}$ Sin embargo, se trata en realidad de un uso arcaizante, frecuente en inscripciones visigóticas desde principios del siglo vı hasta las vísperas mismas de la irrupción musulmana y que reaparece a fines del siglo IX y llega a mediados del siglo X. ${ }^{2 \mathrm{I}}$

El estado de conservación es bueno, aunque, como ya señaló Escalona, presenta dos alteraciones de la superficie que afectan en cierta medida al texto. La más alta es una concavidad que parece fruto de un golpe y que afecta al segundo cuarto de las dos primeras líneas, haciendo que el segundo antropónimo no resulte totalmente claro, lo que explica en parte las vacilaciones (Federicus,

Findericus, Fendericus, Frendericus, Fridericus) de las transcripciones antiguas y modernas, lo que a su vez permite datar esa mella antes de que se hiciese la copia de la parroquial, en torno a i6oo. La otra es una desportilladura que se extiende con forma triangular por la esquina inferior derecha, con base en el extremo derecho de la segunda línea y vértice en la propia esquina. Este daño afecta a la zona de la fecha, lo que podría significar (aunque, desde luego, no necesariamente) la pérdida del final de la misma, según opina Serrano (I935: I, p. 89, n. I): "Le falta una cifra que no puede ser sino X, V, II y I, acaso XL escrito X’; por ende, su fecha puede correr desde 863 hasta 902”. También Escalona (I995: 566) considera que le faltan una V o una X. Sin embargo, la coincidencia de las copias antiguas (incluida la epigráfica) en no incluir nada tras las centenas hace más probable que la expresión de la data esté completa.

I8. Durán Gudiol (i967: 73-74, no. I). Reproduce su interpretación (problemática en algunos puntos) con una excelente fotografía (imagen 8) la entrada correspondiente a “Aratorés” en García Omedes (2002-I6, http://tinyurl. com/gmgngtg).

I9. No es este el lugar de profundizar en este aspecto, pero adviértase que, aunque con factura mucho más simple, el epígrafe de Aratorés recuerda al estilo gráfico de las inscripciones del siglo XIII en Roda de Isábena, que pueden verse en Durán Gudiol (I967 58-59 -útiles tablas alfabéticas- y 63-Io9 -edición completa, lamentablemente, con escasas fotografías), y en García Omedes (2002-I6: http://tinyurl.com/jlrb53d y ss.). La inscripción de Aratorés podría ser, si no una creación ex novo, al menos sí una copia de dicha época (lo que podría explicar como yerros de ejecución por incomprensión del modelo alguna de sus rarezas textuales).

20. También se encuentra en la lápida fundacional de San Pedro de Montes (en el Bierzo leonés), con la fecha, en capitales, ERA dCCCCXXXIII, es decir, el año 895 (Hübner I87r: 79, no. 245; vid. García Lobo I982: lám. VI.I), y aunque la propia inscripción se fecha con ocasión de la consagración de la iglesia, SVB ERA | NOBIES CENTENA : DECIES QVINA: TERNA : ET QVATERNA, es decir en la era 957, correspondiente al año 9I9, su ejecución parece ser en realidad más tardía (como sospechaba Hübner), quizá del siglo XI.

2I. Según los datos de Hübner (I87т: XIII y ıг6; I900: 153) y, sobre todo, el recuento que nosotros hemos hecho a partir de la primera de estas obras y de Diego Santos (1994). Compárese la fecha de un fragmento de inscripción funeraria en pizarra procedente del condado de Chamoso (Corgo, Lugo), datada III N s zccc = 3 de septiembre de 762 (Rodríguez-Vaquero 2005: II4, no. 3). El ejemplo más reciente del que tenemos noticia es el de ER· dccccLxxxxVI = año $95^{8}$ en San Miguel de Celanova, Orense (Hübner ı87ı: 76 no. 23i). 

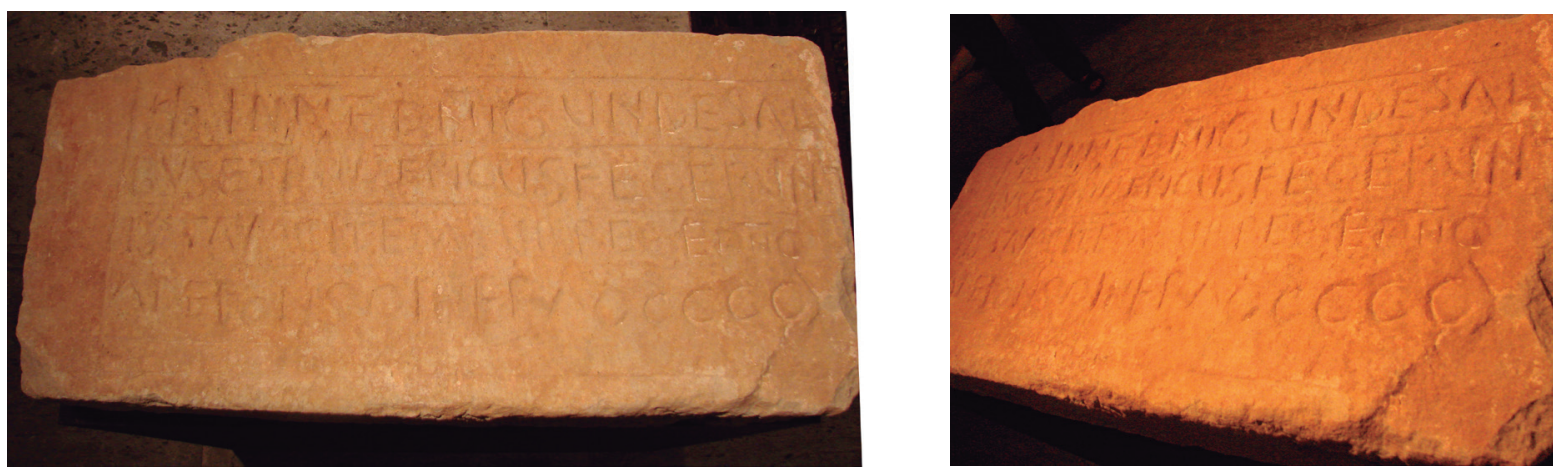

3. La inscripción de la ermita de San Julián en la actualidad, tal como se expone en el Museo de Burgos

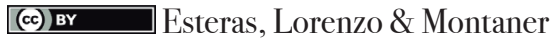

Además la piedra acusa huellas curiosas. Según se la mira de frente, está cortada en el lateral derecho, algo que se intuía en las anteriores fotos, porque se llega a seccionar la línea que enmarca la inscripción, así como el trazo diestro del astil horizontal de la T de FECERVNT, haciendo creer a los transcriptores del Museo de Burgos que había un nexo N-T (véase arriba). Diminutos restos de revoco y mortero, junto a entalladuras en los laterales frontal y posterior, llevan a pensar que posiblemente estuviera enrasada sobre un muro, que se hubiera enlucido en algún momento (dejando los restos de enlucido en el interior del bisel de las letras que hemos resaltado en las transcripción cuasi-facsimilar), y posteriormente se hubiera aislado y hubiera estado colgada, sostenida, por ejemplo, con escarpias de forja que se hincarían en tales huecos por la presión ejercida para sujetarla.

\subsection{Aspectos diplomáticos y filológicos}

Por su contenido, la inscripción de la ermita lareña de San Julián corresponde a la categoría de los tituli honorarï aedificandi. ${ }^{22}$ En este caso no guarda memoria de la erección de un edificio específico o de la construcción o arreglo de una parte del mismo (que son las modalidades más frecuentes), sino de la de una localidad completa, lo que no es infrecuente en la tradición romana, en la que conmemoran una conditio o, más bien, se dedican al conditor coloniae, municipï o, muy raramente, civitatis (De Ruggiero I895-22: II.I, 426-29 y 577). Sin embargo, este tipo epigráfico resulta inusitado en el ámbito medieval (al menos, hasta donde se nos alcanza), ${ }^{23} \mathrm{en}$ el cual las fundaciones conmemoradas suelen ser pías (mayormente templos). El epígrafe se compone de

22. Según los genera titulorum que distingue Hübner (I877: v y VII-VII). En la misma línea, Durán Gudiol (i967: 43), las denomina, con pleno acierto, "inscripciones conmemorativas". Otras designaciones, a nuestro juicio menos precisas, son monumenta aedificationis por parte de García Lobo (I982: 33) y Martínez Tejera (i996: 9o), ya que solo refieren la construcción del templo sin dejar constancia de "la consagración, de la puesta en marcha litúrgica del edificio", aedificationes por Gutiérrez Álvarez (I997: I7, 2I et passim) y monumenta e “inscripciones de construcción” por Salvador (2008: 316 y 322). Más ajustada sería la denominación de monumentum fundationis que le otorga García Morilla (2OI2: 2OI, Ap. I y 2OI3: 252), si no fuese porque el primer término designa en latín un monumento propiamente dicho y no una inscripción (cuya designación clásica es titulus) y porque fundatio es una forma muy rara, en lugar de conditio o erectio.

23. Lo mismo indica Escalona (I995: 566), quien observa con razón que "A primera vista, parece estarse mezclando la terminología habitual de las noticias sobre populationes per iussionem regis características de las crónicas y anales castellanoleoneses con una disposición y una tipología que encajarían mejor en la inscripción votiva de un templo”. 
una invocatio gráfica (el cristus) y otra verbal: "In nomine Domini”, ${ }^{24}$ seguida de la intitulatio, "Gundisalvus et Rudericus", que enlaza con el contenido mismo del epígrafe (equivalente a la dispositio diplomática): 25 "fecerunt istam civitatem", y se cierra con la data crónica, expresada mediante el sincronismo con el regnans: "sub rege Domino Adefonso", ${ }^{26}$ y la indicación del año por la era hispánica: "era DCCCC", equivalente al año 862 d. C.

Frente a lo que ocurre en el plano material, desde el punto de vista formal este epígrafe, que en conjunto responde a los patrones comunes de su época, presenta algunas particularidades dignas de nota. Como acabamos de señalar, el tipo mismo de inscripción fundacional de una localidad carece de parangón en la Edad Media hispánica y la misma ejecución epigráfica cursivizada se adecua mal a la solemnidad esperable de tal actuación pro memoria, cuando menos en caso de ser coetánea del suceso ${ }^{27}$. Salvo el verbo empleado, el resto del tenor no resulta, sin embargo, tan extraño, si se compara con otros tituli honorarï de índole, si no idéntica, al menos parecida. Así, en el que conmemora la refundación de San Miguel de Escalada (León) en 9I4 encontramos la indicación siguiente: "erexit sub valente sereno Adefonso principe", pero el verbo empleado para definir la acción rememorada es diferente, como puede apreciarse en esta frase y en la que señala la nueva construcción del edificio: "demum hoc templum decorum miro opere a fundamine exumdique amplificatum erigitur" ${ }^{28} \mathrm{~A}$ igual verbo se recurre en dos epígrafes de fechas próximas y de tenor muy semejante, el ya citado de San Pedro de Montes: a FVNDAMENTIS MIRIFICE VT CERNITUR DENUO EREXIT, ${ }^{29}$ y el de la restauración de San Martín de Castañeda (Zamora) en 92I: HIC TEMPLVm LITAUIT • | EDIS RVGINAM A FVnDAMine EREXIT (Gutiérrez Álvarez I997: I7-I8, no. 2 y lám. I; vid. también Hübner I871: 87, no. 275, y García Lobo I982, lám. VI.2). En el caso de la notable inscripción fundacional del monasterio de Santa María de Iguácel (en el término de Larrosa, hoy despoblado en el municipio

24. Aunque casi ausente de la epigrafía pleno y bajomedieval, esta invocatio es relativamente usual desde el período tardorromano (por lo general, In Dei nomine) hasta los siglos XI y XII y se corresponde con las pautas formularias de los documentos escritos (Hübner ı871: VIII; Favreau ı999: ı65; Domínguez Sánchez 2008: I82-83). Así una inscripción de la catedral de Toledo, datada el i2 de abril de 587, cuyo comienzo reza "In nomine Domini. Consecrata ecclesia Sancte Marie...” (Canellas i979: I38, no. 33). Especial interés tiene un epígrafe de finales del siglo VII de origen desconocido y atestiguado solo por copias del siglo XVII: "In nomine domini Locuber ac si indignnus abba fecit | et duos coros hic construxit et sacra I te sunt sanctorum Dei eglesiae (!) pridie Idus Ma I [gias (!) era DCC]XXvIIII quarto regno gloriosi domini nostri Egicani” (Rico Camps 2009: 29). Comienzan con la invocación cristológica otras tres lápidas visigodas andaluzas, halladas respectivamente en Guadix, de 13 de mayo de 652, Vejer, de I5 de enero de 674, y Bailén, de I4 de mayo de 69I (Fita I896: 4I6 y 4I9). Del siglo VIII es la mentada inscripción lucense de Corgo, que comienza con esta invocatio (Rodríguez-Vaquero 2005: II4, no. 3). Del mismo modo se emplea la invocación en una inscripción conservada en el Museo de Navarra que procede de la ermita de San Miguel de Villatuerta, de finales del $\mathrm{X}$, aunque discutida. La inscripción fundacional del monasterio de San Salvador de Nogal de las Huertas (Palencia), de Io63, comienza también con la invocación In nomine Domini, al igual que la de Andaluz (Soria), del año III4, que data la construcción de la iglesia (o de su galería porticada) (Josemi Lorenzo ultima una investigación que llevará por título "Dudas sobre el epígrafe fundacional de la iglesia románica de San Miguel en Andaluz (Soria)"), la de San Vicentejo de Treviño (Burgos) o la pizarra que fecha la consagración de la iglesia de Santa María de Castaneda (San Salvador de Cibuyo, Asturias), de ıा66 (Manzanares ı95: 99).

25. García Lobo (I982: 32) denomina a este componente notificación, pero esta corresponde a las fórmulas de divulgación del tipo notum sit, sciant o similares, como bien señala Favreau (I999: I65-66).

26. Aunque este tipo de datación es, en la Edad Media, más propio del registro diplomático, no es en absoluto desconocido en el epigráfico; vid. Francisco Olmos (2004: I2I-22). Veremos algunos ejemplos a continuación.

27. Subrayó ya este aspecto Escalona (I995: 566): “llama especialmente la atención el contraste entre el carácter solemne del acto y su pobre ejecución”.

28. Transmite este epígrafe, datado "Era DCCCC L” y hoy perdido, Risco (I786: 3II); vid. también Hübner (I9oo: IO7, no. 469) y García Lobo (i982: 64-65, no. 8).

29. Véase la nota 20. En la expositio del mismo epígrafe se recoge que San Fructuoso COMPLVTENSE CONDIDIT | CENOBIVM. 
de Jaca, Huesca), que también guarda ciertas semejanzas con la nuestra, los verbos empleados son fundare para el templo tomado en abstracto y fabricare para la fábrica edilicia de la iglesia:
HEC EST P P ORTA DOMINI VN | DE INGREDIVNT | VR FIDELES IN D | OMVM DOMINI QVE ES | T ECGLESIA IN HONORE | SanCtE MARIE FVN | DATA : IVSSV SAN | TIONI COMITIS | EST FABRICATA | | VNA CVm SVA CONIV | GE NOMINE VRRACGA : IN $\mid$ ERA Ta CENTESIMA $X^{\mathrm{a}} \mid$ EST EXPLICITA : REG $\mid$ NANTE REGE SANTIO | RADIMIRIÇ IN ARAGONE | QVI POSVIT PRO SVA $\mid$ ANIMA IN HONORE SanCtE | MARIE: VILLA \NOmiNE LA/RROSSA | VT DET EI DOMINUS REQUiE ETE[RNA] \AMEN/30

El mismo fundare se emplea en algunas expresiones conmemorativas, a menudo incluidas en epitafios, ${ }^{31}$ mientras que en otras ocasiones se encuentran (a)edificare tabernacula, templum, aram o capellam; ${ }^{32}$ condere templum; $; 3$ construere aulam, coros palatium o basilicam. ${ }^{34} \mathrm{Al}$ verbo facere empleado en la inscripción lareña se recurre al recordarse la construcción de algún elemento concreto: ${ }^{55}$ IPSE Fecit ISTE ARCVm | A SVO CABO IACE (epitafio del abad Sabarico en San Miguel de

30. "Esta es la puerta del Señor, por donde entran los fieles en la casa del Señor [ $c f$. Sal II7, 20; Eccl 4, I7 y Ez II, I], que es una iglesia fundada en honor de Santa María, construida por mandado del conde Sancho, junto con su mujer llamada Urraca. Fue acabada en la era de iıIo [= IO72], reinando en Aragón el rey Sancho Ramírez, quien entregó por su alma en honor [ $o$ a la honor] de Santa María la villa llamada Larrosa, para que Dios le conceda descanso eterno. Amén”. La inscripción se completa con esta interesante indicación de autoría: SCRIPTOR HARVM | LITTERARVm NOmInE AÇENAR | MAGISTER HARVm PictVRARVm NominE GALINDO GARCEÇ. Vid. Arco (i942: 292), Durán Gudiol (i967: 32-33, no. 4), García Omedes (2002-I6: http://tinyurl.com/j2v95zf). Transcribimos directamente de las excelentes imágenes contenidas en esta página web. Las plecas corresponden en este caso a la segmentación en sillares de cada línea, mientras que las porciones encerradas entre barras oblicuas están interlineadas y las letras entre corchetes resultan prácticamente ilegibles (en especial la N), por lo que Del Arco leyó “requietet eum”, lo que carece de sentido, y García Omedes “requiem eum”, pero el pronombre es incorrecto y no completa el espacio disponible. La restitución de "requiem eternam" se debe a Durán y es conforme a la liturgia de la misa de difuntos: "V/. Requiem aeternam dona eis, Domine, et lux perpetua luceat eis”. Sin embargo, no es posible situar en el área epigráfica las dos emes de la desinencia de acusativo ni se aprecian los correspondientes signos de abreviatura, por lo que transcribimos sin ellos (cf. In HONORE en 1. I, aunque esto se deberá más bien a una confusión en el régimen de la preposición que a un fallo de declinación, $c f$ la misma expresión, esta vez posiblemente correcta, en la l. 2).

3I. Vid. Hübner (I87ı: 28, no. Ioo, y 87, no. 276, y 1900: 48-49, no. 363), Diego Santos (1994: 37, no. 6.b) y Gutiérrez Álvarez (I997: 3I, no. 25 y 38, no. 40).

32. Vid. respectivamente Hübner (I87I: 33, no. II5; 84, no. 259; 89, no. 284, cf. 31, no. Io9), Diego Santos (i994: IOI-Io3, no. 74) y Durán Gudiol (i967: 98, no. 65). La no. 259 de Hübner, mejor en Diego Santos, ibidem, 37-38, no. 7, (cf. además sus inscripciones no. I79, pp. I74-75; no. 228, p. 206, y no. 240, pp. 2I4-I6). Nótese el uso de aedificare y facere en referencia a las acciones del abad Vicencio y Pascasio en la inscripción del tímpano que apareció formando parte de la mampostería con que se levantó la moderna sacristía de la parroquia de San Juan Evangelista de Villavés (Merindad de Valdeporres, Burgos), fechada en la era MCLXXXXVII = año II59: [...¿ima?] RC [¿̈II?] | EDIFICAVIT AB[BAS ¿VIN?] | CENCIVS BASILICAM [ISTAM IN HONO] | REM SAnCTi IOAnIS EVAnGELISTE DE PRON[IS REB]VS | VT FACVLTATIBVS SVIS VT SIT IN REMISSIO | NEM OMNIVm PeCCatORVM SVORVM ATQVE | OMNIVM FIDELIVM VIVVORVM SI | MVL ET MORTVORUM VT MEREAN | TVR SINE FINE IN CONSORCIO IVTORVM AMEN $\mid$ IN ERA $\bullet \mathrm{M} \bullet \mathrm{C} \bullet \mathrm{L} \bullet \mathrm{X} \bullet \mathrm{X} \bullet \mathrm{X} \bullet \mathrm{X}: \mathrm{V} \bullet \mathrm{II}^{\bullet}$ PASCHASIVS FECIT (ed. Hernando Garrido et al. I99596: 237; los subrayados son nuestros). En este artículo se traen a colación otros epígrafes burgaleses contemporáneos, también de nuestro interés por las fórmulas escogidas, a pesar de que el epígrafe estudiado, en opinión de los autores, "carece de testimonios paralelos en el ámbito burgalés".

33. Vid. Diego Santos (ı99: 37, no. 6.a; ı49, no. I37 y 226, no. 253) y Gutiérrez Álvarez (ı997: ı8-ı9, no. 3).

34. Vid. respectivamente Hübner (I87ı: 55, no. I72; 8ı, no. 253; $c f .35$, no. Ir9), Durán Gudiol (i967: 99, no. 68) y Diego Santos (r994: 208no. 233.a). Añádanse las indicaciones de conclusión consummare edificium o perficere templum que documenta Hübner, ibidem, 3, no. I; 44, no. I35 y IO4, no. $96^{*}$. Esta última también en Diego Santos, ibidem, 37, no. 6.d.

35. A veces, como en los casos citados a continuación, con un complemento directo que identifica expresamente el objeto realizado, aunque lo más frecuente es encontrar fecit sin más, con referencia implícita al soporte epigrafiado (un pórtico, unas pinturas, un bien mueble), que es el objeto que se elide. Sirva de ejemplo la inscripción (año Io8I) 
Escalada, de I059, vid. García Lobo I982: 69-7O, no. I2, y lám. X), FECIT : FIERI : HAnC : SC | ALAm LAPIDEAm (epígrafe conmemorativo de la construcción de la escalera principal de San Juan de la Peña, Huesca, por el abad Pedro de Setzera o Sedzère, en I3or, vid. Durán Gudiol ı967: 95, no. 53), FACTVM : FVIT : HOC : POR[TALE] (lápida conmemorativa de las conquistas y muerte de Alfonso IX de León y de la erección de la Puerta de Olivares en Zamora, de I23O, Gutiérrez Álvarez, I997: 4O4I, no. 44 y lám. XXVII.B). La misma expresión consta en una inscripción de la iglesia parroquial de Rebolledo de la Torre (Burgos), que remata con esta afirmación: FECIT ISTUM PORTALEM IOANES MAGISTER PIASCA, aludiendo a la galería porticada del templo.

No obstante, facere se encuentra también aplicado a edificios completos: FECIT BASELICAm en la iglesia de San Vicente de Serrapio, en Asturias, construida por el presbítero Gagio en 894 (Diego Santos I994: I88, no. I98); FAC| TA ECLesia en la parroquial, también asturiana, de San Julián de Gramedo (Cabranes), de 946 (ibid., 249, no. Add. i2); HANC AVLAM Vv[LFILA? FECiT] en la lápida de la Cripta de Santa Leocadia de la catedral de Oviedo, ca. 905 (Hübner I871: II5, no. 484; Diego Santos I994: 39-4O, no. 8), HANC FECIT SEDEM - QVAM PRIMO FECERAT AEDEM en los hexámetros leoninos del sepulcro de Ordoño II ( $†$ 924) en la catedral de León; $3^{36}$ FECIT | ECCLESIAM HANC en el epitafio de Alfonso V de León († IO28) en el panteón leonés de San Isidoro (Hübner, I87I: IO4, no. 88*, que lo considera posterior; Arco I954: 55), FECIT ECLEISIA [M] (sic) en la parroquial de Pobladura de Aliste (Zamora), erigida por el presbítero Martín en Io82 (Gutiérrez Álvarez 1997: 2I, no. 8 y lám. IV.A), FVIT FACTA [...] | HEC DOMVS en la parroquia de San Miguel de Teberga (Asturias) en IO48 (Hübner I871: 87, no. 276) y, en fechas más tardías, en las dos laudas del convento de Santo Domingo de Zamora: la de su promotora, doña Eulalia, que HANC DOMUm FIERI FECIT y la de su ejecutor, fray Gil, quien IsTAm DOMUm FECIT, hacia I26o (ibid., 50-5I, no. 64-65). También aparece feci( $t$ ) en la inscripción conmemorativa de la restauración de San Miguel de Escalada en Io88, pero allí tiene como objeto restauratione $\langle m>$, aunque, por lo demás, posee una constitución muy semejante a la del epígrafe de Lara:

\section{+ SVB XPistI | NOMinE PETRVS ET EPiscopus DE SanctE MARIE FECI | RESTAVRACIONE IN SanctI MIKAELI DIE V F XVII KaLenDas | IVLI ERA MiLlessimA ET CXXVI REX | ADEFONSO SVERO ALVARIZ $\mathrm{ABAS}^{37}$}

Si se compara este ejemplo con el de la ermita de San Julián se advierte que en el segundo, además de aparecer el problemático facere,$^{38}$ se echa de menos un topónimo identificativo, puesto que el uso del mero deíctico tiene sentido en las inscripciones en que, por estar sitas en o junto al elemento cuya construcción se conmemora, y por carecer de un nombre propio, el demostrativo es la única manera de identificar el referente: iste arcu, hanc scalam, istum portale, hanc aulam,

presente en un canecillo de la galería de la iglesia de San Miguel de San Esteban de Gormaz: IVLIA | nUS MA | GISTER | FECIT | ERA | MC $\mid$ XV | IIII (Lorenzo 2009). No es este el lugar para entrar en la discusión, quizá sin posibilidad de ofrecer una respuesta general, sino casuística, sobre el significado de fecit en tales contextos. La disyuntiva estriba en saber cuándo se alude al artífice de una obra o cuándo al comitente que la encarga.

36. Hübner (I871: 78, no. 242), quien señala que el epitafio es, en conjunto, posterior, "sed cum prior pars posset sane antiqua esse, titulum loco suo non movi”.

37. "En el nombre de Cristo. [Yo], Pedro, obispo de Santa María [i. e. de León] hice una restauración en San Miguel [de la Escalada] el día de la $5 .{ }^{\text {a }}$ feria, I 7 de las calendas de julio de la era de II26 [= jueves I5 de junio de Io88], [siendo] rey Alfonso [VI], abad Suero Álvarez" (vid. García Lobo I982: 7O-7I, no. I32 y lám. XI; cf. Hübner ı87r: Io8-Io9, y Francisco Olmos 2004: 92).

38. Sobre el que llamó ya la atención (si bien refiriéndose a la copia sita en la parroquial de Lara) José Ortiz y Sanz (I84I-42, III: 64): “¿Es modo de producirse fecerunt istam civitatem para decir que la fundaron?” (esta interrogación retórica está ausente de la primera edición I795-I803: III, 297). 
ecclesiam hanc. Por todo ello, la frase "fecerunt istam civitatem" del epígrafe lareño resulta bastante anómala. De hecho, incluso fuera del ámbito epigráfico referirse a la erección de una ciudad con el verbo facio resulta un uso postclásico y, aun entonces, muy infrecuente. El muy completo Thesaurus Linguae Latinae (= TLL, III, I2I9-20, y VI, pp. 82-I33) no recoge ningún ejemplo en sus entradas civitas y facio, lo cual es lógico, dado que en latín clásico civitas no poseía un sentido topográfico, sino jurídico: "È, nel senso proprio della parola, l’insieme politicamente organato dei cives in quanto essi formano uno degli elementi essenziali dello Stato, oltre quello del territoiro, insomma la cittadinanza" (De Ruggiero I895-22: 2.I, 255). ${ }^{39}$ Esta concepción pervive al menos hasta los tiempos de San Isidoro: "civitas autem non saxa, sed habitatores vocantur" (Etymologiae, I5.2.I), es decir, que civitas no se refiere a la fábrica material de la ciudad (esto sería urbs), sino a sus habitantes (Oroz-Marcos ed. I993-94: 2, 226-27). No obstante, en la Edad Media civitas había sustituido al antiguo urbs para significar la ciudad en términos materiales, como revela que esta última voz no haya dejado huellas patrimoniales en las lenguas romances, que, en cambio, emplean derivados del primero: città en italiano, cité en francés, ciutat en catalán, çibdad > ciudad en español, cidade en portugués, entre otros..$^{\circ}$

Aun así, las poblaciones nombradas como civitates en fuentes medievales entre los siglos XI y XII suelen disponer de prestigioso pasado (sedes episcopales, cecas o lugares de cierto relieve), comprendiendo en civitas la localidad principal con su territorio, es decir, grandes unidades territoriales fruto de las repoblaciones de Alfonso III, tal como aparecen citadas desde el siglo IX en la zona más occidental del valle del Duero, en tierras hoy de Portugal. ${ }^{41}$ Induce, pues, a sospecha la utilización de esta categoría en los siglos IX y X aplicada a poblaciones de las que se desconoce pasado de tanto prestigio, y puede ser indicio de argumento de un falsario. ${ }^{42}$ Quizá, a la luz de lo que se conoce de Lara en la Alta Edad Media, sería más correcto definir la población como villa ( $c$. LELMAL, 784-85, s. v. "uilla"). Con todo, no es la única vez que se alude a ella como civitas, pues aparece calificada así en el apócrifo documento de dotación del monasterio arlantino de San Pedro, "in quorum honore baselica fundata est iuxta civitas Lara, super crepidinem fluminis Aslanza", por el conde Fernán González y su esposa Sancha, supuestamente en el año 9I2.43 Lo mismo sucede

39. Cf. TLL, 3, г219, donde se recoge la equivalencia de los glosarios entre civitas y $\pi 0 \lambda \iota \tau \varepsilon i \alpha$.

40. Meyer-Lubke (I935: no. I959). De urbs solo hay un derivado tradicional en antiguo dialecto paviano y únicamente en una lexía: “Apav. orba 'Rom’ in der Formel: vicario in orba, 'Kardinalvikar”” (ibid., no. 9o78).

4I. Vid. Estepa (1978), Monsalvo (2005: 76-77) y Barroca (2008-9: 207). El LELMAL recoge el apelativo de civitas aplicado a localidades con sede episcopal como Oviedo (civitas Ovetensis, pp. 68 y 736), Astorga (civitas Astorica o Asturicensis, pp. 203, 396 y 736), León (civitas Legionensis o, más rara vez, Legio y Legionis, pp. I2, I6, 36, 56 et passim), Zamora (civitas Zemora o Zemore, pp. 2, 9I, 337, 496, $5^{28}$ y 789), Salamanca (civitas Salamantice, p. 135), Coria (civitas Cauria, p. 308) y Toledo (civitas Toletus o Toletana, pp. 93, 340, 384, 463 y 695), aunque en documentación de fecha temprana parece haber tenido un uso algo más laxo, pues se aplica una vez a Simancas, en un documento de la catedral de León de 974: "rex Adefonsus [...] ciuitatem Septimancam audacter abrogauit” (p. I27), y otra a Cea en un diploma del monasterio de Sahagún de 983: "nostra corte propria quam, habemus sine alios heredes in ciuitate Ceia" (p. 215).

42. Ya apuntó en esta dirección Ortiz y Sanz (I84I-42: III, 63-64). Valga como ejemplo el del obispo Pelayo de Oviedo (IIOI-II3O), que en el Liber Testamentorum interpola una noticia falsa que afirma que "Rex iste [el vándalo Unerico] in Asturiis civitatem hedificavit, era CCCLXLVIII (a. 36I), quam Lugo, id est, lucet, vocavit (Lugo de Llanera)" (cit. por Fernández Conde r993-94: 36; la acotación entre paréntesis es suya), con el fin de otorgarle preeminencia y glorioso pasado, y en el Liber Chronicorum, refiriéndose a la misma localidad, asegura que "Rex iste [Fruela I], episcopatum in Ovetum transtulit a Lucensi civitate quae in Asturiis ab evandalis edificata fuit", con subrayados nuestros (ibid., 37; los subrayados son nuestros).

43. Zabalza (I998: ıІ3-30, doc. I). Se sospecha precisamente de la alusión a Lara como civitas en este diploma, copiado en el Becerro de Arlanza (vid. Serrano ed. r925: 5, doc. I), por anacrónica en el siglo X, en que el editor considera que solo León gozaba de este dictado (Zabalza I998: ı24, n. 77). Sin embargo, esto no es cierto, como se ha 
en otro diploma falso atribuido al mismo conde y a su madre Mumadonna en el que, justamente, se asignan términos y fuero a Lara en el año 93I: "in castro vel civitate Larensi”. ${ }^{44}$

Sin embargo, no se trata de un mero hábito de los falsarios arlantinos, porque la expresión aparece en varios documentos auténticos de fines del siglo XI y del siguiente, como el Fuero de Villaespasa y Rucepos, dado por Arlanza en Io89, cuya segunda cláusula estipula "ut non habeatis super vos illud tributum quod soliti estis dare, [...] set per unumquemque annum reddatis nobis per usum vestra annubda, sicuti faciunt in civitate de Lara" . 45 Unos años más tarde, en III6, Pedro Ovéquez entrega a Arlanza el monasterio de San Pedro: "Et est ipsum monasterium situm in civitate Lara". ${ }^{46}$ También en el fuero concedido por Alfonso VII en II35 se la considera así: "facio vobis varones civitatis Larensis cartam de vestros foros, de illos quos habuistis ex parte aviorum meorum, et ego do vobis in illos melioranza", lo que se repite en la suscripción: "Ordono Gustioz, que Laram populavit, et fuit ayudadore in foros bonos ad illam civitatem dare, testis". ${ }^{47}$ La expresión reaparece en una donación a Arlanza del mismo monarca, en II54: "illam nostram villam Sancti Martini de Cutriales, qui extaz iuxta civitate Lara, [...] sicut serviebat nobis cum civitate Lara" ..$^{8}$ Esta consideración de Lara como civitas resulta coherente con su condición de cabeza del alfoz lareño, al que se alude a menudo en la documentación del siglo XI como suburbium quod ferunt Lara o que vocitant Lara, alfoz(e) de Lara o territorio Lara o Lare. ${ }^{49}$

Por otro lado, la fundación de una localidad (colonia, municipium) se expresaba mediante el verbo condo, puesto que se aludía a su constitución formal y no a su construcción material (caso en el que, de todos modos, se hubiesen usado, si no el mismo verbo, aedifico o erigo antes que facio)..$^{\circ}$

visto en la nota 4I, lo que, no obstante, no refuta la falsedad del diploma, perfectamente establecida (vid. Martínez Diez 2005: I, 292). La expresión comentada es sustituida por "in suburbio que vocitant Lara" en otra variante de la misma fecha que atribuye la fundación de Arlanza al conde Gonzalo Téllez y su familia (Serrano ed. 1925: II, doc. 3) y que manipula un documento auténtico, aunque no sabemos si en este punto. Véase la comparación de ambas en Escalona I995: 586-89, y un análisis y contextualización detallados, así como sendas ediciones críticas, en Escalona et al. (2OO2).

44. Serrano (ed. r925: 3I, doc. Io), Zabalza (I998: 79); sobre su falsedad, véanse además Álvarez Borge (ı993, 798I) y Martínez Diez (2OO5: I, 292), quien lo fecha en 922. En el resto del diploma se habla de Lara como de un lugar: "nos vero iam dicti hic habitantes in loco predicto Lara [...] elegimus ipsum lucum, quem iam supra nominavimus Lara, cum omnibus adiacentiis suis”. Respecto de Mumadonna, adoptamos la grafía más frecuente para este nombre en la documentación latina medieval (según se desprende del $C O R D E$ ), que seguramente corresponde a un romance Mumadueña o Momadueña.

45. Serrano (ed. r925: I58-59, doc. 83), las cursivas son nuestras. Comenta esta cláusula Escalona (ı995: 575, n. $870)$.

46. Serrano (ed. r925: i65, doc. 87), las cursivas son nuestras. Sobre esta cesión, cf. Escalona (1995: 564 y 627-628). 47. Serrano (ed. 1925: I76-8I, doc. 95), las cursivas son nuestras. Sobre este fuero, $c f$. Pérez-Prendes (I984: 532), González Díez-Martínez Llorente (1992: 225) y Escalona (1995: 567-70), con bibliografía adicional.

48. Serrano (ed. I925: 206, doc. III), las cursivas son nuestras. Sobre esta donación, $c f$. Escalona (1995: 580-8I).

49. Vid. Serrano (ed. I925: 66 [IO38], 69 [IO39], 73 [IO4I], 8I [IO42], 83 [IO42], 87 [IO44], 94 [IO46 [, 96 [IO46], 99 [IO47], IO2 [IO47], IO8 [IO48], I39 [IO65] у I99 [II5I]; I20 [IO58] у I22-I23 [IO60]; II2 [IO52], I3I [IO62], I45 [IO69], I62 [Iо92] у 208 [II55]; 53 [970], ІІ4 [IO54], I62 [Iо92] у I86 [ІІ35], respectivamente). En las dos primeras fórmulas, suburbium no se toma en la acepción de burgo o arrabal, sino en la de área periurbana, como extensión del sentido de predio extramuros: "suburbanum, Prædium, quod ad urbem est, $\pi \varrho 0 \alpha \sigma \tau \varepsilon \tau \tilde{\nu} v$, in Gloss." (Du Cange et al. I883-87: 7, col. 643). Para estas designaciones, vid. Escalona (I995: 561), quien explica bien la situación que subyace a las mismas: "la ubicación de Arlanza en el suburbio de Lara encaja perfectamente con el significado espacial de la fundación de Arlanza: la articulación bajo el control de la civitas condal del tramo del valle del Arlanza al sur de la Sierra de las Mamblas" (p. 589); cf. además Palomero et al. (I996-97: г36I-82). Sobre la civitas como vertebradora de alfoces, complementando el esquema de las interpretaciones institucionalistas, vid. Monsalvo (2007); sobre el alfoz, territorio, tenencias y fueros de Lara, vid. Álvarez Borge (i993: 79-82).

50. De Ruggiero (I895-22: 2.I, 429 y 577); cf. TLL, 4, I52, s. v. “condo", § II. Véase en la nota 42 un caso de falsificación en que se unen aedificare y civitas. 
Confirman esta situación las bases de datos de la Bibliotheca Teubneriana Latina ${ }^{51}$ y del Corpus Christianorum (CLCLT-3), que arrojan únicamente sendos casos antiguos de facere civitatem, ya algo tardíos y en el que el sentido de 'fundar' no parece el más apropiado. Se trata de Justino, Epitoma, 24.6.6: "Templum autem Apollinis Delphis positum est in monte Parnasso, in rupe undique inpendente; ibi civitatem frequentia hominum fecit, qui admiratione maiestatis undique concurrentes in eo saxo consedere",,$^{2}$ y de San Agustín, Enarrationes in Psalmos, in Psal. 47, § 3: "denique et maior filius qui epulari nolebat, exhortatus a patre ingressus est; et duo iam parietes, tamquam illi duo filii ad vitulum pervenientes, civitatem regis magni fecerunt". ${ }^{33}$ En latín medieval tampoco parece haber sido una expresión habitual. La indicación para designar la "fundación" o "refundación" de núcleos de población en las fuentes medievales hispánicas de este período son del tenor empleado por Sampiro († IO4I), en referencia a tiempos de Ramiro II:

Deinde post II ${ }^{\mathrm{os}}$ menses azeiphan, id est exercitus, ad ripam Turmi ire disposuit, et civitates desertas ibidem populavit. Hee sunt: Salamantica, sedes antiqua castrorum, Letesma, Ripas, Balneos, Alphandiga, Penna et alia plurima castella, quod longum est prenotare. ${ }^{54}$

Lo mismo ocurre en la prosa diplomática, como en el siguiente pasaje de un documento de la catedral de Oviedo de IoI7: "Constituimus etiam ut Legionensis ciuitas, que depopulata fuit a Sarracenis in diebus patris mei Veremudi regis, repopuletur per hos foros subscriptos". ${ }^{55}$ Sin embargo, a partir de finales del siglo XII se empiezan a encontrar textos historiográficos en que se emplea el verbo facio ya de modo parejo al que vemos en Lara. Hacia II73-79 la utiliza así Pedro Coméstor, Historia Scholastica, I, XXVIII:

Cognovit Cain uxorem suam, quae peperit ei Henoch, et fecit civitatem, et dixit eam Henoch ex nomine filii sui Henoch. Hic patet quod iam multi homines erant, etsi non dicatur eorum generatio, quos convocavit Cain ad urbem faciendam, quorum auxilio eam fecit..$^{5}$

Algo más de un siglo después, Salimbene de Adam la emplea dos veces en su Chronica (I282-87):

Imperator, vero, furibundus et totus inflammatus ex ira propter illa que sibi acciderant, venit ad

5․ Consultada en línea el i6-o5-20I6 en http://tinyurl.com/BTL-Unizar, a través de la suscripción de la Universidad de Zaragoza.

52. "El templo de Apolo en Delfos está situado en el monte Parnaso, en un risco de contorno escarpado; allí dio lugar a una ciudad la frecuentación de los hombres, quienes, por admiración de su majestuosidad, viniendo de todas partes, se asentaron en esa roca” (Seel ed. 1985: 197; en esta cita y las siguientes, la traducción y las cursivas son nuestras).

53. "Al fin también el hijo mayor, que no quería participar en el banquete, habiéndole exhortado su padre, entró [Lc I5, II-32], y así las dos paredes, como aquellos dos hijos que acudieron a comer el ternero, han formado la ciudad del gran rey" (Dekkers-Fraipont ed. I956: 54I).

54. "A continuación, tras dos meses, dispuso que fuese una aceifa, es decir, un ejército, a la ribera del Tormes, y allí pobló las ciudades desiertas. Estas son: Salamanca, antigua sede de campamentos; Ledesma, Ripas, Baños, Alfándega, Peña y otros muchos castillos, que sería largo recoger” (ed. Pérez de Urbel I952: 327). Comenta este pasaje Martín Viso (2000: II5-I6).

55. “Establecemos también que la ciudad de León, que fue despoblada por los sarracenos en tiempos de mi padre Bermudo, se repueble por estos fueros infrascritos" (apudLELMAL, 242).

56. “Conoció Caín a su mujer, quien parió de él a Henoc, e hizo ciudad, a la que llamó Enoc por el nombre de su hijo. Aquí queda claro que había ya muchos hombres, aunque no se mencione su estirpe, a los que convocó Caín para hacer la ciudad, con cuyo auxilio la hizo" (PL, I98, col. IO78). La primera frase procede de Gn 4, I7, pero en el pasaje bíblico se emplea el esperable aedifico: "cognovit autem Cain uxorem suam quae concepit et peperit Enoch et aedificavit civitatem vocavitque nomen eius ex nomine filii sui Enoch”. 
Parmam et in contrata que dicitur Grola (in qua vinearum est multitudo et ubi vinum nascitur bonum, et vinum terre illius optimum est) fecit fieri unam civitatem cum magnis foveis in circuitu, quam etiam Victoriam appellavit in presagium futurorum. [...] Et capta fuit uxor predicti domini Manfredi cum duobus filiis suis et cum toto thesauro suo in civitate que Manfredonia nominatur; quam civitatem ipse fierifecit, nomen suum imponens ei. ${ }^{57}$

Ya en el siglo XIV, el scriptor papal Giovanni Cavallino († I349) recurría a ese mismo giro en un par de pasajes de su Polistoria, I.6.4: "unde Philosophus .IIII. Politicorum dicit quod non est minus difficile collapsam civitatem ad bonum reducere, quam de novo bonas facere civitates" y 6.I5.I: "Hercules [...] Capitolium prope fecit civitatem que Valentia dicebatur a valentibus et virtuosis habitatoribus ipsius" ${ }^{8}$ Esta cronología de uso, que no antecede a la segunda mitad del siglo XII, apunta, frente a lo que sugieren los aspectos materiales, hacia una fecha bastante más tardía para la inscripción de San Julián que la consignada en la misma, aunque tampoco sería incongruente con aquellos: "la grosera letra incisa de la inscripción de San Julián se asemeja más a casos plenomedievales como la inscripción consacratoria de Riocavado de la Sierra (año III4)" (Escalona I995: 566).

\subsection{Aspectos históricos}

El sugerido carácter tardío puede dar cuenta igualmente de las singularidades de contenido, no solo por lo que hace al inusitado carácter fundacional del epígrafe, sino por sus incongruencias históricas, comenzando por los dos personajes citados en la intitulación: Gonzalo y Rodrigo. Para aquel ha propuesto por primera vez una identificación Escalona (I995: 566, n. 825): “el nombre de Gonzalo puede ser relacionado con Gonzalo Fernández, conde de Burgos en 899, poblador de Clunia en 9i2, casado con la condesa Mumadona de Lara y cuyo hijo, Fernán González[,] reuniría en su persona ambos territorios”. Esta propuesta es aceptada por García González (2008: I49), quien identifica a Rodrigo con el primer conde documentado de Castilla. Sin embargo, la cronología es problemática.

Gonzalo Fernández, que vivió aproximadamente entre 855 y 920, aparece referido en documentación fiable dos veces como conde de Burgos (años 899 y 9í) y otras dos como conde de Castilla (9ı2 y 9I5), y a él se debe la repoblación de Aza, Clunia y San Esteban de Gormaz (9I2), ${ }^{59}$ así que parece el candidato óptimo para la identificación del primer antropónimo. En cuanto al conde don Rodrigo, sus acciones se documentan entre 86 o y 873 , fecha de su muerte.

57. "El Emperador, ciertamente, furioso y todo encendido de ira por lo que le ocurriera, llegó a Parma y en la comarca que llaman Grola (en la que hay multitud de viñas y donde se produce buen vino, y el vino de esa tierra es excelente) mandó hacer una ciudad con grandes fosos en derredor, a la que también llamó Victoria en anuncio de lo futuro. [...] Y fue capturada la esposa del citado señor Manfredo, con dos hijos suyos y todo su tesoro, en la ciudad llamada Manfredonia, cuudad que él mismo ordenó hacer, imponiéndole su nombre” (Scalia ed. r998-99: 29I y 406).

58. "Por lo cual el Filósofo, en el IV de los Políticos [=Aristóteles, Política, ı289a 3-5] dice que es menos difícil restaurar a un buen estado una ciudad arruinada, que hacer de nuevas buenas ciudades"; "Hércules [...] junto al Capitolio hizo una ciudad que se llamó Valencia por los valientes y virtuosos habitantes de la misma” (Laureys ed. I995: 23 у 158$)$.

59. Martínez Diez (2005: I, 299-3OI). A Gonzalo Fernández se refieren la mayoría de las fuentes cronísticas desde los Anales Castellanos Io Annales Legionenses, § II: “In era DCCCCL [= 9I2 d. C.] p\{opulauerunt commites Monnio Nunniç Rauda et Gondesalbo Te\{lliç\} Hocsuma et Gundesalbo F\{redenandiç\} Aça et Clunia et Sancti Stefani iusta fluuius Doyri” (Martín ed. 2009: 208), a los Anales Castellanos II o Annales Complutenses, § I.Io (ibid., 2I5) o los Anales de Cardeña: "Era de DCCCCL, pobló Munno Nún-/nez a Roda et Gonçálo Téllez a Osma et / Gonçalo Ferrández a Aça et Clunia et a Sant Esteuan” (Martínez Diez ed. 2004: 256). 
De los siete diplomas del siglo IX calendados por dicho conde, aclara Martínez Diez (2005: I, I57-58), "cuatro de ellos, tres emilianenses y uno silense, son falsificaciones muy posteriores", pero los tres diplomas más seguros lo denominan invariablemente comes, así también alguno falso. Precisamente, uno de los textos que inducen a sospecha es aquel en que se data mediante la fórmula "regnante Roderico comite", y se fecha "in era DCCCC", muy cercana a la de las inscripciones aquí estudiadas. ${ }^{60}$ Por otra parte, las fuentes analísticas recuerdan a este conde igualmente como repoblador: "In era DCCCLXLVIII [i e. $898=86 \mathrm{o}$ d. C.] populauit Rudericus commes Amaya et fregit Talamanka" ${ }^{6 r}$ En principio, también da un perfil adecuado para figurar en el epígrafe fundacional lareño. Sin embargo, resulta imposible que ambos personajes hubiesen colaborado en una repoblación o refundación de Lara en 862, cuando el primero de ellos andaría solo por los siete o a lo sumo diez años de edad. Incluso retrasando la fecha a una compatible con tal actuación conjunta (que no podría ser más que 873, último año de vida del conde don Rodrigo y en el que Gonzalo Fernández contaría ya con 18 o 20 años) y dándola por buena pese a su disimetría, la disposición de la intitulatio sería anómala, anteponiendo el iunior al senior y omitiendo el título condal del primero. Esto invalida la conjetura (no basada más que en la nula autoridad de este epígrafe) de García González (2008: I49-50), pese a su viabilidad en términos geopolíticos:

A partir de ahí parecen cobrar cierta verosimilitud noticias tan singulares como la reestructuración de la civitas de Lara en torno a 862/867 por iniciativa de los personajes cualificados: un denominado Gundisalvus y un desconocido Findericus. Si la última lectura de los controvertidos epígrafes de Lara de los Infantes es acertada y el supuesto Findericus no es sino un Rudericus, cabe suponer que, en algún momento avanzado del siglo Ix, el conde titular del microcondado de Castella Vetula, identificado inequívocamente como Rudericus en 86o, se había comprometido con el apoyo del linaje microcondal de Brañosera/Campoo y de la corte regia astur a cumplir dos tareas: por un lado, tutelar la progresión de los excedentes cantábricos por la cordillera Ibérica mediante la contribución a la refundación de la civitas de Lara, y, por otro lado, encuadrar estratégicamente por el norte y por el sur el pasillo del alto Ebro que canalizaba las campañas veraniegas para proceder inmediatamente a su estrangulamiento. A tenor de esto, no parece realmente desquiciado presuponer que fue Gundisalvus Fredinandi, miembro del linaje descendiente del conde repoblador de Brañosera, encuadrado en la cordillera Cantábrica, quien ayudó al comes Rudericus a reestructurar la civitas de Lara, probablemente tras haber emparentado con algún linaje serrano de la cordillera Ibérica a través del matrimonio con Muniadonna, conocida esposa de aquél y madre del futuro Fernán González.

De todos modos, si la identificación de Rudericus con el conde don Rodrigo tiene al menos cierta base en la congruencia cronológica (con la data, no con el regnans), la de Gundesalbus carece de cualquier apoyo en el texto. En realidad, resultaría más lógico identificar a dicho personaje con Gonzalo Téllez, el tío de Fernán González, que con Gonzalo Fernández, su padre, dado que "[e]n varios diplomas que afectan a la zona de Lara en los primeros años del siglo x aparece Flámula acompañada de su esposo, el conde Gonzalo Téllez, que sin duda lo hace en calidad de consorte. En

6o. Vid. Martínez Diez (2005: I, I34-35) y, para más detalles, (1997). Esta falsificación forma parte de las varias docenas de documentos forjados en la primera mitad del XII en San Millán de la Cogolla para justificar o crear títulos de propiedad de pequeños monasterios a él agregados por el rey García de Nájera (IO35-IO54), e igual ocurre con otros diplomas emilianenses atribuidos al siglo IX.

6I. Anales Castellanos Io Annales Legionenses, § 7 (Martín ed. 2009: 208); la mención de Talamanca desaparece en los Anales Castellanos II o Annales Complutenses, § I.8 (ibid., 2I5). La noticia aparece así en los Anales de Cardeña: "Era de / DCCCC XX [= 882 d. C.] fue poblado Amaya por / el conde don Rodrigo et otrossí po- / bló [en tachado] el conde don Diego a Ouir- / na” (Martínez Diez ed. 2004: 255). 
cambio, nunca aparece Gonzalo Fernández, el esposo de Mumadona, conde de Burgos y padre de Fernán González" (Escalona 1995: 577) ${ }^{62}$ La biografía de este personaje no desdice de la atribución fundacional, sino todo lo contrario:

En el agitado período que se extiende entre la época del conde Diego Rodríguez y la unificación del poder condal por Fernán González en 93o, Gonzalo Téllez era uno de los personajes dominantes de la escena política castellana. Aunque el núcleo de su poder eran las zonas de Lantarón y Cerezo, fue capaz de ampliarlo hacia el sur gracias a su matrimonio con Flámula, miembro de la familia dominante en el sector de Lara; por otra parte, los Anales Castellanos I nos han transmitido su papel en la incorporación de la franja meridional del condado, con la población de Osma. La posición de Mumadona, aparentemente subordinada a los dos anteriores, también encaja con el contexto, puesto que la pareja Gonzalo Téllez-Flámula parece haber ejercido el control de la zona de Lara hasta la muerte del conde hacia $915^{63}$.

Sin embargo, tampoco en este caso su presencia es compatible al lado del conde Rodrigo de Castilla. Desde luego, otra opción sería considerar que nuestro Rudericus es un personaje distinto del conde castellano... ¿pero cuál? Ninguno de los comites de la zona occidental del reino asturleonés coetáneos de ambos Gonzalos llevaba ese nombre (vid. Martínez Diez 2005: I, I98-99 y 203). Hay dos personajes así llamados, "Rodericus Gusteuz [var: Gudistioz] cf. / Rodericus Didaz cf.", suscribiendo las dos versiones del diploma fundacional de Arlanza en 9ı2, la más fidedigna de las cuales otorga, como se ha visto en la nota 43, el propio Gonzalo Téllez, pero no hay razón alguna para identificar a ninguno de ellos con el mencionado en la inscripción de Lara. ${ }^{6}{ }_{4}$ En todo caso, de aceptar tal posibilidad, la actuación descrita habría de posponerse al momento en que Gonzalo Fernández accede a la dignidad condal, que no consta hasta 899, como acabamos de ver, y entonces extrañaría no verle aplicado a él el correspondiente título. Lo mismo vale en líneas generales para su coetáneo y cuñado Gonzalo Téllez, cuya primera mención documental conservada data del año 9O2, en que "Gundissalbo Telliz una cum uxore mea Flamula" hace una donación a San Pedro de Cardeña y que no aparece atestiguado como "comite Gundissalbo Telliz in Cerasio" hasta $9 \mathrm{I} 3,{ }^{65}$ aunque, según un testimonio hoy perdido, ya lo era de Lanzarón desde 897 y con seguridad en 9II (Martínez Diez 2005: I, I99, una más completa biografía del personaje en pp. 198-203).

Esto nos lleva al otro problema de contenido, el de la data, ofrecida, como se ha visto, mediante una doble fórmula, por alusión al monarca reinante (Alfonso) e indicación de la era (9oo, es decir,

62. También subrayan este aspecto Escalona et al. (2002: I70), hablando de Mumadonna: “Quizás sorprendentemente, su esposo Gonzalo Fernández parece haber tenido sus bases de poder en Burgos, pero no se documenta actuando en el ámbito de Lara, al revés que Gonzalo Téllez”.

63. Escalona et al. (2002: I69). El pasaje analístico es el citado en la nota 59.

64. Citaremos, de pasada, la posibilidad de que la inscripción haga referencia a Gonzalo Gustioz y a Ruy (Rodrigo) Blásquez, padre y tío, respectivamente, de los siete infantes de Salas / Lara, pero, sin contar con que nada hay en la leyenda que abone semejante posibilidad, sería inusitado que tales personajes apareciesen sin sus patronímicos, lo que, en cambio, no extrañaría tratándose de condes, incluso si no consta su título.

65. Martínez Diez (I998: 26-27, doc. 3, y 30-3I, doc. 6). La localidad mencionada es Cerezo de Río Tirón (Burgos), cabeza del alfoz homónimo ("suburbio quem ferunt Cerasio", según recoge el mismo documento). Luciano Huidobro (I928) especuló con que Gonzalo Téllez apareciese inscrito en el interior de la cercana iglesia de Santa María, en Quintanilla de las Viñas, a menos de cuatro kilómetros de Lara de los Infantes, sobre la representación del capitel septentrional del arco de gloria que representa a la Luna (su esposa Flámula lo hace en el capitel del sur, el del Sol), texto ilegible por perdido ya a principios del siglo xx. El mismo autor afirma haber copiado otras inscripciones de la época condal, antes de su reutilización en el murete del cementerio parroquial de Quintanilla de las Viñas, una de las cuales decía que "en 879 Flámula, hermana de la Condesa Doña Munia y mujer del Conde Gonzalo Telliz, ofrece el edificio a Jesucristo" (ibid., 268). 
el año 862), lo que situaría el contenido del epígrafe en tiempos de Ordoño I (850-866). El Alfonso más cercano a esa fecha sería Alfonso III (rey entre 866 y 9I0), por lo que no hay coherencia entre ambas dataciones. Como queda dicho, podría suponerse perdida una parte de la data. En tal caso, las fechas compatibles con los demás datos (de admitirse, con todo, algunas anomalías) serían, según lo dicho, 873, correspondiente a la era DCCCCXI, o (a costa prescindir de la identificación de Rudericus) alguna de las comprendidas entre 897 (= era DCCCCXXXV) y 9Io (= era DCCCCXLVIII), de las que, por el espacio disponible, solo sería factible $\operatorname{DCCCX}^{\mathrm{V}}$ (i. e. $94 \mathrm{O}=902$ d. C. $)$, pero se trata claramente de una poco atendible conjetura ad hoc.

Como puede apreciarse, las características materiales y formales, conjugadas con el contenido del epígrafe, permiten inferir que no se trata de una inscripción contemporánea a la data, sospecha que late desde que los primeros comentaristas aludieron a ella ${ }^{66}$ pudiendo tratarse de una copia con errores o, directamente, de una falsificación, hipótesis más probable, teniendo en cuenta el grado de manipulación de los testimonios conservados relativos a la etapa prefundacional del condado de Castilla. Según Martínez Diez (2005: I, 292), “de los diez diplomas, datados antes del año 932, que invocan el nombre de Fernán González[,] nada menos que ocho de ellos son ciertamente documentos apócrifos o mal datados, y los dos restantes resultan bastante sospechosos". A los documentos escritos, pues, cabría sumarles los testimonios epigráficos, como sería natural de haber un interés en falsear datos históricos.

No obstante, cabe plantear la cuestión en términos algo distintos, aunque relacionados, debido al carácter conmemorativo de la inscripción. En efecto, a diferencia de un diploma, un epígrafe carece de autoridad jurídica (aunque pueda reclamar una histórica), por lo que solo cabe tildarlo de apócrifo, con propiedad, cuando da una información manifiestamente falsa y manipulada, como señalar la existencia de un sepulcro (de un santo u otro personaje destacado) donde no lo había o, por poner otro ejemplo, la concesión de unas indulgencias inexistentes ( $c$ f. Favreau i999: I83-85). Cuando la inscripción busca simplemente guardar memoria de un hecho, la falsedad del contenido no afecta necesariamente a la de la inscripción, a no ser que esta pretenda hacerse pasar por un testimonio más antiguo o de diferente naturaleza que la mera conmemoración. ${ }^{67}$ Por lo que hace al epígrafe lareño, habría de considerarse falso si se tratase de una pieza moderna que se pretendiera hacer pasar por una medieval, lo que no ocurre. También podría calificársela así en caso de transmitir a sabiendas una información errónea, pero los datos disponibles impiden indagar en las intenciones de quienes la encargaron, de modo que no es posible aclarar este extremo. Ahora bien, lo que sí parece claro es que la inscripción conmemora un hecho falso o al menos deformado, dado que atribuye la fundación de Lara simultáneamente a dos condes distintos, Rodrigo y Gonzalo (Fernández o Téllez), en una fecha (862) en que solo podría haber actuado el primero y en la que reinaba un Ordoño y no un Alfonso, el cual ni siquiera es compatible con un error de datación DCCCC $<_{\mathrm{L}}>$, que adecuaría la fecha de la inscripción a la indicada para las repoblaciones de los condes Gonzalo Fernández y Gonzalo Téllez en 9 I2 según la analística castellana citada en la nota 59, puesto que, como queda dicho, Alfonso III falleció en 9IO. El uso del infrecuente civitas aplicado a una localidad del tipo de Lara sugiere una relación con las ya mencionadas falsificaciones arlantinas del diploma fundacional de Fernán González y su esposa Sancha de 9I2 y de la asignación de términos a la propia Lara por Mumadonna y el mismo conde de 922, aunque, a diferencia de estos, apunta a una memoria bastante imprecisa de fundación en el período condal castellano, más que a

66. En realidad, a la copia (con variantes) de esta inscripción sita en la parroquia de la Natividad de Nuestra Señora de Lara de los Infantes, a la que nos referiremos más abajo.

67. Es el caso, por ejemplo, de los fraudes epigráficos vinculados a los falsos cronicones de Jerónimo de la Higuera y sus imitadores, aunque estos en su mayoría se fijaron solo en papel y no en piedra; vid. Hübner igoo: III. 
una falsificación deliberada, aunque con fines promocionales no demasiado distintos. No obstante, retomaremos esta cuestión al final de las presentes páginas.

Esta inscripción de la ermita de San Julián hay que ponerla en relación con otras dos grabadas en sendos sillares de la fábrica de la parroquia lareña. Creemos que el análisis filológico e histórico de estos epígrafes añade información que alumbra la historia material del templo, y a la inversa, dado el contexto en que se sitúan los sillares. Por lo tanto, previamente a la descripción de tales inscripciones, analizaremos la evolución arquitectónica de este interesante edificio, insuficientemente atendido por la bibliografía. ${ }^{68}$

\section{La parroquia de la Natividad de Nuestra Señora de Lara de los Infantes. Análisis arquitectónico-evolutivo}

Se trata de un templo de origen románico, ${ }^{69}$ que recoge en sus trazas arquitectónicas y elementos decorativos las huellas de las numerosas transformaciones generadas o pretendidas en el mismo desde ese periodo hasta nuestros días, habiéndose convertido, como suele ser habitual, en un magnífico y rico palimpsesto construido. En este caso, afortunadamente por el momento (y esperamos y deseamos que continúe siendo así), este edificio constituye un irrenunciable documento histórico que conserva una parte fundamental de sus páginas, a través de las que poder comprender la historia del propio edificio y de su enclave geográfico. Riqueza y variedad por lo general poco valoradas, que permiten avanzar a los investigadores lecturas arquitectónico-evolutivas como la que estas líneas pretenden esbozar. ${ }^{\circ}$

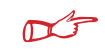

68. "Es esta una interesante construcción del siglo XII con pórtico de arcos tapiado, alta torre y cúpula románica”, se afirma sucintamente en Guía ilustrada de la Diputación Provincial de Burgos (i93o: s.p., Itinerario no. 4 "Burgos-San Pedro de Cardeña.-Los Ausines.-Revilla del Campo-Paules de Lara-Lara de los Infantes-Burgos”).

69. Esta iglesia parroquial fue declarada Monumento Histórico-Artístico de carácter nacional por el Real Decreto 2026/I982, de 25 de junio, BOE 200, de 2I de agosto (Ministerio de Cultura I982).

7o. Las consideraciones que siguen están realizadas a partir del análisis de visu, y las conclusiones parciales extraídas habrán de contrastarse con la documentación de los libros de fábrica de la parroquia, depositados en el Archivo Diocesano de Burgos, que cuenta con una documentación seriada que abarca de finales del siglo XVI a principios del XX (Martí Bonet ed. 2OII: I5I). Concretando más, los libros comprenden los años I588-I706 y I7 I2-I9O3 (tan solo con una laguna de cinco años), según información telefónica facilitada por el personal de dicho Archivo. Por lo que más abajo se dirá, interesa especialmente la información conservada de los primeros años. 


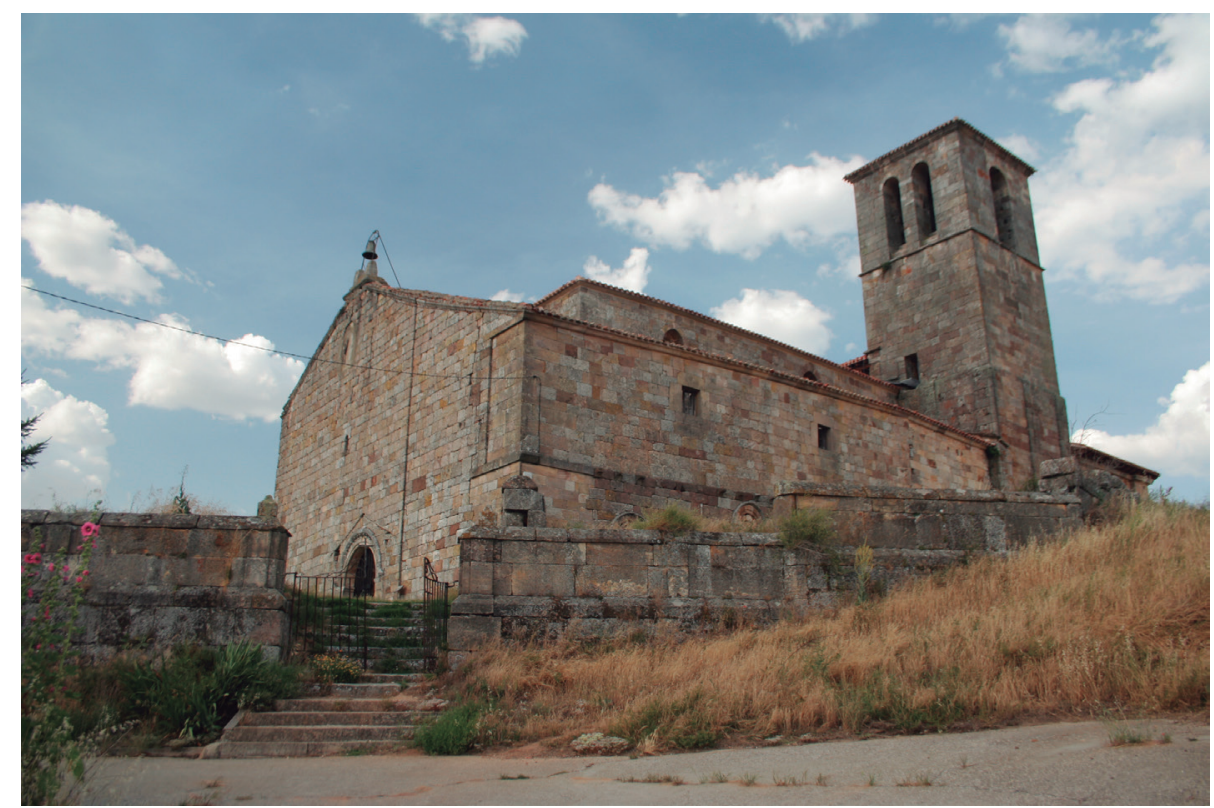

4. Vista exterior de la iglesia parroquial de Lara de los Infantes, desde el ángulo sudoeste (c) BY Esteras, Lorenzo \& Montaner

\section{I. Periodo románico}

La cabecera constituye el más evidente vestigio de este periodo, correspondiente quizá a la labor edilicia de los propios señores de Lara en el siglo XII, en opinión de Escalona (I995: 564), en contraposición a la teoría de Félix Palomero, que hace de este templo el mismo que se dona al monasterio de Arlanza bajo la advocación de San Pedro de Lara en un diploma de inı - de posible falsedad sospechamos -, como se verá luego. Está compuesta por ábside (I) y presbiterio (2) bien diferenciados en planta y en altura. ${ }^{71}$ Románica es la caja de muros del resto del templo (3), hasta la cota en altura definida en sus lienzos norte y sur por sendas hileras perfectamente conservadas de canecillos de singular volumen de aspecto cúbico..$^{7^{2}}$ Pertenecen igualmente a este mismo periodo los dos absidiolos que coronan sendos testeros laterales al oriente de la misma. Del análisis de estos, de lo que pudieran ser los arranques de sendas arquerías desde el arco de gloria hacia la nave, de las secuencias de los canecillos conservados y del perfil exterior del hastial occidental del templo, cabe deducir que esta construcción románica contara con tres naves. De mayor envergadura la principal, las laterales contarían con escasos dos metros de anchura, ${ }^{73}$ siendo amortizadas en posteriores transformaciones por la única que hoy se alza (4). La altura de aquellas sería igualmente

7I. Los números entre paréntesis remiten a la Ilustración 5. Hasta ahora, la mejor descripción de la fábrica románica es la realizada por José Luis Hernando Garrido (2009: vol. IV). Para una justificación más detallada de las atribuciones hechas en este apartado, véase nuestro apéndice final.

72. Que no tienen por qué ser mozárabes, como afirma Félix Palomero (cit. por Escalona r995: 564-65, n. 819). Los canecillos de rollos son muy frecuentes también en el Románico de la zona extremadurana oriental, aunque en estos sea la sección cuadrada la que más llama la atención.

73. Disponen de naves laterales estrechas la vecina parroquia de San Millán de Lara (compárense sus respectivas plantas en Palomero et al. 1996-97: I38I, y en Rodríguez Montañés 20o9: 2520) o los de las iglesias de San Miguel y de San Vicente en la localidad soriana de Almazán (Soria), o de Santo Domingo en Soria capital, entre otros muchos ejemplos. 
inferior a la de la central; las citadas hileras de canecillos serían así el testigo hoy conservado de las líneas de cornisa de sus cubiertas tanto al sur como al norte. Más dudas presenta la torre (5), que al menos en su cuerpo bajo debe de ser románica, coincidiendo prácticamente con la mitad inferior de su altura, si bien el tramo que sigue a este hasta la base del cuerpo de troneras que albergan las campanas podría pertenecer también a este periodo. Guarda interesantes similitudes formales y de planteamiento con la iglesia parroquial del cercano enclave de San Millán de Lara (vid. Palomero et al. 1996-97, y Rodríguez Montañés 2009).

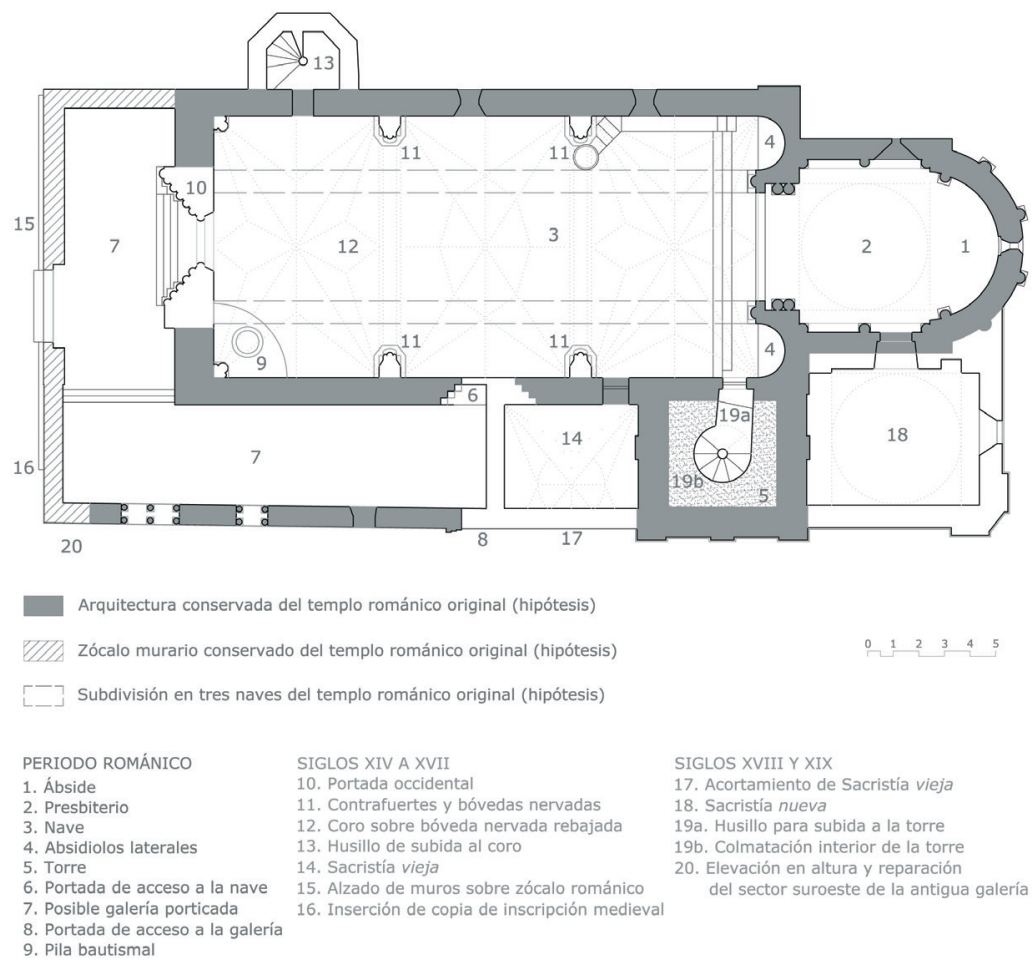

5. Plano de la iglesia de la Natividad de Lara de los Infantes, con indicación de sus fases constructivas (c) Br Bsteras, Lorenzo \& Montaner

El ámbito adosado al exterior de los costados sur y oeste de la nave (7), alterado por reformas, debió de ser también románico, probablemente la galería porticada del templo. Se conserva de ese periodo el zócalo del lienzo oeste, así como la mayor parte del recorrido de su lienzo sur en toda su altura original, bien delimitada y diferenciable en la actualidad gracias a la hilera de canecillos conservada a medio alzado del mismo. A este mismo momento bien pudiera corresponder la portada que todavía es perfectamente perceptible en el lienzo sur de la nave (6), a través de la que se accedería a la misma por el tramo central de los tres en los que actualmente se divide, si bien en la actualidad cabalga en su faz externa entre dos ámbitos bien diferentes, la antigua sacristía y la que consideramos pudo ser galería porticada del templo. Finalmente también adscribimos a este periodo las trazas y elementos decorados de las diferentes arquivoltas que conformaron la portada de ingreso al ámbito descrito como posible galería (8), situada en el costado sur del edificio frente a la anteriormente descrita, y hoy amputada en su mitad oriental. 


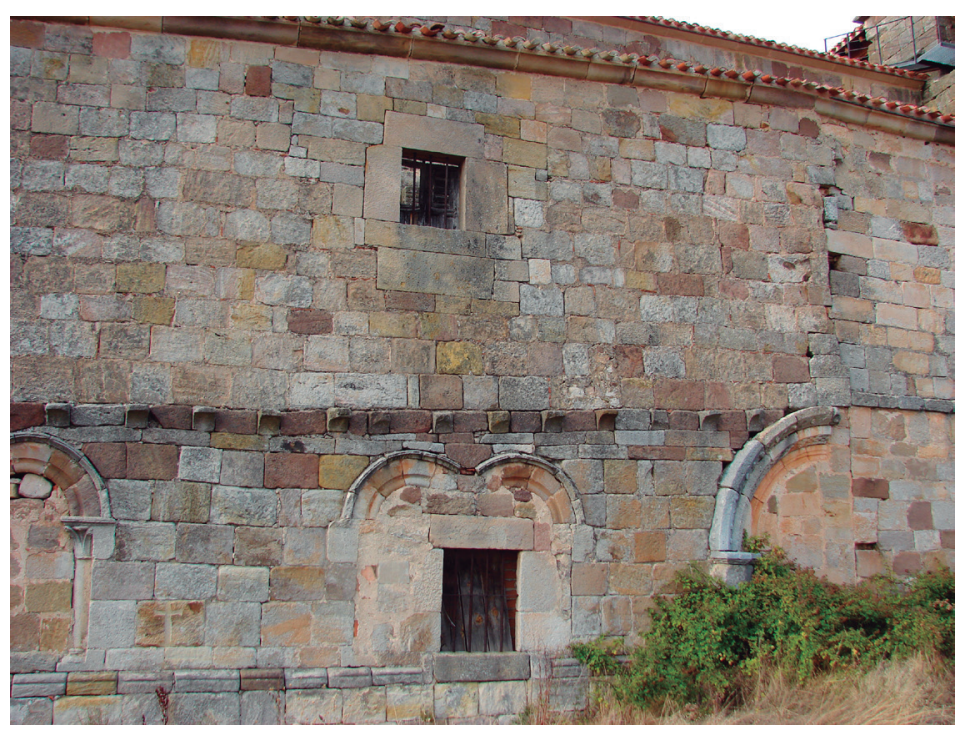

6. Parte del costado meridional del exterior del templo, con restos de la galería porticada románica amortizada para efectuar el recrecimiento en altura e interrumpida al este

(c) BY Esteras, Lorenzo \& Montaner

\subsection{Evolución del templo entre los siglos XIV Y XVII}

En este periodo, el templo sufre importantes transformaciones, que por su traza y definición parecen producirse en varios momentos o con impulsos constructivos claramente diferenciados. La primera, en un lenguaje gótico más inicial y de menor riqueza en el trabajo de labra, conllevaría la mayor transformación espacial del interior del templo que ha llegado a nuestros días. De tres naves se pasaría a una única, dividida en su longitud en tres tramos que pasarían a cubrirse por sendas bóvedas nervadas de terceletes con la implantación de cuatro grandes contrafuertes (II).

Esta obra, sin duda audaz y de gran envergadura, requería, de manera previa y para poder cubrir el nuevo y ahora único espacio así creado, del levantamiento en altura de los muros exteriores norte y sur de lo que hasta entonces eran las naves laterales. A esta operación corresponderían los lienzos de muro que arrancan de las hileras de canecillos conservadas al exterior de ambos costados de este ámbito del templo. Cabría la posibilidad de valorar que, coincidiendo con este recrecido del volumen exterior de la nave del edificio, se diese el proceso similar que tiene lugar en el presbiterio, a fin de equilibrar la relación entre las alturas y volúmenes de ambos cuerpos construidos. La traza, el despiece de sillería, e incluso el propio criterio empleado a la hora de conservar los canecillos, aspectos todos muy similares a los correspondientes a la etapa románica, parecerían confirmarlo. Al interior del presbiterio sin embargo, es la contundente traza posterior barroca la que ha prevalecido hasta nuestros días, de la que más adelante se tratará. Sí parece acometerse en el momento que ahora tratamos alguna ligera transformación del espacio interior de este ámbito presbiterial, modificándose la morfología de sus vanos ciegos, así como sus elementos decorativos, dotándolos de un lenguaje propio del momento. Es plausible relacionar esta ampliación con una noticia rescatada por la erudición dieciochesca, vinculada al padre Flórez pero no recogida en España sagrada. Nos llega por el testimonio de quien fuera tantos años su compañero de viajes y correligionario fray Francisco Méndez, que dejó constancia de este sorprendente dato: "El día nueve [de julio de I769] fue [Flórez] à Lara de los Infantes, lugar de unos cien vecinos [...] y en la iglesia descubrimos un papelillo por donde consta que se consagró el año de I 427 ”, para continuar 
en nota al pie:

Este papelillo estaba metido en una caja redonda de bronce (donde le dejamos) bien cerrada y fuerte. Esta se metia en un ahujero que havia hecho al justo para ella, delante de la misma Ara del Altar mayor: y dicho ahujero se tapaba con un tapon de piedra: todo bien ajustado: el papel dice asi: Manifiesto sea à todos los Cristianos en como el obispo de Bonavela consagró el iglesia de Santa Maria de Lara è el Altar mayor à la dicha iglesia: está en dicho Altar el cuerpo de Dios, è está puesto en una Custodia de bronce. Esta consagracion se fiso à veinte ocho dias del mes de Abril año de millé quatrocientos è veinte è siete años, de special comision de el Señor Obispo de Burgos Don Pablo. ${ }^{++} .74$

Este año, I427, a expensas de ulteriores comprobaciones, puede considerarse provisionalmente como el de la finalización de la obra gótica que cambió sustancialmente la imagen del templo, lo que justificaría la ceremonia solemne de reconsagración, bajo el comisionado del obispo de Burgos, el célebre converso Pablo de Santa María (I353-I435), anteriormente rabino hasta su conversión en I390, prelado de la cátedra burgalesa desde I4I5, y padre y tío de otros varios obispos de diferentes sedes (Cantera 1952: I08), encabezando "un entramado familiar que controlará instituciones concejiles, eclesiásticas y algunos puestos de la administración” (Díaz Ibáñez 2005: 572). El año de la reconsagración de la parroquia era precisamente otro sobrino del obispo don Pablo, Álvar Rodríguez de Maluenda, alcaide del castillo de Lara (Cantera 1952: 39I). Los intereses regionales entretejidos a "una tupida red de relaciones clientelares” (Díaz Ibáñez 2005: 573) no dejarían de influir en el boato de la ceremonia litúrgica que hubo de conocer la parroquia en tal ocasión. De hecho, aunque se carece de una descripción de la misma, sí poseemos la de otra similar, salvando la distinta naturaleza de las dos iglesias concernidas (parroquial la burgalesa y monástica la palentina), realizada por el mismo obispo de Bonavola, fray Juan de San Pablo OP, el 2 de julio de I 437 en el monasterio benedictino de Nuestra Señora de la Misericordia de Frómista. El mencionado obispo, actuando en este caso como delegado del prelado de Palencia,

vestióse de vestiduras e ornamentos eclesiásticos pertenescientes al dicho acto de fundación con otros quatro ministros revestidos otrosí de vestiduras e ornamentos eclesiásticos pertenescientes al dicho acto de fundación con otros quatro ministros revestidos otrasí de vestiduras eclesiásticas, que le administraban las cosas necesarias para la dicha fundación, e tomó una cruz de palo e púsola en medio del altar maior que estaba fecho e adoróla e los quatro que allí estaban, e tomó agua e bendíxola segunt es constumbre eclesiástica, e derramó después la agua bendita sobre aquel lugar donde estaba la dicha cruz e dixo las oraciones e oficios pertenescientes e acostunbrados al tal acto, segunt que se contenía en un libro que ante sí tenía, e otrosí fizo poner en la procesión otras quatro

74. Explica a renglón seguido que “El Obispo de Bonavela, acaso sería Auxiliar de Burgos, ù de Salamanca”. Se trata de un título in partibus infidelium, también documentada como Bonavale, Bonavola, Bonabola, cuya sede no se ha podido identificar (Fort I879: 5I, § XI; cf. López I6I3:I, I7I y I73; 2, III,). Su titular, como explica el propio Méndez, era un fraile dominico, en concreto fray Juan de San Pablo, del convento de San Esteban de Salamanca (López I6I3: 2, III), quien consta por primera vez con esta dignidad en I427, cuando consagra la parroquial de Lara. En I 434 el "episcopum [...] de Bonavola” figura citado, sin nombre, en las actas del Capítulo General de la Orden de Predicadores (Reichert ed. I9oo: 237). En I436, fray Juan de San Pablo, en calidad de obispo de Bonavela, bendijo el convento dominico de Santo Tomás de Tordesillas, Valladolid (López I6I3: 2, III, de quien toma el dato Fort I879: 5, fechándolo por error en I 426; González Dávila ı645-50: I, 639, quien da solo la fecha de I434, que es la de la fundación del convento; Hoyos I966-68: I, 87). En I437 figuró como procurador sustituto en un pleito que mantuvo el concejo de Caleruega con el monasterio de Santo Domingo de esa localidad burgalesa (González I993: I43). Ese mismo año, fray Juan consagró la iglesia del convento franciscano de Nuestra Señora de Gracia, por mandado del obispo don Sancho de Salamanca (López I6I3: I, I7I, y Dorado I776: 305-6, de quien toma el dato Méndez i78o: 235) y también la del monasterio benedictino de Frómista, en Palencia, como se verá a continuación. 
cruces, e a la entrada de la puerta maior otra cruz, e fuera de la dicha yglesia en dos lugares onde avía de ser cementerio otras dos cruces, todas con sus candelas encendidas segunt era necessario e cunplidero al tal acto e oficio e fundación e derramó del agua bendita por la dicha yglesia e procesión e cementerio diciendo todavía sus letanías e oraciones, santiguando e bendeciendo en cada lugar segunt era necesarias, haciendo deternidamente estación en ciertos lugares e derramando en ellas del agua bendita e cercando alderredor por ciertas veces e tornóse al lugar donde avía puesto la primera cruz, que era en el altar maior, e deciendo sus salmos e antífonas en el dicho libro contenidas acabó el dicho oficio e aseñaló cierto lugar para claustra e otrosí para ceminterio e sepulturas, e otrosí para las otras oficinas ncesaris (sic). E fuera, otrosí, de la dicha casa aseñalóles e dióles cierto espacio de término dentro del qual oviesen su clausura e encerramiento, segunt que de presente estaba edeficado e labrado. E luego el señor obispo dixo al altar maior missa cantada e celebró el divinal oficio. ${ }^{75}$

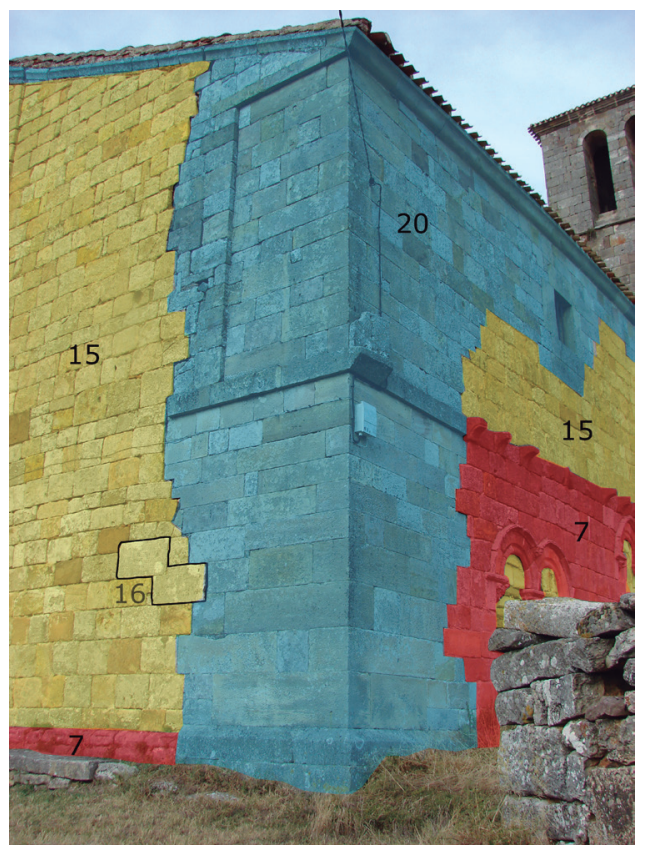

7. Secuencia constructiva de la esquina SO del edificio, con indicación del lugar donde se insertan los sillares epigrafiados (c) BY Esteras, Lorenzo \& Montaner

Dentro de este mismo periodo histórico, pero sin una cronología claramente identificable, hubo de tener lugar la transformación volumétrica y espacial de los ámbitos meridional y occidental al exterior de la nave, es decir, de la que fuera galería porticada del templo. El tipo similar de sillería y de soluciones de aparejo empleadas en la casi totalidad del lienzo occidental del conjunto y en el arranque del recrecido sobre la línea original de canecillos del sector meridional, así como la mera

75. Transcripción de una copia de I723 que obra en el Archivo de Samos del "Testimonio de la ceremonia religiosa de inauguración del monasterio por el obispo de Bonavola el 2 de julio de I 437 ” realizado por el notario Diego Mudarra (Zaragoza I998: II4-II5). Compárese la descripción que hace López (I6I3: III) de la consagración de la iglesia conventual de Santo Tomás de Tordesillas, realizada el año anterior: "Fauorecia mucho el padre Maestro el conuento, y con este animo el año de mil y quatrocientos y treynta y seys, dia de santa Catalina martyr, que es a veynte y cinco de Nouiẽbre, lleuo consigo al Reuerendissimo padre fray loan de san Pablo de la Orden de Prddicadores, Obispo de Bonauale, que bdndixo la Iglesia, y el cimenterio, y puso cinco cruzes. Bendixo vna capilla en vna esquina del claustro, y dedicola a la santa virgen Catalina. Hizo este auto con gran solenidad, diziendo Missa de Pon[ti]fical el señor Obispo, hallándose presente la mayor parte del pueblo”. 
lógica constructiva y compositiva, apuntan a que ambos ámbitos fueron recrecidos a la par. A buen seguro debió de producirse este cambio en el momento en el que estos, que en su día conformaran una amplia galería porticada con planta en forma de L, debieron de perder su función y carácter originales. Aunque carentes hoy de cubierta y de los forjados y paramentos internos que desde entonces fueron contribuyendo a definir las diversas funciones que albergaron, ${ }^{76}$ la atenta lectura de sus paramentos ofrece muchos datos de interés acerca de su posible evolución histórica. ${ }^{77}$

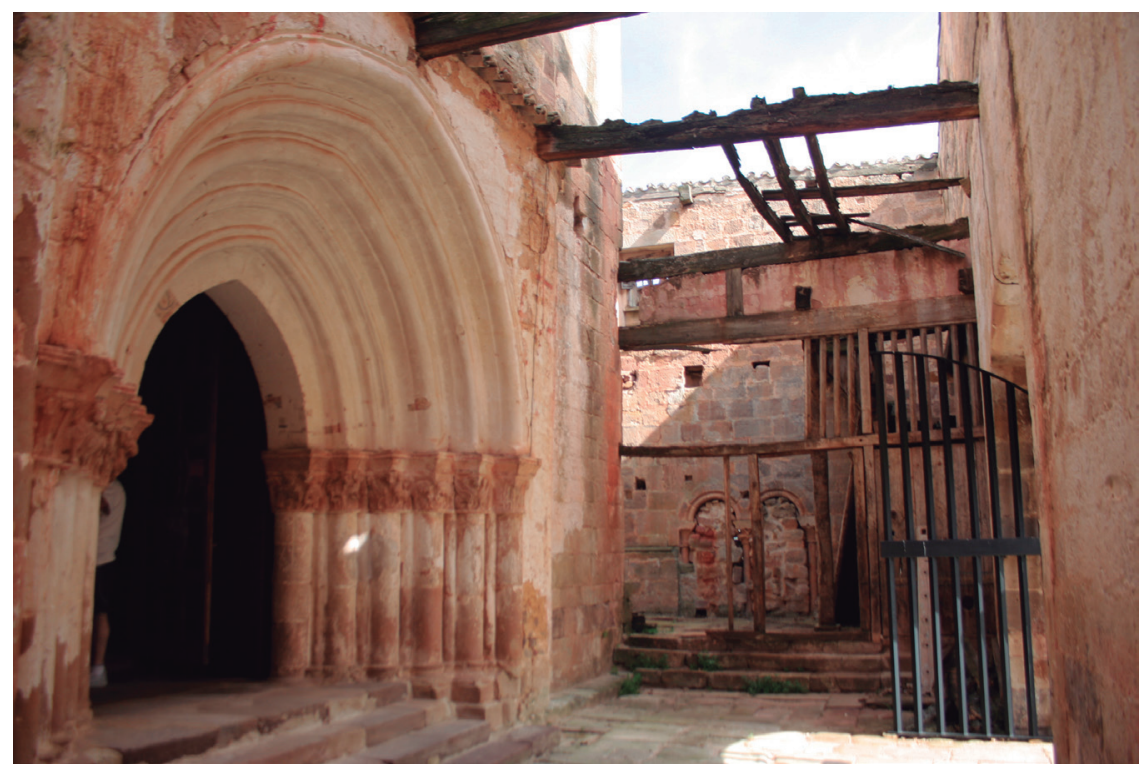

8. Portada románica de acceso al templo y esquina NO de la antigua galería porticada vista desde su interior, con restos de la compartimentación que tuvo después de que se amortizase

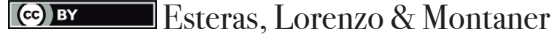

Partiendo de un análisis meramente volumétrico a partir del perfil que todavía hoy dibuja la línea de cornisa del hastial occidental de la nave, que avala la tesis de la triple nave antes expuesta, la respuesta compositiva de cubierta adoptada para el que fuera posible espacio porticado parece defender que se acometiera cuando todavía el templo contaba con tres naves de cubierta bien diferenciada. De ello daría buena muestra una pretendida búsqueda de encuentro entre la cornisa de cubierta de este ámbito y la correspondiente a la nave lateral norte del templo; pretensión que carecería de sentido de haberse acometido aquella una vez recrecida esta. De producirse entonces la

76. Fausto Heras de Domingo, lareño encargado de enseñar la iglesia, preguntado por la función de este espacio, nos contó que desde siempre oyó decir en el pueblo que era el lugar donde "los monjes cobraban los diezmos”. No está de más recordar que Mumadonna, madre de Fernán González, escritura una donación de diversas tierras el 28 de enero de 929 al monasterio femenino de Santa María de Lara, según el Becerro de San Pedro de Arlanza (Serrano ed. I925: I8-2I, doc. 5 [923]; Zabalza I998: I3O-I3I, doc. 2 [929?]; Martínez Diez 2005: I, 295 y 304). Obviamente, no se puede tratar de la iglesia parroquial que hoy se conserva, pero no se debe despreciar el hecho de que la tradición oral haya mantenido la memoria de un monasterio (ahora personificado metonímicamente en "los monjes") que se documenta en la documentación altomedieval. Por este mismo diploma, por cierto, sabemos que Fernán González era ya conde de Lara en dicha fecha (comite Fredinando Gundisalviz in Lara). Agradecemos a don Fausto la amabilidad que mostró en todo momento con nosotros, y la desinteresada labor que realiza en beneficio del edificio y su conservación.

77. Para una lectura de paramentos que siga los principios de la Arqueología de la Arquitectura serán de inestimable valor los restos de pinceladura (de línea simple, blanca, sobre fondo gris) que todavía se conservan en la parte meridional, tanto en el muro exterior de la nave como en correspondiente interior de lo que fuera galería, una vez amortizada. También en el interior de la nave se conservan distintos niveles de pincelados. Finalmente, unos curiosos grafitos zoomórficos de apariencia postmedieval son apreciables en el exterior del muro meridional de la nave. 
transformación y la consiguiente elevación de volúmenes, la cubierta del ámbito igualmente reformado al costado sur de la nave se dibujaría como una continuación de la correspondiente a esta última.

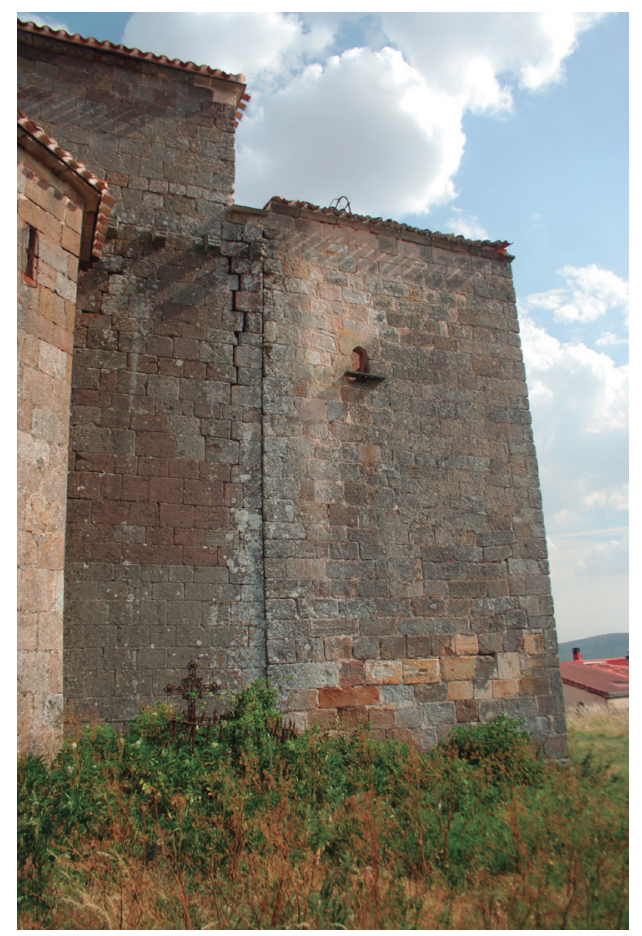

9. Encuentro de las cornisas de cubierta de la primitiva nave norte y del posible recinto porticado

(c) BY Esteras, Lorenzo \& Montaner

La esquina suroccidental de este nuevo conjunto reformulado, que cierra a mediodía y a poniente el conjunto del edificio, constituye el primer punto de aproximación del visitante al templo tras haber traspasado la cerca de su recinto. Finalizada la descrita transformación acometida en el conjunto, fue este el lugar escogido para colocar las piedras epigrafiadas objeto y origen de la presente investigación, las cuales se hallan a medio camino en el recorrido del visitante hacia el portal de acceso a la iglesia (I9). Como más adelante se indica, sin embargo, la esquina suroccidental del conjunto en toda su altura, como buena parte del recrecido en este periodo de la que fuera ala sur de la galería porticada románica del templo, responden a una reparación de época moderna de la que más adelante se trata. La discontinuidad entre ambos periodos está claramente reflejada por una línea escalonada de fractura que sigue y separa los sillares del muro más antiguo, el que acoge las dos inscripciones, de los del más moderno (figura 7).

La segunda gran transformación que en este periodo se produce en el templo, afectó principalmente a su espacio interior. En un lenguaje todavía gótico, ${ }^{78}$ estilísticamente más avanzado

78. No resulta extraño encontrar y constatar en estas zonas geográficas, un tanto ajenas y alejadas de los grandes polos y ejes culturales de la época, cómo el empleo de los estilos artísticos se dilata en el tiempo mucho más allá de los límites que nos marca la historiografía generalista. Los modos de construir que se conocían y que durante décadas habían funcionado en estas áreas, como los hoy asociados al románico o los posteriores al gótico, se continuaban utilizando tiempo después de que los nuevos aires se impusieran en lugares próximos y a la vez tan lejanos para la época. En no pocas ocasiones se constata documentalmente que esto ha venido ocurriendo hasta varios siglos después del declive hoy aceptado para el correspondiente "estilo", lo que nos invita a reflexionar sobre la necesidad de relativizar los presupuestos de evolución estilística que hasta hoy siguen primando. 
y con mayor calidad de labra en su trabajo de sillería, se erige un imponente coro a los pies de la nave (I2), cuya destacada bóveda rebajada presenta una decoración propia de la evolución del estilo. Para posibilitar la subida al coro sin desestabilizar compositiva ni constructivamente esta magnífica bóveda, se construyó un husillo de planta poligonal (I3), de fábrica y bóveda esférica en sillería, adosado al exterior del costado norte de la nave de la iglesia, a medio desarrollo de la anchura del coro. No tan recargada como la bóveda de este sotocoro, pero de similar pericia, resulta la ejecución de la bóveda nervada que debió de cubrir el espacio de la sacristía vieja (I4), que todavía hoy permanece en el ámbito confinado entre el muro sur de la nave y el costado oeste de la torre. La construcción de esta sacristía, actualmente espacio en desuso, supuso la condena definitiva de las portadas originales de templo y galería (6 y 8), si es que previamente, en el momento de levantar la portada oeste de acceso al templo, no habían sido ya amortizadas.

\section{3 Últimas transformaciones importantes en su fábrica: siglos XVIII y XIX}

A estos momentos parece corresponder la última gran transformación que sufre el edificio, entre cuyas acciones sobresalen el acortamiento de la sacristía vieja, el recrecimiento en altura de ábside y presbiterio, la nueva sacristía, el cuerpo de campanas de la torre y el husillo que permite acceder a él, y la sobreelevación de los muros de lo que pudo ser galería porticada.

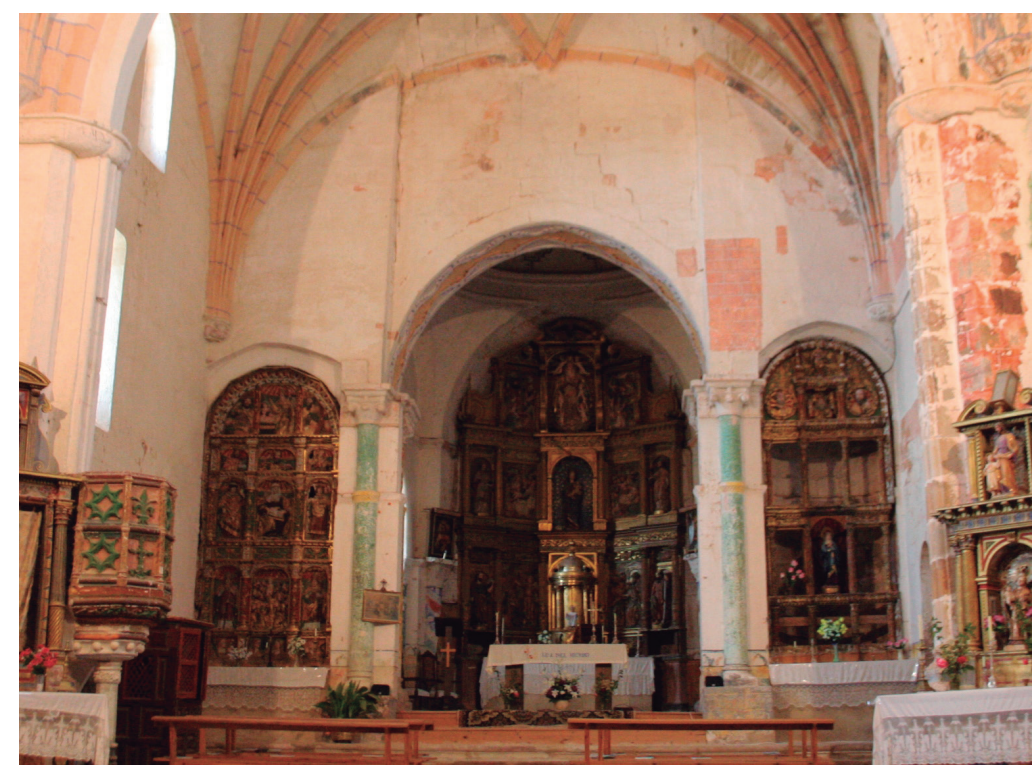

Io. Presbiterio y cabecera del templo en su estado actual, producto de la transformación barroca del edificio

(c) Br 1 Esteras, Lorenzo \& Montaner

Por razones desconocidas, se decidió acortar la sacristía vieja (I5), cuya bóveda milagrosamente pudo mantenerse en pie hasta la actualidad pese a perder parte de su traza en su flanco sur. Es el mismo momento en que se recrece el ábside y presbiterio, o al menos se modifica su aspecto y morfología interior, levantando sobre este último una cúpula semiesférica en escayola con decoración típica de este periodo. A buen seguro es entonces, al dotar al espacio conjunto de la cabecera de una mayor apertura y proporciones más ostentosas, cuando se sustituye el arco de gloria románico original por el arco simple decorado que hoy se aprecia. Destruida parcialmente la sacristía antigua, se levanta una nueva (I6), esta vez en el costado sur del presbiterio, para cuyo acceso se horada el correspondiente vano ciego, de igual modo que para la apertura de diversos 
accesos de luz se perforan otros tramos de los muros del presbiterio. Un cambio fundamental y coherente con el propósito de magnificar la iglesia es el añadido en la torre del cuerpo superior de campanas que actualmente domina el entorno de Lara, así como la construcción en sillería del husillo que permite la subida a la misma (Iza). Para su construcción se maciza y colmata la totalidad del espacio interno de la torre preexistente (I 7 b).

Es en este mismo periodo cuando, derivado de algún posible problema constructivo o derrumbe, se rehace la esquina suroccidental del conjunto, en el ámbito de la que suponemos fue en su día galería porticada románica del templo. A su vez se reforma buena parte del recrecido del que fuera flanco sur de la misma: se abren o reformulan sus vanos y se rehacen sus cuerpos superiores, incluyendo la totalidad de la línea de cornisa de este costado meridional (I8).

Aunque resulta complicado ofrecer una datación, al intervalo propuesto debe de corresponder el magnífico solado que hoy cubre la nave de la iglesia. Se trata de un elemento constructivo al que se suele prestar poca atención, si bien cumple una función fundamental en la definición del espacio arquitectónico. La concreción de sus niveles de asentamiento, de sus posibles cambios de cota, así como las texturas y tonalidades de sus materiales compositivos, contribuyen en buena medida a la consecución de la percepción del volumen construido por parte del visitante. Se conservan con profusión en el ámbito castellano solados como el que mantiene esta parroquia de Lara, compuesto de diversas filas y calles que delimitan espacios de enterramiento, que a buen seguro han continuado en uso hasta bien entrado el siglo XIX. Suele ser habitual que estos pavimentos se materialicen en madera: rastreles divisores y tableros de una única pieza cubriendo cada sector confinado entre aquellos. En el caso de Lara este esquema se define todo él en piedra, solución no tan habitual, completando además la composición con el juego cromático de combinación de tonalidades diferentes entre sus piezas. Las tapas de las filas centrales se completan en una piedra caliza de tono claro, que en contraste con la tonalidad más oscura de las piezas que forman los rastreles y con la correspondiente al resto de las tapas, configuran una via sacra central en el eje longitudinal de la nave. A los valores descritos, se suma la rica documentación de carácter etnográfico que este importante elemento del templo, sin duda digno de preservar, es capaz de depararle al investigador.

Finalmente, destacamos dos elementos de interés e imprecisa data: la presencia visible de restos de pincelados en este espacio, un falso despiece simulado con pintura gris con junta blanca simple, para lograr un módulo de sillar más pequeño que aquellos a los que se superpone, regularizándolos; y la conservación de cuatro grafitos históricos incisos de grandes dimensiones sobre la sillería de la nave, representando tres cabezas de animal y lo que recuerda a una hoja de espada.

\section{$3 \cdot 4$ Continuidad decorativa: el Románico repintado}

Finalmente queremos destacar lo que posiblemente es la última gran transformación de "lenguaje románico" que tiene lugar en este templo de Lara, y que bien pudiera datarse en el siglo XIX.79 Se trata de la decoración interior de la cabecera del mismo mediante el repintado de sus elementos románicos, en particular los fustes de las columnas. Hacemos especial hincapié en esta manera de embellecimiento porque constituye un destacado y singular ejemplo de este aspecto decorativo, generalmente menospreciado por la historiografía al uso, pero que resulta de gran singularidad, como testimonio de la estética de una época, y supone un estrato más que "leer" (en consonancia

79. El citado don Fausto, preguntado al respecto, nos dijo que él y su padre vieron siempre así el interior. Es difícil asignar una cronología a estas nuevas policromías, que en este caso exceden de los más habituales "jaspeados", que comienzan a aparecer en la documentación parroquial por esta zona oriental castellana a principios del siglo XVIII. 
con la Arqueología de la Arquitectura, que entiende los edificios históricos como documentos estratificados), susceptible de ofrecer nueva información.

Estos repintados constituyen la continuidad popular casi subconsciente de una tradición que entronca con el mismo momento de concepción del Románico, que siempre se encaló y decoró. Finalmente, guardan en sí mismos un destacado valor etnográfico que singulariza al edificio que los contiene, un aspecto muy digno de tener en cuenta a la hora de analizar en estos edificios y más, si cabe, a la de intervenir en ellos, por lo cual conviene llamar la atención y recomendar el mayor cuidado al respecto (vid. Esteras-Lorenzo 2009).

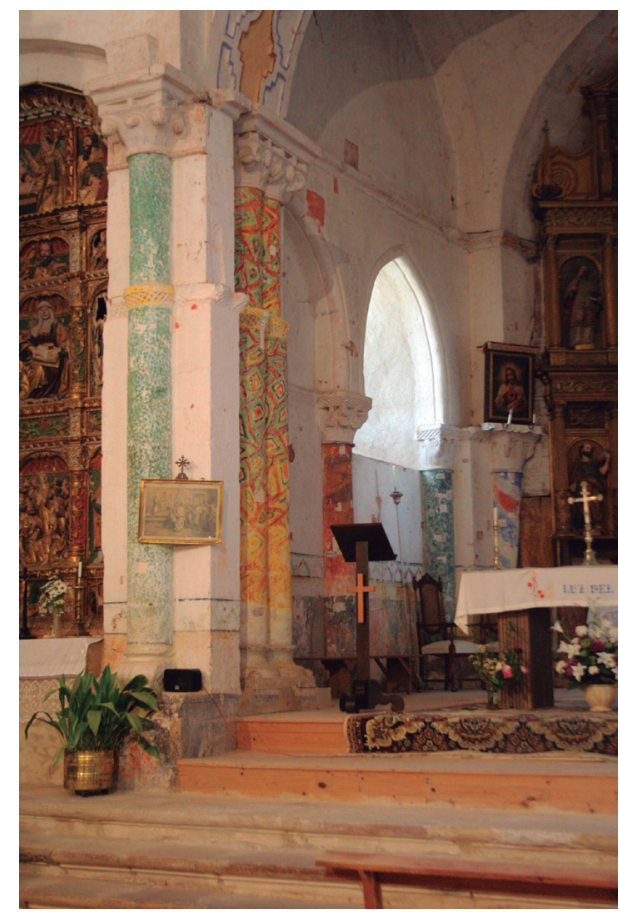

II. Fustes repintados de las columnas románicas del arco de gloria y del presbiterio (costado norte)

(c) Br Bsteras, Lorenzo \& Montaner

\section{Las inscripciones de la galería de la iglesia parroquial de la Natividad de Nuestra Señora de Lara de los Infantes}

$\mathrm{C}$

Como queda dicho, cuando el visitante se aproxima a la esquina sudoccidental de la galería de la parroquia de Lara, se encuentra con dos sillares inscritos, cuya disposición puede sorprenderle. En el costado oeste de dicha estructura, a unos tres metros sobre el nivel del suelo, aparecen dos inscripciones de una misma mano, o quizá una inscripción distribuida en dos sillares dispuestos en distinta hilada y engatillados. ${ }^{80}$ Estas dos piedras están atacadas por líquenes que los decoloran en diversas partes de su superficie, pero que no atacan a todos los sillares de ese paramento por igual.

8o. Hiladas quinta y sexta desde el suelo, a partir del pequeño zócalo románico sobre el que se asienta este paramento. Ambos sillares son de tamaño superior a los de su hilada. El inferior (quinta hilada) linda al sur con la línea de fractura que advierte de un remonte de esta esquina (véase lo expuesto en el § 3.2: "Evolución del templo entre los siglos XIV y XVII”). El sillar donde comienza la inscripción (sexta hilada), engatilla también el dispuesto en la hilada superior hacia el norte, de tonalidad cárdena (véase la ilustración 7). 
Por otra parte, la presencia de sillares escantillados puede ser un indicio de un remonte del muro por encima de su zócalo, consecuencia de un posible derrumbe.

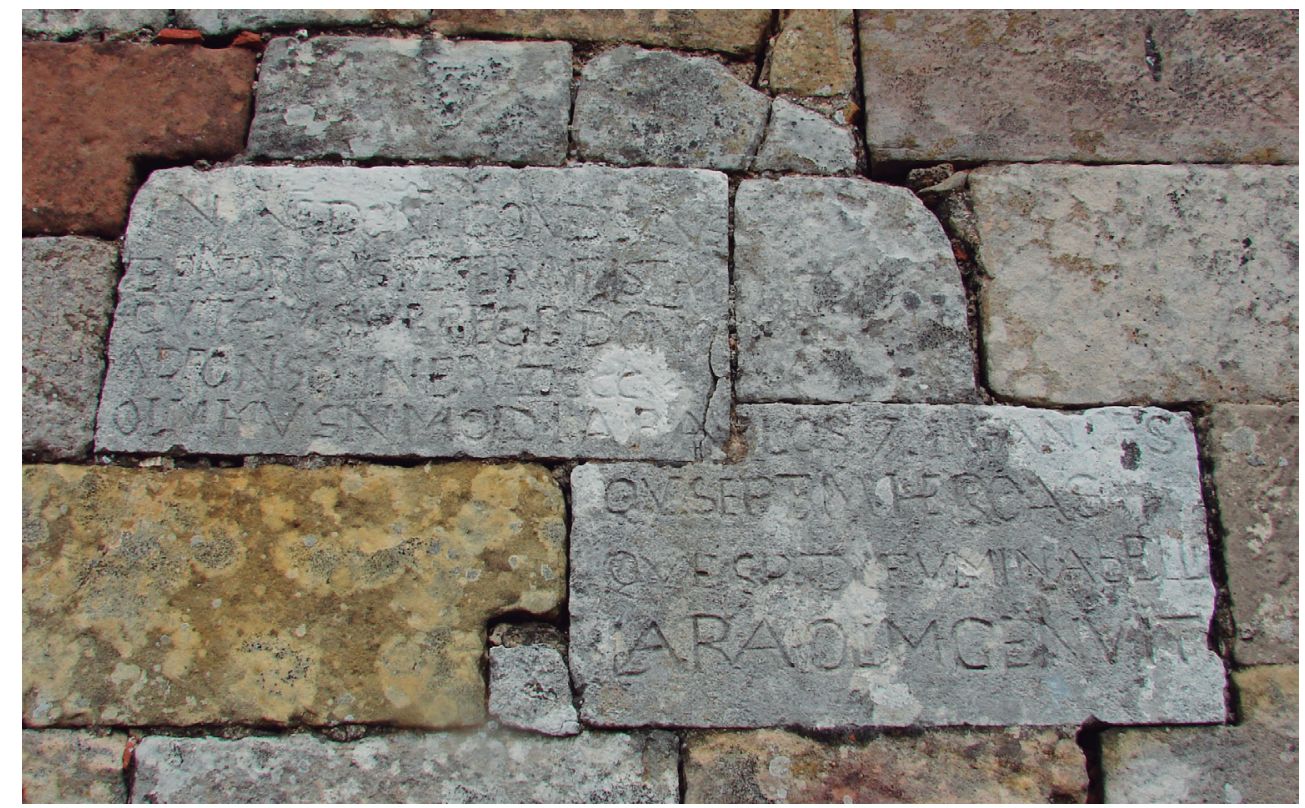

I2. Los epígrafes de la iglesia parroquial de Lara de los Infantes

$\left(\right.$ (c) Br $_{\text {B }}$ Esteras, Lorenzo \& Montaner

Se trata de dos epígrafes relacionados con la previamente estudiada inscripción de la ermita de San Julián. Su transcripción cuasi-facsimilar, manteniendo la disposición engatillada de ambos epígrafes, es la siguiente:

\section{IN ÑE DOÑI GONDISASS \\ E FNE RICVS FECERVNT ISTA \\ CIVITÆM SVB REGE DONO \\ ADEFONSO IN ERA OccC \\ OLM AVSAM OE LARA | LOS .7. INFANTES \\ QE SEPEM HEROAS \\ QEE SEPEMFVMINA BELIi \\ IARA OİM GENVITT}

I3. Transcripción cuasi-facsimilar de los epígrafes de la parroquial de Lara de los Infantes

Pese a la yuxtaposición de la última línea del primer epígrafe con la primera del segundo y al hecho de que el antecedente del relativo que (por quae) en el inicio del segundo parece ser la Lara que cierra el primero, la aparición de la rúbrica romance LOS .7. INFANTES y el cambio de sillar en diagonal y no en vertical constituyen razones suficientes para considerar ambos textos por separado. Ratifica esta decisión el hecho de que, aunque relacionadas, las inscripciones se refieren a temas 
diversos y poseen orígenes diferenciados, siendo la primera una obvia adaptación de la lápida de San Julián, mientras que la segunda es de procedencia desconocida. Finalmente, el primer texto está en prosa y el segundo (lo que no se había advertido hasta ahora), en verso.

\section{I. Introducción historiográfica}

Como se ha visto, la noticia más antigua sobre la primera de estas inscripciones se debe a Sandoval (I6I5: 27I [= 283]), quien señaló su fecha reciente: "se asentó en la pared de la puerta principal de la parrochia ha pocos años", lo cual, teniendo en cuenta que su obra se publicó en I6I5, ${ }^{\text {8I }}$ permite situarla hacia i6oo. Su transcripción reza In nomine Domini, Gundisaluus, \& Findericus fecerunt istam ciuitatem sub Rege Domino Adefonso in Era DCcC. Olim Ausina, modo Lara. A mediados del siglo XVII Antonio Zapata, en su historia de la localidad riojana de Canales de la Sierra escrita en I6 $57,{ }^{82}$ incluyó otra transcripción de la misma, basada en el original, aunque seguramente de forma mediata y en todo caso notablemente corrupta: Gundisalvus Hildericus fecerunt istam civitatem, regnante Rege Alphonso era DCCC, olim Maussina, modo Lara (Fita ed. 19O7c, 4OO-I) o Gundisaluvis Hildericus fecerunt istam Civitate regnan [sic] Rege Alphonso era DCCC, olim Mausina, modo Lara (Martínez ed. 1934: I70). ${ }^{83}$

A partir de Sandoval, transcribieron este primer epígrafe, con un número creciente de inexactitudes, Gregorio de Argaiz (I675: 283): In NOMINE Domins. | Gundisaluius, \& Findericus istam Ciuitatem sub Re |ge Domino Adephonso, in era DCCC. olim Mausina modo Lara; Sota (I68I: 423): In nomine Domini, Gundisalbus, | Et Findericus fecerunt istam Ciuitatem, | Sub Rege Domino Adefonso, | In Era 80o. olim Ausina, modo Lara, y Luis de Salazar y Castro (I696-I697: I, 23 y 40): In nomine Domini, Gundisalvus, EF Findericus facerunt (facerunt en p. 40) istam Civitatem, sub Rege Domino Adefonso, in Era DCCC. Olim Ausina, modo Lara. Un caso peculiar es el de José Pellicer de Ossau, quien, antes de i676, ofrece la siguiente transcripción comentada:

i alli cerca la Ciudad de Lara, que Poblaron los Condes Don Gonçalo, i Don Sigerico, Hijos del Príncipe Don Fruela, i Consta de la Inscripcion que trahe Sandoval: In Nomine Domini, Gundisalvus \&'Sigericus (no Findericus) Feçerunt Istam Civitatem, sub Rege Domino Adefonso in Ara DCCC...... olim Ausina modo Lara. Y aquí tuvieron Principio los Condes de Lara, i de Castroxeriz, que Proceden los Vnos del Conde don Gonçalo, i los Otros del Conde don Sigerico. ${ }^{84}$

Las variaciones introducidas por Pellicer (cambio de lectura del segundo antropónimo y marca de texto faltante en el numeral) podrían hacer pensar que el erudito aragonés tuvo a la vista, si no el original, al menos una nueva copia o calco. Sin embargo, el texto deriva claramente de Sandoval,

8I. La aprobación está firmada por Diego de Medrano “En este Colegio de la Compañía de IESVS de la Ciudad de Pamplona, à i6. De Hebrero, I6I5” (Sandoval I6I5: f. I2r), de modo que la redacción de la obra tenía que estar concluida como mínimo a fines de i6 4 .

82. Martínez Ariz-Navarreta (ed. I934). Previamente se disponía de una descripción y extractos editados y anotados

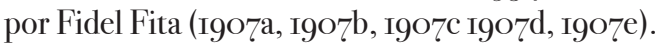

83. Seguramente el manuscrito original de Zapata rezaba Gundisaluius Hildericus fecerunt istam Ciuitatem regnante Rege Alphonso era DCCC, olim Mausina, modo Lara. Según el mismo Zapata, la inscripción "está encima de la puerta de la iglesia de Santa María de Lara” (Fita ed. r9o7c, 400 = Martínez Ariz-Navarreta ed. r934: I7o), hoy de la Natividad de Nuestra Señora, lo que, como se ha visto, es inexacto.

84. Pellicer de Ossau (I68I: 242; $c$. también 220). La obra se publicó póstumamente al cuidado de su hijo Miguel Antonio, pues el autor había fallecido en i679, y llevaba trabajando en ella al menos desde i676 (vid. Oliver r995: 62 y 87). 
como el mismo autor señala, y las modificaciones realizadas so capa de enmienda proceden en realidad de conjeturas ad hoc realizadas por Pellicer para cuadrar sus fabulosos datos genealógicos. Pese a que el bien documentado y crítico Salazar y Castro (I696-I697: I, 4O) aceptó esta versión (incluso si, como acaba de verse, adoptó la transcripción de Sandoval), lo cierto es que tales personajes no aparecen documentados en las crónicas asturianas del período, que conocen como único hijo de Fruela I al futuro Alfonso II: "Froila [...] Uascones rebelantes superauit huxoremque sibi Muniam nomine exinde adduxit, unde et filium Adefonsum genuit" (Chronica Adefonsi III Rotensis, I6; Gil et al. ed. 1985: 134). A Argaiz y a Pellicer sigue, a su vez, Francisco de Berganza (I7I9-I72I: I, II3), quien, no obstante, tuvo también información más directa, como revela su comentario:

En su Iglesia Parroquial está vna lapida, que dize: In nomine Domini Gundesalvus, \& Findericus fecerunt istam Civitatem sub Rege Adephonso in Era DCCC. Don Joseph Pellizer después de los numeros DCCC. puso algunos puntos, para dár à entender faltaban algunos numeros de la Era. Constame, que está entera la lapida, y que à los numeros se siguen inmediatamente las otras palabras.

En Sandoval, Argaiz y Pellicer se basó Aniceto de la Cruz González (I795: 43), que edita In nomine Domini, Gundisalbus et Frindericus fecerunt istam Civitatem, sub Rege Domino Adephonso in cera DCCC. También se basa en Sandoval Juan Francisco de Masdeu, en I79I, aunque, a diferencia de los anteriores, lo hizo en su segunda transcripción (la de la p. 355) y, además de reproducirlo en versales con disposición de copa de Médicis, para darle un aspecto más epigráfico, según su costumbre, adaptó algunos detalles y consideró que en la última línea había que transcribir m Avsina, interpretándolo como Municipium Ausina:

\author{
IN NOMINE DOMINI \\ 盾 \\ GVNDISALVVS ET FENDERICVS \\ FECERVNT ISTAM CIVITATEM \\ SVB REGE DONO ADEFONSO \\ IN ERA DCCC. \\ OLIM M AVSINA MODO LARA. ${ }^{85}$
}

El primero en dar cuenta de los dos epígrafes, y hacer además su crítica, fue Enrique Flórez (1772: cols. 619-622; 2. ${ }^{\mathrm{a}}$ ed. I824: 3IO-II), cuya transcripción del primero reza: In nomine Dni. Gundisalvus \& Findericus fecerunt istam Civitatem sub Rege Domino Adefonso in Era DCCC. Olim AUSINA, modo LARA, y añade: "Pero ni la piedra, ni el nombre son seguros: pues no dice Ausina, sino Mausina ò Amusina: porque la A. está enlazada en las dos primeras lineas de la M. siendo mas propia de AM que de MA: pero de ningún modo corresponde à AVS: y en efecto el Sr. Sandoval en la version castellana no puso Ausina, sino Mausina”. Además, por no haber prestado suficiente atención a Sandoval, cree que ambos son innovaciones, alegando, respecto del copiado, que "no tiene indicio de antiguedad, sino que algun Cura la dispuso como le pareció, tirando á dar antiguedad al lugar, y no acertó" (ibid., col. 620; 2. $\left.{ }^{\mathrm{a}} \mathrm{ed} ., 3 \mathrm{IO}\right)$. Al mismo supuesto párroco atribuye la paternidad del segundo epígrafe, que transcribe así (ibid., col. 622; 2. ${ }^{\mathrm{a}} \mathrm{ed} ., 3 \mathrm{II}$ ):

85. Masdeu (I783-I805: 9, 4O, art. XXI, no. I). Retoman su texto y explicaciones, sin citarlo, Barbosa Canaes de Figueiredo (I853: II), pese a citar a Flórez, al que, por otra parte, tergiversa, y Castor de Caunedo (I854:45). 
LOS 7. INFANTES

QVE SEPTEM HEROAS

QVE SEPTEM FVLMINA BELLI

LARA OLIM GENVIT.

Sus planteamientos fueron retomados y desarrollados por José Ortiz y Sanz ${ }^{86}$ reaccionando contra el empleo de la misma como prueba para fijar la cronología de Alfonso I de Asturias por parte de Noguera (I787: 419), quien a su vez se basa en Sandoval y en Salazar, pero ofrece solo la traducción del epígrafe. La transcripción de Ortiz (I84I-42: 3, 63) sigue la de Sandoval: In nomine Domini, Gundisalvus et Findericus facerunt istam civitatem sub rege domino Adefonso in Era DCCC. Olim AuSInA, modò LARA. Sin embargo, no se basa solo en él, pues da precisiones que no aparecen en su texto, lo que revela que, o bien conoció el epígrafe de primera mano, o bien le proporcionaron una copia bastante fidedigna, pues luego comenta que "Lara nunca se ha llamado Ausina. Ni la piedra tiene Ausina, sino - mvsina, que parece decir Amusina. Sandoval en su traducción puso Musina" (Ortiz I795-I803: 3, 297; I84I-42: 3, 63, donde se estampa MVSINA).

Las bien fundadas críticas de Flórez y Ortiz fueron retomadas y sistematizadas por José Caveda y Nava (I879: I2-I3) y por Louis Barrau-Dihigo (I92I: 272), quien la considera "inscription criante de fausseté”. Su texto se basa en Sandoval, Pellicer y Hübner, con lo que combina lecciones de las dos versiones de la inscripción y añade como variante la lección imaginada por el segundo: "Gundesalvus et Findericus [ou Sigericus] fecerunt istam civitatem, sub rege Dno Adefonso in era DCCC, olim Ausina, modo Lara" (ibid., 272, n. 3). Con todo, hay que esperar a los ya citados trabajos de Escalona (I995: 565-566, y 2000: I6I, n. Io9) para encontrar una nueva transcripción, hecha directamente sobre los testimonios, y a un análisis más detallado de estas piezas, que compara por vez primera con la inscripción procedente de la ermita de San Julián. Su transcripción es la siguiente:

In N(omin)E Do(mi)Ni GONDISALVS | E(t) FINDERICVS FECERVNT ISTAM | CIVITATEM SVB REGE DO(mi)NO | ADEFONSO IN ERA DCCC | OLIM AUSINA MODO LARA. LOS 7 INFANTES | QUE SEPTEM HEROAS | QUE FULMINA BELLI | LARA OLIM GENUIT.

Por lo que hace a la segunda (parte de la) inscripción, ha sido mucho menos reproducida y comentada que la anterior, ya que carecía de especial valor histórico. Sin duda ello se debe a la inclusión de la mención en romance de los siete infantes y a transmitir un dato que, para la época de su ejecución, ya se daba por sentado, puesto que desde fines de la Edad Media los infantes, que originalmente lo eran de Salas, ya habían pasado a serlo indiscutidamente de Lara, lo que solo sucede a partir del siglo XV. ${ }^{87}$ Como queda dicho, el primero que dio noticia de la misma fue Flórez (I772: col. 622; 2. ${ }^{\text {a }}$ ed., 3II), quien la juzga así: "El mismo Cura que puso aquella Inscripcion, seria Autor de otra piedra que está junto à ella, y dice: LOS 7. INFANTES [...] cuyo barbaro estilo muestra bien la poca autoridad del inventor”. De él la toma Ramón Menéndez Pidal (I896: I79), que repite

86. Ortiz y Sanz (I795-I803: 3, 297-98). El comentario aparece notablemente ampliado en la póstuma segunda edición (I84I-42: 3, 63-65), como se ha visto en las notas $3^{8}$ y 42.

87. Como ya señaló Menéndez Pidal (ı896: I79). Vid. también Escalona (ı995: 566-67, n. 827). De esa confusión en torno al solar de los Infantes ya parece hacerse eco hacia I289 la Versión amplificada de la Estoria de España, cuando anuncia que "Agora [...] diremos de los siet infantes de Salas -et otros les dizen de Lara-" (Menéndez Pidal ed. r955: 2, 43I), coletilla ausente tanto de la Versión primitiva, redactada hacia I272 (ibidem, n. 25), como de la Versión crítica elaborada entre r282 y г284 (Campa ed. 2009: 334). Sin embargo, no se da ahí un traslado (como siempre se ha creído), sino un paso de lo local (Salas) a lo comarcal (el alfoz de Lara), pues la leyenda se refiere solo a este último y nunca a la villa epónima. Volveremos sobre este aspecto en el apartado final. 
su valoración: “una bárbara inscripción donde se expresa esta errada creencia”, es decir, que los infantes eran naturales de Lara y no de Salas. En su estudio, Escalona (I995: 565-66) la tilda de “torpe alusión a los Siete Infantes de Lara” y de "patrañas", para concluir que "no contento el falsificador con lo burdo del texto urdido, además desliza un numeral arábigo en la primera línea" ".8 Más recientemente, García Morilla (2OI3: 254-55) ha incluido en su corpus epigráfico burgalés esta inscripción, ${ }^{89}$ que caracteriza como "chronica historica sobre el origen de los siete infantes de Lara”, pero, al desconocer su ubicación y basarse solo en Flórez (I772: col. 622), la considera originalmente sita en el "atrio de la fortaleza" y "actualmente desaparecida". Aunque consciente del carácter tardío de la inscripción, le asigna a su referente histórico la fecha de circa 867, que carece de apoyo en la cronología interna de la leyenda, pues, como explica Martínez Diez (20I4: I74):

El Cantar de los siete infantes de Lara sitúa cronológicamente su acción en los años en que regía el condado de Castilla el conde García Fernández (970-995), hijo de Fernán González (93I-970), y gobernando Almanzor el califato de Córdoba como háchib [sic pro hạğ́ib ‘chambelán’] o primer ministro y valido todopoderoso entre los años $97^{8}$ y IOO2.

Finalmente contamos con otra transcripción, manuscrita e inédita, que parece proceder de la observación directa y no es, por tanto, producto de la tradición erudita. Se trata de la que realizara a finales del siglo XVIII Víctores Juez (I796: f. 234r-v), párroco de Tinieblas de la Sierra, pueblo cercano a Lara, en las respuestas ofrecidas al interrogatorio del geógrafo real Tomás López con vistas a su (finalmente inédito) Diccionario geográfico de España. Curiosamente repitió la respuesta, en dos versiones muy parecidas. De las “antigüedades” presentes en Lara, afirmó el sacerdote, en la primera versión:

aparecen en la Poblacion, y sus contornos monedas de plata, y cobre con caracteres antiguos, y varios en los actuales edificios se manifiestan insertos muchos fragmentos de otros mas sumptuosos con armas, e inscripciones ignotas a los no versados en antigüedades. Tiene una sola Parrochia, cuio titulo es Santa Maria de Lara, y esta es una Ymagen antigua, y venerable de Maria Santisima. A la entrada de la Yglesia en el frontispicio exterior se presentan colocadas en el paredon dos piedras sillares con inscripciones, que de la una es: in Nomine Domini. Gondisalvus et Federicus fecerunt istam civitatem sub Rege Alfonso in era DCCC. Olim Mausina modo Lara. y la de la otra contigua: Los \%. Infantes de Lara.

\author{
QuAE septem Heroas. \\ QuAE septem Fulmina Belli \\ Lara olim genuit. ${ }^{\circ}$
}

88. El mismo Escalona (2000: I6I-62, n. Io9) la presenta como “una torpe falsificación que yuxtapone una mala copia de otra inscripción conservada entonces en la iglesia de San Julián de Lara y una breve noticia que pretende hacer a los siete infantes hijos de Lara y en la que no falta el numeral arábigo 7 ”.

89. Este autor no incluye el primer epígrafe, cuya existencia desconoce, aunque, como se ha visto, sí recoge la inscripción original de San Julián.

90. Las grafías $Q u A E$ aparecen así en el manuscrito. La segunda noticia apenas varía, sino en detalles nimios: “En el frontispicio exterior cerca de la entrada a la Yglesia se presentan en el paredon dos piedras sillares contiguas con inscripciones que dicen, la de la una: Gondisalbus, et Federicus fecerunt istam civitatem sub Rege Alfonso in era DCCC. olim Mausina, modo Lara. y la otra: Los \%. Infantes de Lara. QuAE septem H[e]roas. QuAE septem fulmina belli Lara olim genuit" (Juez I796: f. 242r). La carta impresa con el interrogatorio del que dio cuenta este sacerdote llegó al arciprestazgo de Salas de los Infantes el I5 de junio de i796 (f. 239r). Una de las respuestas se data en Tinieblas [de la Sierra] el ı3 de octubre del mismo año; la otra respuesta carece de data. El párroco afirma "que solo ha contribuido a las pocas luces, que participo, la larga, y continuada residencia de 30 años en el Pais” (f. 237r). Esto podría explicar algunas 


\subsection{El primer epígrafe, la fundación de Lara}

Pese al concienzudo trabajo de Escalona, es posible afinar algunos aspectos de interpretación gráfica, según muestra el siguiente calco:

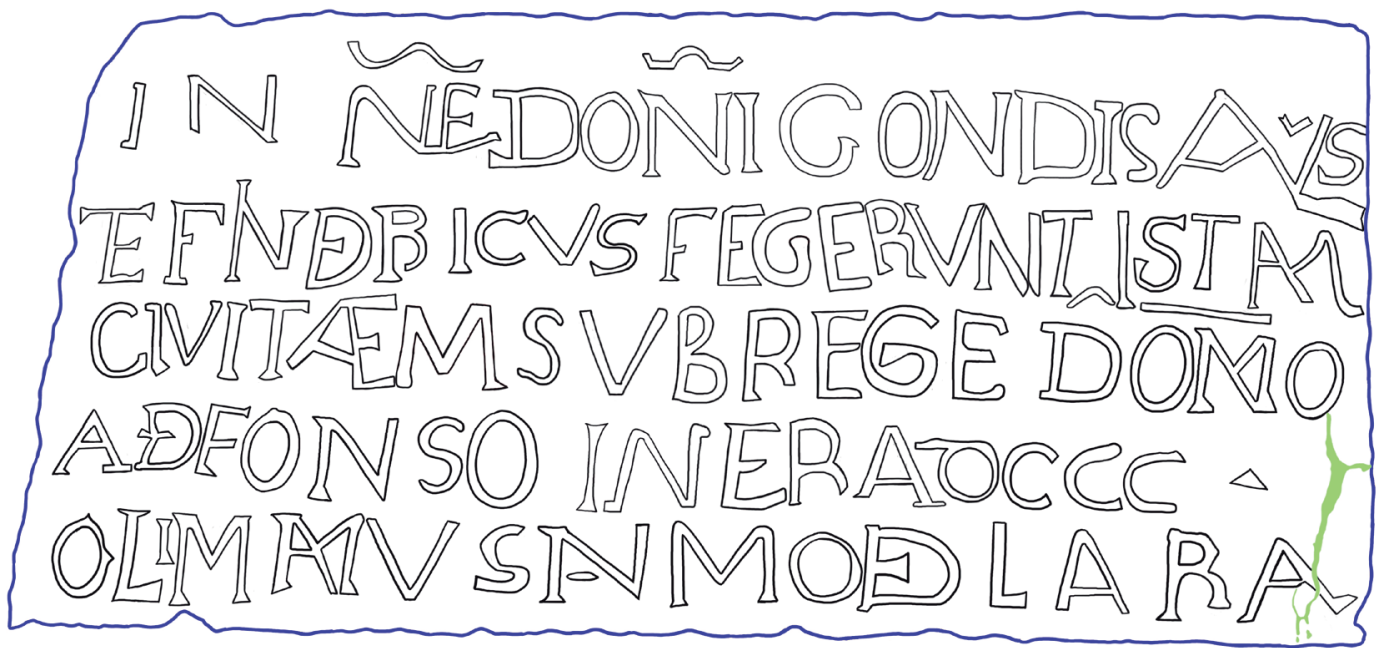

I4. Calco del epígrafe conmemorativo de la fundación de Lara en la parroquia de la Natividad (c) Br Esteras, Lorenzo \& Montaner

Por lo tanto, nuestra transcripción del primer epígrafe es la siguiente:

IN NOMinE DOMiNI GONDISATLVS

2. ET FINDERICVS FECERVNT ISTAM CIVITATEM SVB REGE DOMINO

4. ADEFONSO IN ERA JCCC . OLIM AMVSTNAM ODIE LARA ${ }^{91}$

La inscripción carece de pautado, aunque la mitad inferior de la cuarta línea parece presentar una línea que la separa de la siguiente y que, en tal caso, delimitaría el final del texto copiado del epígrafe la ermita de San Julián. Está tallada en letras capitales humanísticas (las "letras Romanas” que decía Sandoval) incisas, excepto la fecha, que, como en el caso de su modelo, presenta $d$ cursiva

de las particularidades de su transcripción, que parece hecha de memoria.

9I. Las variantes de los demás editores, por número de línea, son las siguientes: I) IN Nomine DominI : sin abreviar en todos los editores anteriores a Escalona, excepto Flórez, que ofrece Dni. : om. Zapata y Barrau || GONDISALVVs : Gundisaluus Sandoval, Flórez: Gundisalvius Argaiz y seguramente Zapata (vid. nota 93) : Gundisalvus Zapata (ed. Fita), Pellicer, Salazar, Ortiz : Gundisaluvis Zapata (ed. Martínez) : Gundesalvus Berganza, Barrau : Gundisalbus Cruz González : Gondisalbus Juez (f. 242r) : Gondisalvs Escalona. 2) ET : E(t) Escalona : et Sota, Cruz González, Ortiz : \& los demás editores || Findericvs : Fendericus Sandoval (solo en p. 358), Masdeu: Hildericus Zapata : Frindericus Cruz González : Sigericus Pellicer, Barrau (como variante) : Federicus Juez | | FECERvNT : facerunt Salazar (solo en p. 40, por errata) : feçerunt Pellicer. 3) SvB : regnan Zapata (ed. Martínez) : regnante Zapata (ed. Fita) | I Domino : sin abreviar en Sandoval (p. 283), Argaiz, Pellicer, Sota, Salazar, González y Ortiz : om. Zapata, Berganza y Juez. 4) ADEFonso : Alphonso Zapata : Adephonso Argaiz, Berganza, Cruz González : Alfonso Juez : ADFonso Escalona | | IN : om. Fita || ERA : æra Cruz González, Pellicer || DCCC : DCCC... Pellicer : 8oo Sota. 5) Cruz González la omite entera || Amvsinam : Ausina Sandoval, Pellicer, Sota, Salazar, Berganza, Barrau, Escalona : Mausina Sandoval (en p. 358), Zapata (ed. Martínez), Argaiz, Juez : Maussina Zapata (ed. Fita) : Mausina o Amusina propone leer Flórez : m[unicipium] Avsina Masdeu $:$ mVSINA $=$ Amusina o Mausina Ortiz || ODIE $:$ modo todos los editores. 
(uncial) y está en minúsculas, aunque con una centena menos: “дccc”. Muestra numerosos nexos, marcados en la transcripción por una curva sobrescrita, y dos letras inscritas, la segunda v de GONDISALV ${ }^{\vee}$ S y la I de OL'M. Las escasas abreviaturas se hacen por contracción y se marcan mediante una tilde suprarrayada horizontal, en los dos primeros casos con un realce semicircular en el centro y remates en diagonal hacia arriba, diseño frecuente todavía en este período, aunque ya habitual en la práctica epigráfica desde el siglo XII. Las palabras abreviadas son casi las mismas que en la inscripción original e incluso se conserva la primera, pese a ser menos frecuente, $\mathrm{N}^{-} \mathrm{E}=$ Nomine (lín. I), mientras que en las formas de Dominus se añade una $\mathrm{O}^{\mathrm{DON}^{-} \mathrm{I}}=$ dominI (l. I), $\mathrm{DON}^{-} \mathrm{O}=$ DomiNo (1. 3), y desaparece la de $\mathrm{CI}^{-} \mathrm{T}^{-} \mathrm{EM}=$ CIvitaTEM, voz que se escribe plena, aunque en lo que debería ser el nexo A-T-E solo es posible distinguir $\nRightarrow$, y no se aprecia el trazo izquierdo del astil horizontal de la T, por lo que cabe la duda de si hay que transcribir sin más dicha letra o suplirla: CIVI $<\mathrm{T}>\mathrm{ATEM}$. Optamos por la primera opción a la vista de otros casos en que la letra subsumida en el nexo resulta obvia, pero tampoco es claramente apreciable, lo que sucede sobre todo con la I. Es precisamente la abundancia de nexos y letras enclavadas lo que ha dado lugar a buena parte de las variantes y dudas de transcripción consignadas en la nota 9i. Ello responde a una costumbre característica de los epígrafes renacentistas con pretensiones de factura a la antigua, especialmente si eran copia de otros preexistentes. ${ }^{92}$ Se trata de una especie de hipercaracterización respecto de los modelos que sus artífices conocían, tendencia frecuente en los pastiches de toda índole, plásticos, gráficos o textuales.

En este caso, los términos que han dado más problemas han sido los de la última línea, por incluir un topónimo desconocido y carecer de la pauta del más legible epígrafe original. Respecto de AMVSINAM, la ligadura de las iniciales A-M está clara y dado que el astil horizontal de la A se sitúa en la primera mitad de la m y no en la segunda, el orden de lectura no plantea dudas. No obstante, podría sugerirlas el siguiente pasaje atribuido a un supuesto Martirologio Helnense: "In Hispania Tarraconense, in urbe Segiditana, non procul a Mausina civitate, fortissimi martyres Aulus miles, Severa virgo et alii qui in persecutione Trajani sub Preside Tertulio post multos labores martyrio coronati sunt", citado por el ya mentado Zapata, Historia de Canales, que aduce a continuación la inscripción de la parroquial de Lara. En efecto, cabría la sospecha de que quienes añadieron la quinta línea del epígrafe al texto preexistente se basaran en dicha noticia para elaborarla, en la creencia de que la tal Mausina era Lara. Sin embargo, el mismo Fita (I9O7d: 400, n. 3) advierte que estos pasajes son invención del propio Zapata, y por tanto posteriores a la inscripción citada. ${ }^{93}$ Esto queda confirmado por el hecho de que la mención de una desconocida Mausina en este contexto solo tiene sentido de tener una referencia previa a su localización, lo que a su vez permitía ubicar en Canales de la Sierra la ya conocida pero aún no ubicada Segeda, mencionada por Apiano, Diodoro y Floro, lo que se apoyó con la falsificación de un epígrafe romano ad hoc. ${ }^{4}$ Ello deja claro que la supuesta Mausina del falso cronicón es solo fruto de la (errada) lectura de la inscripción lareña y no a la inversa.

En cuanto a la -M final, viene exigida por el hecho de estar Amusinam en aposición al civitatem

92. Compárense los ejemplos reunidos por Diego Santos (I994: 244-47) y Gutiérrez Álvarez (I997: láms. LXVIILXXIV).

93. Fita (ed. I9O7d: 4OO), mejor que en Martínez (ed. r934: 126-27). Solo hemos encontrado otra mención del Martyrologium Helnense, pero en una obra posterior a la de Zapata, la de Alva (I663: col. 228): "Helnense, cun Bichensi \& Tarraconensi, [...] recitabat de Conceptione, imo, \& in Martyrologio Helnensi”, quien dice tomar el dato del conocido forjador de falsos cronicones Antonio Lupián Zapata, pseudónimo del archivero de la catedral de Burgos Antonio de Nobis (vid. Godoy i868: 265-76, quien, no obstante, no cita esta obra entre sus falsificaciones, aunque sí un Martirologio de san Gregorio Bético).

94. Burillo (I988: 32-35). Para más detalles sobre la localidad celtibérica de Segeda, véase Burillo (2005). 
de la tercera línea y, por lo tanto, en acusativo. En rigor, Lara también debería estarlo y es poco probable que un redactor que acertó a concordar el primer topónimo con su antecedente dejase sin declinar el segundo. Cabe pensar que el lapicida lo omitió, por acabársele el espacio, o que el signo de abreviatura de nasal se confunde con la línea horizontal que separa esta parte de la línea quinta de la anterior, como queda dicho. En cualquier caso, parece claro que se ha de restituir LARA $<_{\mathrm{M}}>.95$ En cuanto a modo, es aquí una palabra fantasma, pese a la unanimidad de los editores. Restituida la -m a la desinencia de Amusina, se advierte que lo que queda es ODIE, es decir, hodie con aféresis de la $h$ - y ligadura D-I-E. Es, además, lo que pide la sintaxis, según la bien establecida correlación olim... hodie... 'antaño... hogaño... ${ }^{96}$ que, en cambio, en caso de haber una correlación con modo, se habría construido con nunc o tunc, significando 'entonces... ahora...', aunque se trata de un giro más raro, pues el sentido propio de modo es 'en seguida; hace un momento; poco después'. ${ }^{77}$ En todo caso, quizá fue esta construcción tunc / nunc... modo... (aunque infrecuente) la que, ante los problemas de legibilidad de la inscripción, confundió a sus primeros transcriptores.

La estructura diplomática del epígrafe comentado es lógicamente idéntica a la de su modelo, la inscripción de San Julián, con la salvedad de la citada adición de la quinta línea donde, a modo de aposición desplazada, campea la comentada glosa sobre CIVITATEM. Así, las cuatro primeras líneas inscritas en el epígrafe parroquial copian, con algunas variantes y distinta distribución por renglones, las también cuatro primeras de la inscripción de la ermita de San Julián. Se transcribe de manera distinta el nombre de Gonzalo, antes GVNDESALBvS y ahora GONDISALVvs, seguramente como lectio facilior gráfica. ${ }^{9}$ Mayor alteración experimenta el antropónimo del segundo personaje, convirtiendo en un inusitado FINDERICVS al que antes era un usual RVDERICVS, y debemos resaltar que ningún Finderico aparece recogido en los citados documentos atribuidos a la etapa condal ni, en general, en otras fuentes medievales. ${ }^{99}$ Resulta bastante sorprendente la sustitución de un nombre tan frecuente como Rudericus por un auténtico hápax. A nuestro juicio, esto se explica por la concurrencia de dos factores: por un lado, la existencia de la melladura que desfigura parcialmente

95. No es óbice que en los diplomas citados en el apartado i, así como en el grueso de la documentación que la menciona, Lara aparezca como forma indeclinable, puesto que ello responde al colapso del "sistema orgánico de declinación” en latín medieval diplomático no reformado; $c$. Pérez González (2008: 67-7I). No obstante, ya en la concesión de libre paso para los peregrinos de Lara hacia San Millán otorgada por el rey Sancho IV de Navarra en IO74, el topónimo aparece en acusativo: "unde comes Gonsalvo Salbatorez, qui Laram dominabatur, missit michi suos nuntios" (Serrano ed. I93O: 222, doc. 2I5).

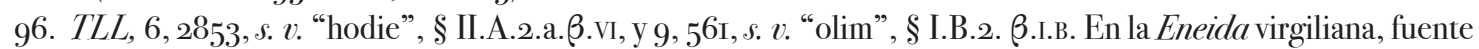
conocida por el autor del texto nuevo de estas lápidas, como a continuación veremos, en referencia a los Capitolia, se lee: "aurea nunc, olim silvestribus horrida dumis" (VIII, v. 348).

97. TLL, 8, І3Іо, s. v. “modus”, § II.A.2. El Oxford Latin Dictionary (Glare ed. I996: II24), s. v. “modo”, recoge las siguientes acepciones temporales: “5. Only recently, just now; [...] b (w. reference to present time) just now. c (w. reference to future time) in the immediate future, just now”. De la rareza de la correlación tunc... modo da cuenta el hecho de que cuando la emplea la Vetus Latina bíblica, la Vulgata la sustituye por tunc... nunc, como en Os 2, 7: "melius mihi tunc erat quam modo" (= 'era mejor para mí entonces que ahora'), transformado en "bene mihi erat tunc magis quam nunc”. A cambio, es mucho más abundante la correlación modo... nunc 'recientemente... ahora' (aunque en general equivale a modo... modo... 'ora... ora...').

98. El ya citado $C O R D E$, arroja los siguientes datos, por orden decreciente, para el intervalo temporal 8oo-I3Oo (marcamos en negrita las formas de nuestros epígrafes): Gundisalv (o, -us, - $i z$, - $e z)=325$ casos $(54,91 \%)$, Gundisalb(o, $-u s,-i z,-e z)=$ I $4 \mathrm{I} \operatorname{casos}(23,82 \%), \operatorname{Gundesalv}(o,-u s,-i z)=33 \operatorname{casos}(5,57 \%)$, Gondesalb $(o,-i z,-e z)=28$ casos $(4,73$ \%), Gondisalb(o, -iz, -ez) $=26 \operatorname{casos}(4,39 \%)$, Gundesalb(o, -us, -iz) $=20$ casos $(3,38 \%)$, Gondisalv(o, -us, -oz) $=$ I 4 casos $(2,36 \%)$, Gondesalv $(o,-u s,-o z)=5 \operatorname{casos}(0,84 \%)$. En rigor, la forma original aparece más veces que la modificada, pero la segunda viene inducida por la mayor frecuencia de las formas con - $i$ - y con - $v$-, que, como se ve, son la mayoría $(55,75 \%)$.

99. Cf. Zabalza (I998). Tampoco se documenta dicho antropónimo en el CORDE, el CODOLGA o el CODOLCAT, ni en la edición digital de los $M G H$. 
dicho antropónimo en el epígrafe de San Julián y, por otro, la predisposición de quienes lo transcribieron a encontrar una onomástica más exótica y quizá, para ellos, más claramente gotizante, sobre todo si se piensa en una mala lectura de Singerico, un nombre auténticamente germánico documentado desde la Antigüedad tardía, a través de una grafía "findericus" o similar. ${ }^{100}$

Con todo, más asombrosa resulta la omisión de la última letra de las centenas de la data cronológica (otra c), restando un siglo a la noticia epigrafiada, y situándola por tanto en el año 762 (durante el reinado de Fruela I), ${ }^{\text {ro }}$ sobre todo teniendo en cuenta que había espacio de sobra al final de la tercera línea, donde se sitúa la fecha, por lo que queda un renglón más corto que los otros tres de la propia inscripción. En este caso es imposible determinar si estamos ante un yerro de transmisión (una haplografía cometida sobre el papel al trasladar el texto del modelo o al redactar la nueva versión, o ya sobre la piedra al ejecutar la copia epigráfica) o si se trata de una omisión deliberada para retrasar la fecha de la fundación de la localidad, pese a ocasionar un mayor desajuste entre la datación cronológica y mediante el regnans, que en este caso, por proximidad, habría de identificarse con Alfonso I, rey de Asturias entre 739 y 757 . En todo caso, y a pesar de la corrupción de este texto, la ausencia de numerales después de las centenas y su buen estado de conservación confirman la lectura de la data hoy visible en la inscripción más antigua.

En la quinta línea, el añadido en aposición a civitatem informa del presunto nombre antiguo y actual de esta población, Amusina Lara, supliendo de este modo la información que se echaba en falta en el epígrafe original, como ya hemos comentado arriba, en un claro intento, no solo de identificar el enclave fundado, sino de dotarlo de antigüedad asociándole un topónimo de sabor latino que, por cierto, no encuentra correspondencia en ninguno de los 8I diplomas atribuidos a la época condal castellana (entre 9I2-IO29), ni en ninguna otra fuente que conozcamos. ${ }^{102}$ En ese sentido, se comprende la generalizada confusión de dicha forma con Ausina, que podía hacer pensar en Ausin, hoy Los Ausines, localidad del mismo alfoz de Lara donde hubo un convento de benedictinas titulado de Santa María (que en i6or pasó a Burgos bajo la advocación de santa Apolonia) y con la cual se identificaba la sede del Theodorus Ecclesiae Ausesinae episcopus que aparece en algunos testimonios del decreto de Gundemaro (por Auresinae), llevando a considerar que esa Ausina constaba por la sede de Auca u Oca ${ }^{103}$ En cuanto a la propia frase, Escalona

IOo. El nombre aparece once veces en siete documentos en el CODOLGA entre 919 y 944 , y una vez en los $M G H$, en las Epistolae Austrasicae 3.22.

Ior. Así desde Sandoval (ı6 I5: 355), que ya afirmó que "la piedra se puso cinco, o seys años después de su muerte [de don Alfonso el Católico], en tiempo que reynaua su hijo don Fruela”.

IO2. Debido a la secuencia - aus-, cabría pensar en la mala interpretación de alguna de las inscripciones que han llevado a proponer la identificación de Lara de los Infantes con la Nova Augusta de las fuentes geográficas clásicas, como Plinio y Ptolomeo (vid. Gimeno-Mayer 993 y Abásolo 2005), pero no se ve cómo dos términos tan comunes podrían haber producido un hápax como Amusina, ni siquiera combinados en el gentilicio nouagustana que atestiguan las inscripciones romanas (cf. Abásolo 2005: 138).

IO3. "Llamose esta gran ciudad [sc. Lara] en sus principios Ausina, y Agosina; y della todas las gentes que morauan en aquella comarca, hasta donde agora es Burgos, se llamaron Ausines, y assi el Obispo de Oka, en cuya jurisdicion cayan estas gentes, se llamaua en algunos Concilios de los que se celebraron en tiempos de los Godos, obispo de la ciudad Ausina" (Sandoval ı6r5: 280). Se ocupa de todo ello, enderezando el entuerto, Enrique Flórez (I77I: 32-34, y I772: col. 6I7-620 = I824: 309-IO). Lo resume Ortiz (I84I-42: 63-64). Todavía en el siglo XX se sigue manteniendo la confusión: “Si place continuar la expedición hacia las heroicas tierras de Lara se encuentras los Barrios de los Ausines, recuerdo de la ciudad romana de Ausina, de los cuales el más interesante es el que se halla después de una serie de rocas llamado de la Peña, donde estuvo establecido antiquísimo convento de religiosas” (Diputación Provincial de Burgos I930: s. p., Itinerario no. 4 "Burgos-San Pedro de Cardeña.-Los Ausines-Revilla del Campo-Paules de Lara-Lara de los Infantes-Burgos"). La continuidad "goda" se refuerza por diversas mistificaciones, como la relativa a este convento de monjas que se acaba de citar: “En los tiempos del piadosísimo rey Recaredo, según opinión corriente, construyóse un monasterio de Benedictinas en Lara de los Infantes, el cual monasterio era llamado de Lara y de las Viñas, de donde 
considera que "la mejor prueba de falsedad es la adición de la última línea, sobre el cambio del antiguo nombre de Ausina por Lara y la continuación con el elogio de los Infantes; el empleo en ambas [inscripciones] del adverbio OLIM, no demasiado frecuente, denota una misma mano tras ambas patrañas" (Escalona 1995: 566). La conclusión podría quizá ser correcta (asunto del que nos ocuparemos luego), pero las premisas no, porque el término es común en latín medieval hispánico ${ }^{\mathrm{I0}} \mathrm{e}$ incluso se documenta su ocasional uso epigráfico en la inscripción que informa de la reconstrucción de la basílica de San Isidoro de León en Io65, que comienza así: HANG QVAm CERNIS aVLam SanctI IOHANNIS Babtiste | OLIM FVIT LVTEAm (apud Santiago Fernández 2002: II9). Además, en este caso, y con la lectura que proponemos, forma una estructura paralelística adverbio + topónimo | adverbio + topónimo basada en la ya vista correlación clásica olim... hodie, lo que justifica su inclusión. Se ha de advertir, por último, que la recta incisa que separa este renglón del anterior establece la frontera entre el texto más antiguo y la moderna adición, como si quisiera diferenciarlas, aunque esto no dejaría de resultar extraño para los usos epigráficos del momento. Cabe, pues, que esa línea delimitase el final de la inscripción, si en un primer momento incluía solo la copia errada del epígrafe de la ermita de San Julián, y que la última línea se añadiese posteriormente, quizás a la par que la inscripción relativa a los siete infantes, aunque, en todo caso, por el mismo lapicida y en fechas inmediatas.

\subsection{El segundo epígrafe, los siete infantes}

Esta inscripción, cuyas transcripciones no presentan las variantes que afectan al anterior, ${ }^{105}$ debido a la mayor claridad de su factura, reza así:

LOS .7. INFANTES

2. QVE SEPTEM HEROAS

QVE SEPTEM FVLMINA BELLI

4. LARA OLIM GENVIT

Las características epigráficas son las mismas que las de la inscripción colateral, aunque carece de abreviaturas y la inicial de BELLI adopta forma de minúscula en lugar de versal, como el resto. Como puede apreciarse, abundan los nexos y además presenta letras enclavadas en el grupo L' en las líneas 3 y 4 , aunque la única palabra que ha planteado algún problema es el numeral de la tercera línea, que Escalona transcribe como “ ¿s(e)p(t)Em?". Sin embargo, la primera E fue omitida e interlineada bajo la p por el lapicida, y las demás letras aparecen agrupadas en los nexos T-E y M-F, este segundo en la unión de septem fulmina, por lo que no cabe duda sobre la correcta lectura del texto. Este disimula, en su actual disposición epigráfica, su verdadera naturaleza métrica, no advertida hasta ahora, en parte como resultado de los prejuicios con que se han examinado los dos epígrafes de la parroquial de Lara. Atendiendo a su versificación, pueden ofrecerse las siguientes transcripción regularizada,

debió tomar el nombre la imagen que, al decir de la tradición, allí se veneraba; y en aquel monasterio consagró el devoto rey Recesvinto a sus dos hijas Ericiana y Astrocia al servicio de la Santísima Virgen. En el año 7ı8 fué arrasado

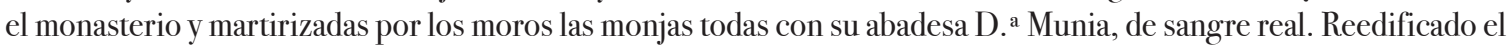
sagrado recinto y poblado por nuevas religiosas, fueron también sacrificadas, en número de cuarenta y una, por los moros" (Janáriz 1924: 8).

IO4. Vid. LELMAL, 52I, s. v. Añádase, por poner un ejemplo oriental, el relativo a Arañones (Huesca) que se lee en el Cartulario de Somport en III5: “villa illa que olim vocabatur Araniones” (apud Durán Gudiol 1986: 24).

IO5. Hechas las salvedades de la transcripción del párroco de Tinieblas, que añadió “de Lara” al final de la l. i y ultracorrige la monoptongación de los pronombres de relativo de las ll. 2 y 3: QuAE (Juez, I796: ff. 234v y 242r). 
escansión y traducción:

Que septem heroas, que septem fulmina belli

Lara olim genuit. [...]

Quē sēp- | te(m) hērō- | às || quē | sēptēm | fūlmǐnă | bēllī

Lāra $\bar{o}^{-} \mid \lim$ gĕnŭ- | ît || [- $\left.|\underline{u}-| \underline{u} \underline{u}-|\cup \cup-|--\right]$

La cual a los siete héroes, la cual a los siete rayos de la guerra,

Lara antaño engendró. [...]

El primer verso es un hexámetro clásico (con penúltimo pie dactílico) y cesura pentemímeres que genera dos hemistiquios de estructura paralelística, salvo que el segundo presenta el incremento belli como complemento del sustantivo fulmina. La elisión de la tercera sílaba, pese a la frontera visual que establecen la - $m$ y la $h-$, revela a un buen conocedor de las reglas prosódicas clásicas, puesto que en tal caso es muy fácil, para alguien que compone aplicando reglas meramente aprendidas, no percatarse de la obligación de la sinalefa (que era lo más frecuente en la Edad Media). El segundo verso es el primer hemistiquio de otro hexámetro con cesura pentemímeres, que de nuevo presenta una elisión, aunque en este caso más obvia. Dada la calidad métrica de este verso y medio, es de suponer que la grafía monoptongada de que por quoe se deba al lapicida (o a su modelo escrito inmediato) y no al autor del carmen epigraphicum. A ello han de sumarse los claros ecos del verso 842 del libro VI de la Eneida que trae el segundo hemistiquio del primer verso:

Quis Gracchi genus, aut geminos, duo fulmina belli,

Scipiadas, cladem Libyae, parvoque potentem

Fabricium vel te sulco Serrane, serentem? ${ }^{\text {106 }}$

El influjo de Virgilio y en particular de la Eneida en la epigrafía es bien patente tanto en la Antigüedad como en determinadas inscripciones medievales. ${ }^{107}$ Sin embargo, si a ello se añade la presencia de sinalefa, rehuida por los poetas latinos medievales (Klopsch I972: 8o-82; Favreau I999: IO2), está claro que se trata de una composición coetánea de su incisión y realizada por un humanista. ${ }^{108}$ El evidente carácter trunco del texto (que comienza por un relativo sin antecedente, el

Io6. “¿Quién [silenciará] la estirpe de Graco, o la pareja, dos rayos de la guerra, / de los Escipiones, ruina de Libia, y al opulento en lo mísero, / Fabricio, o a ti, Serrano, sembrador de surcos?” (Virgilio, Eneida, VI, vv. 842-844). El símil estaba ya casi lexicalizado, pues lo habían utilizado también Lucrecio, De rerum natura, III, v. IO34: “Scipiades, belli fulmen, Carthaginis horror" = "Escipión, rayo de la guerra, terror de Cartago" (verso que, según la crítica, es imitado aquí por Virgilio) y Cicerón, Pro L. Cornelio Balbo oratio, I5: “cum duo fulmina nostri imperi subito in Hispania, Cn. et P. Scipiones, extincti occidissent" = "cuando a los dos rayos de nuestro poder, Cneo y Publio Escipión [= Cneo Cornelio Escipión Calvo y su hermano Publio Cornelio Escipión], los abatieron súbitamente en Hispania, quedando extinguidos".

IO7. Véase, en general, Massaro (I984) y, para la epigrafía cristiana hispánica altomedieval, Hübner (I9Oo: I58).

Io8. El verso de Virgilio se hizo prácticamente proverbial en el Renacimiento. Sirva de ejemplo el prólogo del Primaleón de I512: "Dexo agora la línea del primogénito, de donde ovieron comienço illa duo fulmina belli, don Alonso de Aguilar y Gonçalo Fernández, su hermano, al cual, por la grandeza de sus hazañas, los contrarios pusieron nombre de Gran Capitán” (Marín Pina ed. 1998: 2). La expresión rayo(s) de la guerra aparece en dieciséis ocasiones en singular y tres en plural entre $c a$. I580 y i662, según datos del CORDE. Uno de los ejemplos más tempranos es el de Rodrigo Caro en su Canción a Itálica, quien, hablando de Trajano, dice que "Aquí nació aquel raio de la guerra” (v. 35; Pascual Barea ed. 2000: I5I). De forma más perifrástica, también Quevedo se hará también eco de la cita virgiliana: "Fallecieron los Curios y los Fabios, / y no pesa una libra, reducido / a cenizas, el rayo amanecido / en Macedonia a fulminar agravios", anotando su editor: "Además de aludir al rayo soñado por la madre de Alejandro durante su embarazo, 
cual enlaza a la vez catafóricamente con el topónimo del segundo verso), el uso de QVE por QVAE (con monoptongación postclásica, pero frecuente incluso en textos renacentistas) y la mezcla de romance y latín, debido a la aparición del epígrafe que precede a los versos latinos, han despistado a los estudiosos, haciendo que la sentencia de Flórez sobre el "bárbaro estilo" del epígrafe se haya dado acríticamente por buena. ${ }^{109}$ Se trata, por el contrario, de una composición de cierto nivel, extraída sin duda de otro lugar, donde seguramente figuraría con el rótulo que identifica a los septem fulmina belli engendrados por Lara. En efecto, tal indicación parece provenir de una fuente intermedia que recogería una relación de este tipo de inscripciones o de una cita en alguna obra historiográfica

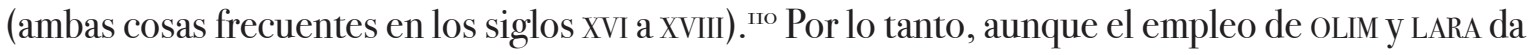
cierta unidad a los epígrafes de ambas piedras, al situar tales palabras en la última línea de cada una de ellas, todo indica que se trata de composiciones independientes y meramente yuxtapuestas.

En cuanto a la procedencia del poema incompleto, parece tratarse del fragmento de un epitafio en hexámetros funerarios al estilo de los redactados en Oña, hoy perdidos, o del que se conserva en la tumba del Cid en Cardeña, ${ }^{\text {II }}$ si bien estos son, sin duda, medievales, aunque no coetáneos de los sepulcros que ilustran. Como es sabido, los cenobios que pretendían contar con tumbas vinculadas a la leyenda eran el de San Millán, pero allí las presuntas sepulturas de los siete infantes carecían de inscripción alguna, y el de Arlanza, donde, además de los pretendidos sarcófagos de Gonzalo Gustioz y sus hijos, se mostraba un sepulcro de Mudarra anepígrafo (un lucillo cobijado bajo un soberbio arcosolio románico de hacia ı200, que desde i896 se conserva en el claustro de la catedral de Burgos). ${ }^{12}$ Sin embargo, la única inscripción funeraria arlantina de que tenemos noticia es la del padre de los infantes, que estaba pintada en la pared, de la que Menéndez Pidal (ı896: ı82) llegó a ver una parte y que Sandoval (I6I5: 364) transcribe, señalando que este y otros varios, todos en romance, “à pocos años que se pusieron”. Según dicho autor, rezaba así:

Quevedo también tiene en cuenta el conocido sintagma 'rayo de la guerra' para aludir a quien sería vengador de agravios a su patria. Fulmina belli llama Virgilio a los Escipiones” (Rey 2003: 440). En el mismo siglo, Johann Gerhard Vossius (ı649: 304) ofrece como ejemplo paradigmático de metaphora el pasaje virgiliano en sus Rhetorices contractae IV.IV.I: "Dixit cum Ennio Virgilius: --_- duo fulmina belli / Scipiadas. Propriè in tempestatibus est fulmen; impropriè de homine dicitur in bello. Similitudo in eo consistit, quod, ut fulmen est animantibus terribile ac noxium, ita Scipio hostibus terrori esset maximo", pasaje que Gregorio Mayans $(1757: 2,48)$ traduciría de la siguiente manera: "Así Virgilio llamò a los dos Cipiones, Rayos de la guerra. El Rayo es propiamente de las tempestades; impropiamente de la guerra. La semejanza consiste en que assi como el Rayo es dañoso, i terrible a los vivientes, i arruinador de las cosas temporales; assi los Cipiones fueron dañosos, i terribles a sus enemigos, i destruidores de sus cosas" ( $c f$. Aradra Sánchez I999: I798I).

Io9. Más condescendiente se mostró Víctores Juez, el párroco informante de Tomás López, que intentó explicar el porqué del uso de este incorrecto latín haciendo referencia a las características materiales del epígrafe y a sus avatares de conservación: "Y aunque esta latinidad no suena tan arreglada puede provenir de que el sillar está mutilado en su margen superior e inicial, o de que algunas letras deformadas del azote de aguas, y vientos no manifiestan bien su figura, y lo mismo sucede en los caracteres, que cuentan la era de la anterior inscripción” (Juez, r796: f. 234v, vid. n. 9o).

IIO. De lo segundo se han visto aquí numerosos ejemplos; para lo primero, además del caso citado en la nota 9 , vid. García Cubero (1992: no. 1252, I253, 1971, 1973, 1974, 2072, 2508-25I4, entre otros) y, aunque se trata en general de materiales más tardíos, Abascal-Cebrián (2005: pass; ; vid. índices en 6r5-75).

III. Cf. Arco (1954: 72-73, epitafio del Cid; 78-86, epitafios de Oña); García Morilla (20I3: 303-5, no. 45, epitafio del Cid; 272-79 y 28I-84, no. 22-27 y 29-3I, epitafios de Oña). El primero está pendiente de estudio (aunque ya hizo una fundamental observación sobre el mismo Francisco Rico 1984: 200, n. 18), tarea que Alberto Montaner se propone completar en breve en su trabajo en preparación Los epitafios del Cid: Alfonso X, Cardeña y la canonización de la materia cidiana; sobre los segundos contamos ahora con la importante contribución de Senra (2O12). Para la historia del panteón cidiano de Cardeña, véase Martínez Diez (2008).

II2. Vid. Menéndez Pidal (I896: I80-82). Un detallado estudio de este arcosolio y su tardía asociación con el sarcófago de la fata Dei Goto de IO75 en Senra (1999). 
Aqui reposa, y en la gloria goza, el muy valiẽte cauallero dõ Gonçalo Gustios padre de los valerosos, y extrenuos siete Infantes de Lara, de sangre Imperial, u de los Reyes de Leon, y de quiẽ la sangre noble de los Mãrriques de Lara descienden : el qual hizo valientes, y famosos hechos en defensa de la santa Fê Catolica. Falleciò en la Era de ıozo. año del Nacimiento 992.

Resulta, pues, imposible, a día de hoy, determinar el origen del verso y medio incisos en el muro de la parroquial de Lara, aunque su adscripción al género de los tituli o letreros conmemorativos típicos del humanismo historicista consideramos que queda suficientemente probada. ${ }^{13}$

\section{Propuesta de explicación}

Aunque la información disponible no permite alcanzar un alto grado de certeza, sí que contamos con elementos suficientes para exponer una hipótesis sostenible sobre el origen y función de las inscripciones lareñas, para cuya constatación, con todo, harían falta datos complementarios, difíciles de encontrar con respecto a la más antigua, pero que quizá una investigación de archivo pueda proporcionar, por lo que hace a las más recientes. Según ha podido apreciarse, desde el punto de vista factual, el contenido tanto del epígrafe procedente de la ermita de San Julián como el que, en dos partes, se conserva en la parroquia de Lara de los Infantes son falsos (o, si se prefiere, ficticios), precediéndole el primero, que sirve de modelo para la primera parte del último. Aunque sus razones son, en último término, coincidentes, se produjeron en períodos y circunstancias muy distintos, lo que seguramente alcanza también a sus motivaciones inmediatas.

Por sus características materiales, el epígrafe de la ermita de San Julián ha de situarse, a más tardar, durante el siglo XII, antes de que las capitales lombardas que acompañan a la letra carolina sustituyan por completo en el ámbito epigráfico a las versales visigóticas. También apunta a dicha centuria como periodo más tardío posible la mención de los condes Gonzalo y Rodrigo, sobre todo si el primero ha de identificarse con Gonzalo Fernández, porque a su final ya se había perdido la pista de la auténtica nómina de los primitivos condes castellanos y de la genealogía de Fernán González, para hacerle entroncar con los Jueces de Castilla, la otra gran leyenda fundacional castellana. ${ }^{{ }^{14} 4}$ A cambio, el empleo del giro facere civitatem sitúa ese mismo siglo como el momento más temprano posible, por lo que parece oportuno situarlo en algún momento del mismo.

Esto concuerda con la designación de Lara como civitas, que, como se ha visto, se documenta, descontando los testimonios apócrifos, entre Io89 y II54.

El siglo XII resulta, a este respecto, de sumo interés, porque en él se forjaron las falsificaciones arlantinas que hemos comentado en el apartado primero, y en particular las dos en que se habla de la civitas Lara: el diploma fundacional de Arlanza supuestamente otorgado por Fernán González y su esposa Sancha en el año 9I2 (así como la manipulación de la primitiva dotación por Gonzalo Téllez y su familia) y la asignación de términos a la propia Lara en 922, atribuida a Mumadonna, madre del conde castellano, y a este mismo. Más concretamente, la falsificación de la carta fundacional del conde castellano puede datarse en torno a II5O-56, mientras que la manipulación de las anteriores corresponde al período de elaboración del primer bloque del Becerro de Arlanza, que se sitúa entre III9 y II35 (Escalona- Azcárate 200I; Escalona et al. 200, I78-I8I; Azcárate et al. 2006: 370-

II3. Compárense las inscripciones redactadas por los cronistas de Aragón para las efigies (no los sepulcros, en este caso) de sus reyes: Jerónimo de Blancas, Martín Carrillo y Diego José Dormer (Redondo y Morte ed. I996). Otro ejemplo, este sí funerario, de Cardeña en Arco (1954: 7I).

II4. Para su cronología y desarrollo sigue siendo la obra fundamental la monografía de Georges Martin (I992). 
73). Se trata de un momento en que el monasterio está intentando fijar una determinada imagen institucional al servicio de un proyecto de consolidación gracias a las donaciones recibidas durante el reinado de Fernando I, pero aquella cambia de forma radical y con efectos permanentes con la redacción del apócrifo de Fernán González, que vincula al cenobio al mito fundacional de la propia Castilla, con el que se combinará inextricablemente en lo sucesivo, en un proceso de fusión que culmina con la redacción del Poema de Fernán González un siglo más tarde:

En la segunda mitad del siglo XII, en el contexto de su separación del reino de León, se produjo en Castilla una intensa revisión del pasado histórico, una de cuyas claves fue la magnificación de la etapa condal y, sobre todo, de la figura de Fernán González. El monasterio de San Pedro de Arlanza parece haber jugado un papel especialmente activo, tanto en el desarrollo de las leyendas sobre el conde como en la utilización de las mismas para dar prestigio a la abadía y situarla en el centro de los procesos históricos en los que se basaba la nueva identidad política castellana, incluyendo la reformulación de sus propios orígenes, al postular, con el apoyo de la falsificación documental, una ficticia fundación por Fernán González. ${ }^{15}$

Este punto de inflexión es importante también para explicar el epígrafe lareño, porque de él depende seguramente la identificación de los antropónimos que cita. En efecto, establecida la falsedad de su contenido, la cuestión no es determinar quiénes fueron realmente los personajes aludidos, sino quiénes se pretendía que fueran, algo que para sus redactores debía de ser obvio, puesto que no dejaron muchas pistas al respecto. Si el epígrafe se remonta a la tercera década del siglo XII, lo más probable es que la mención de Gundesalbus corresponda al mismo Gonzalo Téllez que suscribe el que entonces era el primer documento del becerro, la carta fundacional de Arlanza. Si se retrasa hasta mediados de siglo, entonces es más probable que se pensase en Gonzalo Fernández, como padre del "nuevo" fundador del monasterio. En ambos casos, situar la "hechura" de Lara en la era DCCCC = año 862 tiene sentido como preparación de la del propio monasterio, efectuada "in suburbio que vocitant Lara [var.: iuxta civitas Lara], super crepidinem fluminis Aslanza" ${ }^{116}$ En principio, el empleo de civitas en el diploma atribuido a Fernán González parecería zanjar la cuestión a favor de la contemporaneidad con el mismo, pero hay que recordar que la contrahecha hitación de Lara, que pertenece al mismo bloque textual que la dotación de Gonzalo Téllez, también se refiere (de un modo bien sospechoso de interpolación) al "castro vel civitate Larensi” (Serrano ed. 1925: 3I, doc. IO). No obstante, puestos a elaborar un titulus honorarius tan posterior al suceso conmemorado, parece más lógico que sea con ocasión de una acción de la envergadura del cambio de fundador, que simplemente como fruto de la confección del becerro y sus consiguientes manipulaciones documentales. Por lo demás, una ejecución en torno a II5O no desdice de los rasgos materiales del epígrafe.

La inscripción lareña surgiría, por tanto, como refuerzo de la adopción de Fernán González como fundador del monasterio arlantino o al menos inspirada por ella. Esta última posibilidad deriva del hecho de que, para que el epígrafe responda al mismo impulso que la falsificación del diploma, es preciso justificar una acción abacial de Arlanza en Lara, villa realenga. ${ }^{\amalg z}$ De no darse

II5. Azcárate et al. (2006: 360), véanse además las pp. 369-73 y 393-94 para su desarrollo, así como Senra (I999: 26-27). El mismo autor explora las posteriores estrategias de Arlanza para arcaizar sus orígenes, enlazándolos con los monarcas visigodos (Senra 2006).

II6. Serrano (ed. I925: II, doc. 2, y variante en 5, doc. I), Escalona et al. (2002: I88 y variante en I97).

II7. Lo fue hasta I255, en que Alfonso X cede la villa de Lara, con sus lugares, a la ciudad de Burgos, pasando esta a ejercer un "señorío colectivo" (la cesión se encuentra en el Archivo Municipal de Burgos, Sección Histórica, no. I35 (ı255, julio ı8, Valladolid), vid. Bonachía (เ978: ı48-49). 
una intervención directa, la inscripción lareña sería una simple secuela, aunque su razón de ser resultaría menos obvia. Ahora bien, según recuerda Sandoval (I6I5: 27I [= 283]), "la hermita de San Iulian [...] dizen fue Monesterio”. De ser cierta esta tradición, la ermita podría corresponder al ya citado monasterio de San Pedro "situm in civitate Lara" y cedido a Arlanza en III6 por Pedro Ovéque $\mathrm{Z}^{\mathrm{II}} \mathrm{o}$ a otro que perteneciese al patrimonio arlantino. En tal caso, la intervención directa de la abadía es mucho más plausible y explica mejor la existencia de este epígrafe, al que, a la vista de las circunstancias y a tenor de lo dicho al final del apartado I, empezaría a cuadrar mejor el calificativo de falso. Ha de advertirse, no obstante, el claro riesgo de circularidad de tal argumentación: el epígrafe sería arlantino porque lo es el (supuesto) monasterio, pero este sería patrimonio de Arlanza porque esto justifica mejor la inscripción.

En este contexto, el proceso que llevó a la redacción del epígrafe parece haber sido el siguiente: al fijar la fundación de Arlanza en 9ı2 por Fernán González "iuxta civitas Lara”, la población de la misma tenía necesariamente que precederle en el tiempo. Dado que Gonzalo Téllez figuraba en otra dotación del mismo 9², lo que no cuadraba bien con una intervención acaecida unos cuantos años antes (aunque en rigor tampoco la excluía), era más lógico que se atribuyese la erección de Lara a Gonzalo Fernández, habida cuenta además que, al hacer retroceder la dinastía condal castellana una generación, este parecía el candidato "natural” para esa acción, antes que su homónimo, el conde de Lanzarón y Cerezo. Esto lo situaba a la par que el conde Rodrigo, que, como queda dicho, aparece en un documento (suspecto) como regnante "in era DCCCG", es decir, el año 862. La combinación de ambos personajes en una tarea fundacional seguramente se debe a una mezcla de las noticias analísticas sobre ambos (recogidas en las notas 59 y 6I), donde dicho conde aparece repoblando Amaya en la era de DCCCXCVIII, correspondiente al año 86o, y Gonzalo Fernández haciendo lo propio con Aza, Clunia y San Esteban de Gormaz en DCCCCL, que fácilmente podría convertirse en DCCCC y proporcionar así la fecha del epígrafe lareño. Cierto que eso contradice la entronización de Alfonso III "In era DCCCCIII" (Anales Castellanos I, § 9; Martín 2009: 208), es decir, en 866, consignada en esas mismas fuentes, pero las fechas son suficientemente cercanas como para que a un historiógrafo medieval (falsario o no) le planteasen el menor problema, a la vista de anacronismos mucho más flagrantes producidos en sus contrafacta, como el mismo de situar a la pareja condal de Fernán González y Sancha en 9ı2, cuando no se casaron hasta 93i o 932, las mismas fechas en las que el primero accede al comitatus. ${ }^{\text {п9 }}$

La inspiración historiográfica de epígrafes con valor conmemorativo (sobre todo obituario) no constituye de suyo ninguna rareza. En el ámbito burgalés es notorio el caso de la inscripción necrológica de los doscientos mártires de Cardeña: ${ }^{120}$

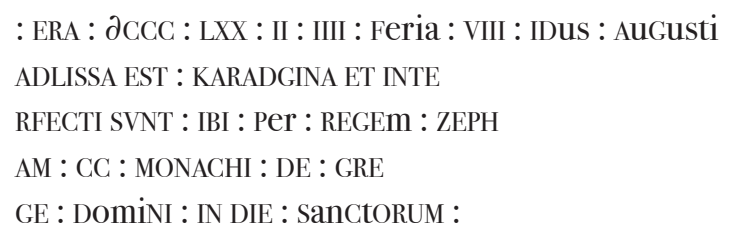

II8. Serrano (ed. г925: 165, doc. 87), las cursivas son nuestras. Escalona (เ995: 564) discute la posibilidad de que la iglesia de este monasterio fuese la base de la actual parroquia de la Natividad, pero en realidad no hay ninguna prueba al respecto. En todo caso, esto no invalidaría la hipótesis de que San Julián dependiese de ese monasterio de San Pedro, aunque, desde luego, la complica. Otra opción, que cuadra mejor con la hagiotoponimia disponible, es que ninguna de las dos iglesias pueda identificarse con el monasterio que Arlanza poseyó en Lara.

II9. Nótese, sin embargo, que anacronismo no es sinónimo de falsificación. Se trata de un problema inherente a la concepción medieval de la historiografía, vid. Montaner (2014).

I20. Puede verse en García Morilla (2OI3: 25I, no. 4, y 626, lám. LXII.I), pero damos nuestra propia transcripción. 
MaRtyruM : IUSTI : ET : PASTORIS

Este texto, epigrafiado en el siglo XIII, se basa en una noticia analística caradignense, ${ }^{\text {I2I }}$ reinterpretada a la luz de Lucas de Tuy, Chronicon mundi IV, $3^{\mathrm{I}-32}$, quien convierte en el nombre propio de un caudillo andalusí el sustantivo (a)zeyfa 'incursión hecha en verano’ y 'ejército que la realiza', derivado del árabe andalusí $a$ șșáyfa, propiamente 'el tiempo de la cosecha', que es el sentido primitivo del árabe clásico asss â ifah. ${ }^{\mathrm{I2}}$ También una buena parte de los epitafios de San Isidoro de León toman como base un previo obituario de la colegial, inspirado a su vez en la Chronica Naiarensis (Suárez González 2003; Sánchez Ameijeiras 2005; Montaner 2009: §§ 2629).

Una ventaja añadida de suponer como punto de partida un texto analístico o uno cronístico conexo, como la recensión pelagiana del Chronicon Sampiri 23, que recoge ambas noticias (Pérez de Urbel ed. 1952, 327-28), es que en ellos Gonzalo Fernández aparece sin el título condal, lo que también contribuye a explicar la formulación del epígrafe. Con todo, no puede excluirse que la mención del conde don Rodrigo, innecesaria desde el punto de vista de la inserción de Lara y Arlanza en las actuaciones de los condes castellanos, se haga eco de una tradición local lareña sobre el responsable de su poblamiento, la que, de ser así, posiblemente tuviese alguna base histórica, dado el escaso recuerdo que ha quedado del personaje.

Todo apunta, pues, a que el titulus honorarius de Lara se ejecutó en dependencia (aunque quizá mediata) de las actuaciones con las que, a mediados del siglo XII, Arlanza pretendía reconducir su pasado y el de su entorno para injertarlo definitivamente en el tronco de la dinastía condal castellana, columna, a su vez, de la identidad de Castilla como territorio pujante hecho a sí mismo, aunque este proceso no es solo causa, sino en buena parte también consecuencia de la decisión arlantina, en un característico fenómeno de retroalimentación. ${ }^{123}$ En cuanto a la configuración definitiva del epígrafe, surge (como ya hemos apuntado arriba) de la confluencia de este tipo de registros analísticos con la formulación típica de las inscripciones conmemorativas de la construcción de un edificio, único modelo epigráfico asimilable a la (re)fundación de una ciudad que resultaba familiar a sus ejecutores. Finalmente, la atribución ex aequo a Gonzalo y Rodrigo del acto fundante justifica el plural del verbo, hecho en sí mismo también inusitado, puesto que en general es una sola persona la que suele protagonizar este tipo de acciones, empléese el verbo que se emplee, en la tradición clásica y medieval, lo que en esta última justifica el uso en plural de facere o cualesquiera de los verbos de los que más arriba se hizo repaso, que siempre aparecen en singular. ${ }^{124}$

I2I. Afín a la que traen los Anales de Cardeña: "Era de DCCC. LXXII / uino el rey Aceffa en Castiella et / andido por toda la tierra et uino / al monesterio de San Peydro de Cardenna et mató y CC monges, que mo- / rauan” (Martínez Diez 2004: 255).

I22. Sobre este término, que ha despistado notablemente a los comentaristas del epígrafe (cf. García Morilla 2OI3: 250-52), vid. Montaner (2OII: I39-4I). Para el epígrafe cardeñense, véase Smith (I982).

I23. Proceso que alcanza su apogeo textual e ideológico, incluso más allá del Poema de Fernán González, en la obra de fray Gonzalo de Arredondo, último de los priores perpetuos de San Pedro de Arlanza, titulada Corónica brevemente sacada de los excelentísimos fechos del vienaventurado caballero de gloriosa memoria conde Fernán Goncales, conquistador de la seta de Mahomad y muy famoso ensalmador de la santa fe cathólica, por quien el condado de Castilla que era subjeto por estonçe al reygno de León y muy perseguido dél, y así veresímile de los circumiacentes sus vezinos, fue vuelto en muy exçelente reygno, cabeça y primado de las Españas (Real Academia de la Historia, ms. 9/2047, cit. por Ladero Quesada 2006: 27I, n. I; el mismo autor compuso una síntesis versificada: Vida rimada de Fernán González; Vaquero ed. 1987). Se conservan varias copias de esta crónica (p. ej. MSS/693o de la Biblioteca Nacional de España y ms. I952 de la Biblioteca Universitaria de Salamanca), una de las cuales (BNE MSS/2788) data de I5OI.

I24. No valoramos la interpretación hipotética de un posible fecerunt con que se ha especulado en un anagrama que no se llegó a inscribir en la parte exterior de la cabecera de la iglesia de Santa María de Quintanilla de las Viñas, así como 
De ahí la inusitada utilización del giro fecerunt istam civitatem, mera adaptación al caso de la fórmula fecit istam ecclesiam, con la entonces innovadora juntura semántica entre facere y civitas y la mera utilización del deíctico en lugar de la aparición del topónimo correspondiente, que en este caso y a tenor de los ejemplos diplomáticos, habría generado la frase fecerunt civitatem Lara $(m)$, con aparición opcional del morfema de acusativo.

Carecemos de cualquier noticia de esta inscripción desde que se realizó en la ermita de San Julián hasta que se ejecutó su copia renacentista y ni siquiera sabemos en qué parte del edificio se situaba, aunque lo más probable, dada la ubicación habitual de este tipo de epígrafes en las iglesias que los presentan y su voluntad propagandística, es que se hallase enrasada en el paramento exterior del templo, lo que explicaría el tipo de enlucido que lo cubrió en un momento dado y del que, como ya hemos explicado, aún quedan restos visibles. El hecho de que presente una mella en el lugar donde las transcripciones antiguas, tanto la del perdido Memorial de San Pedro de Arlanza como la que sirvió de base a la inscripción de la parroquia de Lara, muestran mayores problemas de lectura, sugiere que antes de i6oo recibió un golpe, lo que podría haberse producido al eliminar con martillo o piqueta algún elemento que la ocultaba. ${ }^{125}$ Este afloramiento del epígrafe podría ser contemporáneo de la ejecución de su copia pétrea y de hecho justificaría su realización precisamente como forma de exponer un dato por entonces desconocido, mientras que, como veremos, había otras razones para hacer valer en ese momento la vinculación de los siete infantes a la localidad. Posiblemente a raíz de ese descubrimiento se empotró "en el plano del altar de la ermita", ${ }^{126}$ ubicación, por cierto, más propia para contener inscripciones de consagración o de relaciones de reliquias, como las que el propio Sandoval informa que se trasladaron a la parroquia (según se ha explicado en la nota 8), aunque no podamos tener certeza sobre el momento de este reacomodo interno. En cualquier caso, allí estuvo hasta que a principios de los años veinte del pasado siglo, al amenazar ruina el edificio de la ermita, se trasladó al atrio de la iglesia parroquial, momento en que, seguramente, se suspendió mediante las escarpias que enganchaban en las muescas de sus laterales, como queda dicho. Entre r929 y r935 el sillar epigrafiado fue trasladado al Museo de Burgos, donde ya hemos visto que se exhibe en la actualidad.

En cuanto a la copia incisa en el muro de la iglesia, bien pudo deberse al cura pár roco que por entonces la regía, como dio por sentado Flórez (I772: cols. 620 y $622 ; 2 .{ }^{\mathrm{a}} \mathrm{ed}$. $3 \mathrm{IO}$-II), aunque, frente a lo que este conjeturaba, es muy difícil que fuese él (o quien promoviese la copia, si se trató de otra persona) el autor de la aneja inscripción sobre los infantes de Lara, que claramente está tomada de otra fuente. Lo que sin duda sí se debe al mismo promotor de estos epígrafes es la última línea del texto fundacional, con la inclusión de esa Amusina de apariencia arcaica, pero de la que no hemos localizado correspondencias antiguas ni medievales, mediante una cláusula sintácticamente correcta, pese al hipérbaton que implica la inclusión parentética de la era. La doble actuación de planificar la copia y de añadir esa referencia a un supuesto antecedente pretérito, procedimiento muy propio de los círculos humanísticos ${ }^{127}$ revela la actitud de quienes entonces eran llamados

que el propio Gonzalo Téllez fuese otro de los nombres elididos, junto a su esposa Flámula, antropónimo este que sí se llegó a labrar ( $c f$. Sepúlveda González ı986: ı222); esta autora cita, además, un votum fecerunt en una inscripción del complejo de edificios de Cornus (Cerdeña) fechable entre los siglos VI y IX (ibid., I.22O, n. I2).

I25. Compárese, por poner un ejemplo entre tantos posibles, aunque reciente, que "En la iglesia parroquial de San Julián de Gramedo, en obras de reparación del pasado año (I99I), al levantarse el revoco en la pared del imafronte, se descubrieron, el 24 de mayo, dos fragmentos de la piedra con la inscripción fundacional” (Diego Santos r994: 249 , no. Add. I2).

I26. Según informa hacia r926-29 la Comisión Provincial de Monumentos de Burgos (véase arriba la nota 4), que da noticia igualmente del traslado del epígrafe al atrio de la parroquia.

I27. Como ocurrió hacia mediados del siglo XVI con Madrid, cuando comenzó a afirmarse que era la antigua Mantua 
anticuarios o "curiosos de las cosas antiguas". ${ }^{22} 8$

Por otro lado, la yuxtaposición del texto sobre los infantes revela el deseo de dejar constancia simultánea de los dos constituyentes fundamentales de las viejas glorias de Lara (aunque ambos sean, hoy lo sabemos, falsos): la fundación de la ciudad por los más remotos y venerables condes castellanos, y el alumbramiento en la misma de los siete héroes y rayos de la guerra cuya fama perduraba por doquier gracias a crónicas y romances. Dos sucesos además vinculados por la propia genealogía condal, uno correspondiente al abuelo, Gonzalo Fernández (Núñez, para los coetáneos de la copia, por efecto de la leyenda de los Jueces de Castilla), y otro al nieto, García Fernández. El vínculo se había completado, además, gracias a las mistificaciones arlantinas, puesto que, justo en medio, las acciones legendarias de Fernán González vinculaban a Lara y al linaje de los infantes gracias a la apócrifa carta puebla de Lara de 93I, ya citada (véase la nota 44), y a la inclusión al narrar la batalla de Hacinas en el Poema de Fernán González (compuesto en San Pedro de Arlanza ca. I25OI270), de un ficticio Gustio González cuya onomástica lo identificaba inequívocamente como padre de Gonzalo Gustioz y, en consecuencia, como abuelo de los siete infantes:

A Gustÿo Gonçález, el que de Salas era, a él e a sus fyjos dioles la delantera; con ellos don Velasco, tanbién d'essa rybera, ca por miedo de muerte non dexaryén carrera. ${ }^{\mathrm{I} 9}$

Hay que tener en cuenta, además, que si el conde Gonzalo Fernández se presentaba como el patriarca fundador de la civitas, los infantes representaban, metonímicamente, a su medio hermano Mudarra, considerado genearca de la poderosa familia de los Lara, como resultado de una doble transferencia temporal y espacial, producida en orden contrario del que en principio cabría esperar, pues, según los datos disponibles, en el siglo XIV se retrotrajo el origen familiar de la casa de Lara a los prestigiosos tiempos fundacionales de Castilla y por atracción, ya en la centuria siguiente, la patria chica de los infantes se desplazó desde Salas a Lara. ${ }^{130}$

Precisamente, el siglo XVI verá establecerse una polémica sobre la cuna y la sepultura de los

Carpentanea / Carpetana / Carpentana, de fundación griega; vid. Lorenzo (2OII).

I28. Como los define Sebastián de Covarrubias, Tesoro de la lengua castellana o española, s. v. "antiguo" (ArellanoZafra 20o6: I77).

I29. Libro de Fernán Gonçález, estrofa 445 (Guil ed. 200I: 294). Véase al respecto Escalona (2000: I58), quien señala, con razón, que el personaje sin duda hacía su aparición en la previa batalla de Lara, pasaje lagunar en el códice único, pues está atestiguado en la prosificación de la Estoria de España alfonsí: "Et fue y muy bieno Gustio Gonçalez con dos sos fijos que tenie y consigo mancebiellos, et fazien muy grand danno en los moros" (Menéndez Pidal ed. r955: 2, 395). No parece, sin embargo, que San Pedro de Arlanza tenga nada que ver con la elaboración ni con la difusión inicial de la leyenda de los infantes, como defiende Escalona (2000: I63-68), según demuestra, entre otras cosas, que ninguna de las crónicas alfonsíes registre sus pretendidas sepulturas arlantinas. Adviértase además que la supuesta fuente lareña que serviría de puente entre la presunta elaboración arlantina de la leyenda y la Crónica de r344 es en realidad una Genealogía del Cid Ruy Díaz Campeador hecha en Cardeña, como ha demostrado Francisco Bautista (20II: esp. $§ \$ 36$ y 49), en parte basada en una refundición del Liber regum realizada en el mismo monasterio, sobre la cual véase Bautista (2OIO).

I30. Véase lo dicho en la nota 87 y, para más detalles, Menéndez Pidal (I896: 432-36), Escalona (2000: I53-63), Bautista (2OII: $§ \S 23^{-29}$ ) y Ferreira (2OII: $§ \S 3^{8-42}$ ). Un buen resumen del hilo argumental histórico y legendario de las disputas entre Lara y Salas en Peña Pérez (2008). Estas cuestiones de apropiación identitaria han llegado hasta nuestros días: "En la sala de sesiones del Ayuntamiento de Lara de los Infantes o de Jurisdicción de Lara, recuerdo haber visto pendientes de sus paredes los retratos pintados de los Infantes de Lara y de los demás personajes de la Leyenda incluso Almanzor y su hija Aaja. Son cuadros de tamaño mediano, pero de pintura moderna, lo más de últimos del siglo XVIII; tengo idea que sustituyeron a los antiguos, según me contaron, y que tienen todos la misma factura y colorido" (Hergueta i934: I6I-62). 
infantes, mientras desde el monasterio de San Pedro de Arlanza se insistía en la reivindicación del vínculo privilegiado con el primer conde de Castilla, que desde antiguo le disputaban San Millán y Silos (cf. Azcárate et al. 2006: 39I-394). Será entonces, hacia I565-7O, cuando se realice la atribución del supuesto "sepulcro de Mudarra" arlantino, en realidad del inicio del siglo XIII (Senra I999: 29), y si en I579 tiene lugar la "invención” de las cabezas de los infantes en la iglesia parroquial de Salas (Menéndez Pidal I896:I93-I94; Senra I999: 28; Escalona 2000: I52), en I580 se establece en el contrato para la construcción de los púlpitos de los refectorios de San Millán de Yuso, que en ellos se esculpan las (supuestas) armas de San Millán, del rey don García y del conde Fernán González, además de las del convento (Arrue 2000: I36), mientras que en i6oo son los cuerpos decapitados de los siete infantes los que se cree haber descubierto en los correspondientes sepulcros de la galería del primitivo cenobio emilianense (Menéndez Pidal ı896: ı80-8ı; Senra ı999: 28). Como ha señalado Escalona, en este contexto de hallazgos y falsificaciones, aunque quizá en fechas algo anteriores, se labran en un sepulcro anónimo del monasterio de San Pedro de Arlanza las armas del linaje de los Velasco, señores de Salas, más un epitafio que los entroncaba histórica, aunque no genealógicamente, con Fernán González (siguiendo el pasaje del Poema citado arriba), puesto que "nadie con aspiraciones postizas serias podía prescindir de entroncar con las tradiciones legendarias de la comarca". ${ }^{\mathrm{I}{ }^{\mathrm{I}}}$

Por lo tanto, la ejecución de las dos inscripciones lareñas en los sillares del hastial de la remozada fábrica de la iglesia parroquial de la Natividad bien puede corresponder a la segunda mitad del siglo XVI, en que nuevamente las aspiraciones de monopolización de la memoria condal volvían a la palestra, y parece constituir la respuesta de la villa de Lara a las pretensiones tanto de los citados monasterios como de la vecina Salas. Por otro lado, su realización debió de coincidir con un momento de cierto esplendor de la localidad, quizá el propiciado por su buena situación geoestratégica en el comercio lanero castellano al ser jalón de la ruta entre las ciudades de Burgos y Soria, ${ }^{132}$ sustanciado con las reformas por las que el templo cambia notablemente su fisonomía, magnificándose, ¿y qué mejor sitio que el hastial exterior occidental del mismo, donde se situaba el único acceso, ya cegada la galería porticada, para proclamar la cuna de los infantes? La actual arquitectura gótica de las cubiertas de la iglesia, con bóvedas estrelladas, parece datarse en un período inmediatamente anterior (siglos XV-XVI) y la inclusión de esos sillares implica un remonte del paramento desde el propio cimiento, no siendo razonable pensar que se incrustaran ex novo sobre un lienzo anterior ni que se realizaran directamente sobre el propio muro ya levantado, puesto que no se aprecia distinto desgaste en el bisel de la inscripción con respecto a la superficie del propio sillar en que se inserta. El propósito de esta doble inscripción fue, obviamente, prestigiar a Lara mediante el procedimiento de subrayar su condición de ciudad (que era la categoría oficial más elevada, por encima de villas y lugares o aldeas) ${ }^{\mathrm{r} 33}$ y de aducir testimonios “antiguos" con los que

I3I. Escalona (2000: I62, n. IO9). Como señala el mismo autor, “los Velasco [...] convertirán Salas en auténtico baluarte de sus dominios en el sur de Castilla, instituyendo en primer lugar un mayorazgo sobre la villa y finalmente, transformando la antigua behetría en señorío solariego" (ibid., I50). Sobre este sepulcro de Velasco, $c f$. también Senra (1999: 29).

I32. Motivación última que impulsa a la ciudad de Burgos a redactar unas ordenanzas en I459 en las que se recuerda y regula el sometimiento de Lara y sus lugares a su señorío, en detrimento del poder que estaban adquiriendo los tenentes del castillo lareño, decididos a suplantarlo, según Juan Antonio Bonachía (I985: 534-35).

I33. En la Edad Media, como se ha visto, el uso de civitas era restringido, pero villa y locus se podían usar para referirse a casi cualquier núcleo de población. En la Edad Moderna, tales denominaciones se conciben como dictados honoríficos jerarquizados y su empleo estaba, al menos teóricamente, sujeto a una atribución de la Corona, como expresa (siguiendo de cerca el citado Tesoro de Covarrubias) el Diccionario de Autoridades: “CIUDAD. s. f. Poblacion de gentes congregadas à vivir en un lugar, sujetas à unas leyes, y à un gobierno, gozando de ciertos privilegios y exenciones, que los señores Reyes se han servido de concederlas según sus servicios. Unas son cabezas de Réino, como 
vincularla a personajes fundacionales, en el contexto de las disputas coetáneas por la apropiación de la memoria de Fernán González y de los infantes de Lara, en especial las comarcales, otorgándole, además y como complemento, un pasado remoto con el recurso al nombre supuestamente latino de Amusina, topónimo cuya función en el epígrafe es obvia, pero cuyo origen sigue siendo un enigma pendiente de resolver.

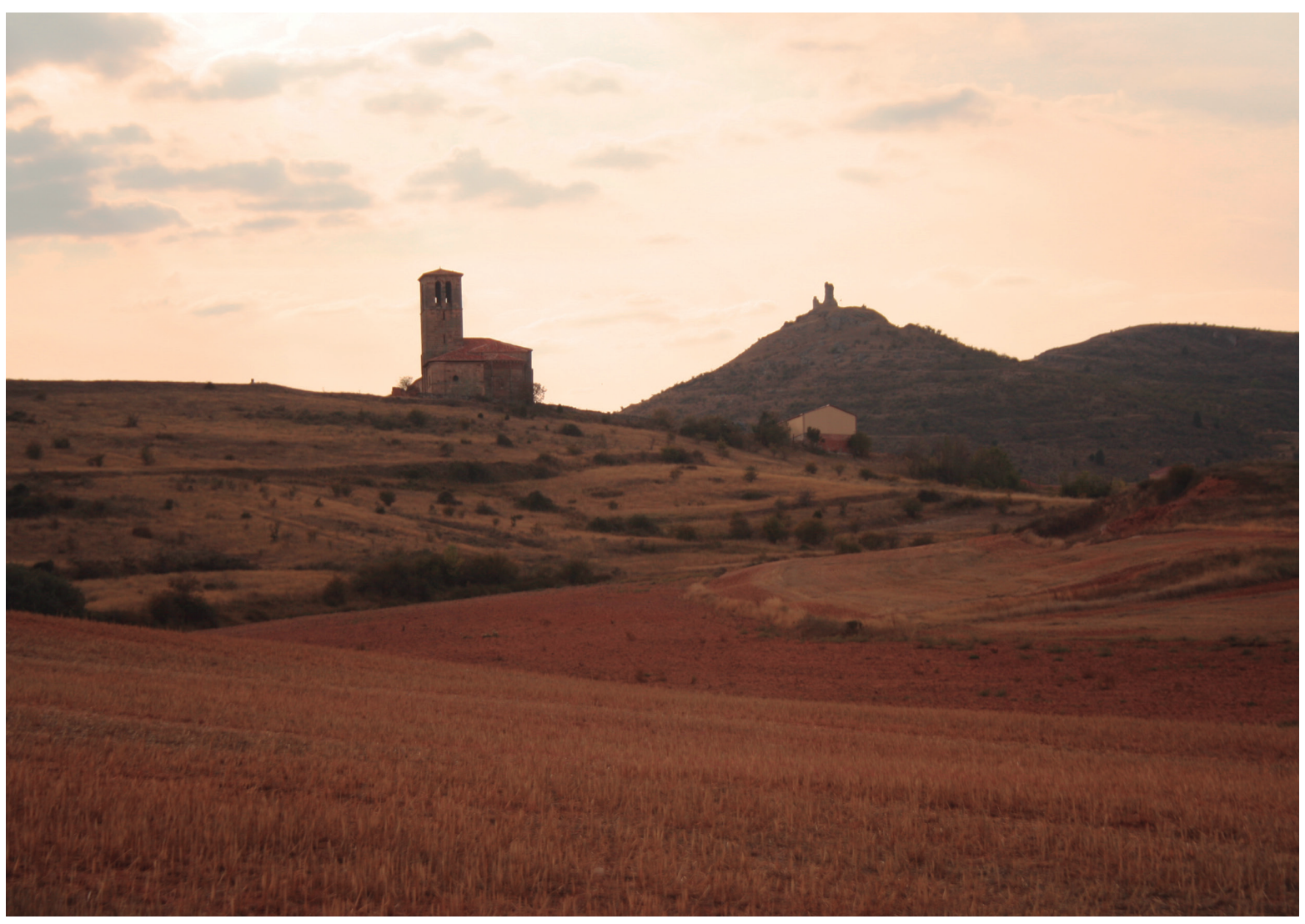

I5. Tierras de Lara, con la iglesia parroquial de la Natividad y las ruinas del castillo al fondo, coronando el Picón de Lara

Esteras, Lorenzo \& Montaner

\section{Conclusiones}

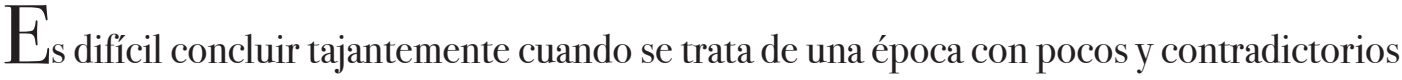
testimonios conservados, a lo que hay que sumar posteriores mistificaciones e intereses contrapuestos de poderosas instituciones que utilizan, entre otras estrategias, la escritura como herramienta de propaganda para legitimar (legalizar, sería más propio) sus intereses, pero también a la voluntad de, al menos, determinados sectores de la población por fijar la memoria histórica colectiva, sin necesidad de apelar a maniobras o manipulaciones deliberadamente propagandísticas. ${ }^{134}$ A partir de la materialidad, contenido y ubicación de tres inscripciones,

Burgos, Tolédo, Leon, Sevilla, \&c. Otras tienen voto en Cortes, como las referidas, y Valladolid, Salamanca, Cuenca, \&c. Viene del Latino Civitas, que significa lo mismo" (Real Academia Española I726-39: 2, 363).

I34. Sobre esta posibilidad de tipo epistémico, a menudo postergada por las interpretaciones en exclusiva clave propagandística, véase Montaner (20I4 y 20I5). 
procedentes, una de la ermita de San Julián y dos de la parroquia de la Natividad de Nuestra Señora, ambos templos en Lara de los Infantes, hemos tratado de inferir líneas de discusión que nos ofrecieran respuestas a tres problemas: la fecha de realización de los epígrafes, la información que ofrecen sobre la cronología de la propia iglesia parroquial donde se insertan dos de ellos, y su aportación a la historia general de la creación e intentos de apropiación de la leyenda de los siete infantes en el contexto regional. De los datos manejados, las conclusiones son las siguientes:

La inscripción proveniente de la ermita de San Julián de Lara de los Infantes conmemora un hecho falso o deformado, pues no hay correspondencia entre los hechos relatados, sus protagonistas y la datación, según el análisis epigráfico e histórico-filológico. En torno a II5O se inscribiría en un sillar una noticia que remite al año 862, pero que no pretende necesariamente hacerse pasar por una pieza coetánea, pues posee un carácter obviamente conmemorativo. El origen de la misma sería un texto analístico o cronístico sin determinar, unido a una tradición local lareña igualmente desconocida, pero seguramente influida por la reescritura de la fundación de Arlanza.

* La gran obra gótica de la nave del templo posiblemente date de I427, año de su reconsagración, coincidente con un momento de esplendor económico y quizá motivada también parcialmente por estrategias familiares de la aristocracia local. Se amplió considerablemente la iglesia románica, que quedó embebida en la gótica que hoy se aprecia. Según la lectura estratigráfica, las dos inscripciones de la parroquia son coetáneas y se labran e insertan en la remozada fábrica parroquial en algún momento entre los siglos XV y XVI (después de I427, por la relación de posterioridad del paramento donde se halla con respecto a la fábrica gótica de la nave, y antes de I6 55, cuando ya Sandoval las encuentra in situ), probablemente en la segunda mitad de este último, añadiendo a la información del epígrafe medieval entonces sito en la ermita nuevos datos que vinculan la fundación de la ciudad a las tradiciones del monasterio de Arlanza.

* El tenor de la nueva inscripción es muy típico de los producidos en los entornos humanistas y publicita la gran antigüedad de Lara, ahora refundada sobre una localidad más antigua por los primitivos condes de Castilla y cuna de los siete infantes. De este modo, la ciudad de Lara se anuda legítimamente a los genearcas de la dinastía condal castellana, tomando como referentes polémicos implícitos las similares pretensiones de los monasterios de San Pedro de Arlanza, Santo Domingo de Silos y San Millán de la Cogolla, así como la política de apropiación de la vecina localidad de Salas, que también se disputaba su memoria. La ampliación parroquial, la obra de más envergadura en fábrica que se ha realizado en los ochocientos años de historia del templo, servirá de marco monumental formidable para la reiterada vindicación identitaria lareña. 


\section{Apéndice. Elementos románicos en la iglesia parroquial de Lara de los Infantes}

Sobre varios de los ámbitos o elementos arquitectónicos del templo románico avanzamos seguidamente una somera descripción de la hipótesis planteada sobre sus características originales y su evolución posterior. ${ }^{135}$

\section{CABeCERA (I Y 2$):{ }^{136}$}

Al exterior, la cabecera se presenta como un cuerpo de sillería perfectamente escuadrada, de igual modo que el conjunto del edificio, si bien cuenta con las lógicas particularidades en su labra, que la diferencian con claridad de otros tramos del templo.

En la actualidad únicamente el costado septentrional del presbiterio es perceptible por su cara externa. Su línea de cornisa actual responde al recrecido barroco de este volumen, como bien lo denotan la propia traza de la misma, y los canecillos de corte románico que todavía hoy se conservan embutidos en el muro, a la altura que apoyaría la línea de cornisa románica de este presbiterio. Esta coincide actualmente con la línea de cornisa románica del ábside del templo, que conserva los canecillos y capiteles que coronan las semicolumnas adosadas que dividen su lienzo en cinco tramos, todo ellos típicos de ese periodo.

Sin embargo, parece deducirse del análisis de la sillería que conforma esta cara externa del ábside que este se recreció en altura, concretamente en tres hiladas, remontándose la línea de cornisa y de canecillos desde su cota original hasta la actual. Ello justificaría el hecho de que en la actualidad el ábside cuente con una sobrecubierta de madera que genera una cámara sobre la bóveda de este espacio, y permitiría que la línea de cornisa original de este ámbito cumpliera los cánones habituales de este estilo, al quedar ligeramente por debajo de la correspondiente románica del presbiterio. De esta última son testigos los mencionados canecillos todavía hoy embutidos en su liso lienzo. El volumen interior del presbiterio es de grandes dimensiones para lo que suele ser habitual, y de proporciones casi cuadrangulares en planta. Presenta arcos ciegos en sus muros norte y sur, siguiendo una tradición habitual del Románico de este territorio, que continúa estando bien presente en numerosos templos sorianos del entorno de San Esteban de Gormaz (Soria). En este caso, estos falsos vanos están confinados por arcos apuntados, de factura más próxima al gótico, aunque se sustentan en semicolumnas bajo capiteles y cimacios que remiten claramente al periodo románico. La propia línea de imposta que corona el cuerpo inferior de los lienzos norte y sur del presbiterio, sobre los citados arcos, presenta un perfil de un tiempo en el que el Románico había quedado desfasado.

Por encima de esta línea de imposta aparece una trasformación sustancial de este espacio presbiteral: lo que a buen seguro debió o pretendió ser una bóveda de cañón apuntado. Levantada seguramente en sillería, pasó en época bar roca a presentarse como una cúpula semiesférica sobre pechinas, aprovechando a la perfección el carácter cuadrangular en planta de este ámbito eclesial, y a su vez se completó sobre los arquillos ya mencionados con sendos arcos ciegos de nuevo, mediante serlianas lisas, esta vez uno por cada uno de los flancos presbiterales, al sur y al norte del mismo.

Siguiendo este juego compositivo barroco, es muy probable que en este mismo momento se sustituyera el arco de gloria original del templo por el actual, cuya altura y desarrollo coinciden con los arcos ciegos descritos y responden a ese mismo estilo. La bóveda de cuarto de esfera en sillería

I35. Hasta ahora contábamos con las plantas de la iglesia realizadas por Palomero (2OO4: I54) y la incluida en Hernando Garrido (2009: 2418).

I36. Los números entre paréntesis remiten a la ilustración 5 . 
que cubre el ábside se adivina tras el retablo mayor de la iglesia, que la oculta parcialmente.

La cabecera en su interior conserva lo que parece fueran las pilastras de apoyo del arco de gloria románico del edificio, sobre las que más que sobradamente se asienta el arco actual.

Por otro lado, en el plano perpendicular a las citadas pilastras y arco, y ya en el comienzo del espacio de la nave, se conservan prácticamente adosadas a ellas sendas pilastras dobles coronadas por capiteles de aspecto gótico. Tras ellas y en toda la altura de la nave, se mantiene la huella de las que pudieran ser sus "retropilastras". Todo ello parece apuntar a lo que pudo ser el arranque de sendas arquerías que fragmentarían en tres el espacio de la nave única actual. Esta responde en la actualidad a la transformación renacentista de la misma, en la que se convirtió en un espacio único por mor del levantamiento de unas nuevas bóvedas nervadas.

\section{NAVE (3):}

Futuros estudios arqueológicos podrán responder a las hipótesis que de la atenta mirada a la cara interior de sus muros se deduce. Bien parece que en origen el templo contara con tres naves, de mayor envergadura la principal que, tras arco de gloria que no ha llegado a nuestros días, se abriría hacia la cabecera hoy conservada. Las laterales contarían con escasos dos metros de anchura y rematarían en sendos absidiolos de planta semicircular (4), que perfectamente trabajados en el espesor de los flancos laterales del muro que separa nave de presbiterio, pueden todavía admirarse tras los restos de los magníficos retablos que los ocultan parcialmente.

Se debe resaltar que naves laterales de esta estrechez no son inusuales en la Península, y este modelo hubo de tener éxito regional, pues se repite en la cercana parroquia de San Millán de Lara, como se apuntó en la nota 73. Hay evidencias para afirmar lo anterior en la parroquia de Lara. En primer lugar, la importante distancia entre las caras interiores de los muros norte y sur de la nave (más de diez metros), es inusual que se cubriera en un solo tramo en el periodo románico en este ámbito geográfico, ni en madera conforme a la tradición más habitual, ni en bóveda de sillería. También da pie para desarrollar este razonamiento la presencia de sendas pilastras de planta cuadrada, que apoyadas y seguramente trabadas en el muro del presbiterio, se perciben por encima de las semicolumnas y capiteles que flanquean el frente del actual arco de acceso al presbiterio desde la nave. Estas pilastras, cubiertas en su traza y posiblemente regularizadas en su acabado por el encalado que las cubre, parecen marcar el encuentro con el muro de separación de nave y presbiterio de las arquerías que definirían las tres naves del templo románico original.

A un momento ligeramente posterior pertenece la portada, en el que comienzan a introducirse formas y modos gotizantes, aunque continúe bien anclada a la tradición decorativa románica. Se abre a los pies de la nave (Iо), en el centro del hastial occidental del templo. Muy probablemente en este momento se reformaría en su totalidad este lienzo, introduciendo a su vez la ventana que hoy abre luces al coro de la iglesia. Es posible que este nuevo acceso, más ceremonial quizás, pudiera convivir durante un tiempo con el original románico abierto en el centro del muro sur de la nave (6), y con mayor seguridad, con la distribución inicial de este espacio en tres naves. ${ }^{137}$

\section{RECINTO PORTICADO PERIMETRAL (7):}

El ámbito perimetral exterior mencionado, cuyo lienzo delimitador al sur correspondería a un

I37. Una cata realizada sobre el enjalbegado arco de ingreso de la portada (a media altura en su mitad septentrional) descubre que este, al menos, está recorrido por una inscripción pintada, subyacente al encalado. La cata descubrió una $Q$, que por morfología, pero a falta de más datos, ha podido hacerse desde el siglo XVI al XVIII. 
Románico ligeramente más evolucionado que el original del templo, parece que pudo constituir una singular variante de lo que en Castilla se dio en llamar galerías porticadas..$^{13^{8}}$ De ellas difiere en la preeminencia del muro ciego frente al vano abierto, y en la discontinuidad en altura tanto de la coronación como de la cota de arranque de los vanos conservados. ${ }^{139}$ Este último hecho, sin poderlo calificar como una excepción ante el tipo más generalizado, no deja de abrigar dudas sobre su origen funcional, que nos hace traer a colación los interrogantes en torno al posible origen monástico de un templo anterior a este, en el mismo lugar, que algunos autores parecen haber esbozado. ${ }^{140}$

I38. Esteras et al. (2009). En la p. I 49 se incluye un gráfico que muestra la “Dispersión geográfica del Románico porticado en el territorio español”. Se apunta también en este trabajo (pp. I57-58) cómo la provincia de Segovia es la que cuenta con mayor número de galerías porticadas románicas conservadas (unas sesenta), seguida de la de Soria (en torno a veinticinco), Guadalajara (diecisiete) y Burgos (once). En un radio de treinta kilómetros en torno a la galería románica porticada aquí tratada, y en la actual provincia de Burgos, cabe citar las de las parroquiales de Jaramillo de la Fuente, Vizcaínos de la Sierra, Pineda de la Sierra, Tinieblas de la Sierra, y la de la ermita de Santa Cecilia en Santibáñez del Val, todas con orientación meridional. No está de más recordar que los siete infantes también unen legendariamente su memoria a otras galerías porticadas románicas (Esteras-Lorenzo 2OI4: 220-23)

I39. Es casi seguro que dicha galería se organizaba a diferentes alturas, siguiendo los desniveles naturales del terreno, algo similar a lo que hemos descubierto en la (también en forma de L) galería porticada de Alcozar (Soria), después de la intervención arqueológica (Yusta et al. 20IO). Encontramos otras galerías románicas en L en las parroquias de San Miguel de Andaluz (Soria), El Salvador (Carabias), La Asunción (Sauca), estas dos en la actual provincia de Guadalajara, y en las segovianas de La Asunción (Duratón), San Juan del Arenal (Orejana), San Pedro Ad Vincula (Perorrubio), El Salvador y Virgen de la Peña (Sepúlveda), San Esteban, San Juan de los Caballeros, San Lorenzo y San Martín (en la capital).

I40. Este (problemático) vínculo monástico que, como se señaló, guarda la memoria oral del pueblo, se documenta por primera vez en un diploma del siglo $\mathrm{X}$, y a él podrían pertenecer los canecillos de rollos, según algunos autores. 


\section{Obras citadas}

Abascal Palazón Juan Manuel; Cebrián, Rosario. 2005. Manuscritos sobre antigüedades de la Real Academia de la Historia (Madrid: RAH)

Abásolo, José Antonio. 1974. Epigrafía romana de la región de Lara de los Infantes (Burgos: Aldecoa)

Abásolo, José Antonio. 1977. 'Las estelas decoradas de la región de Lara de los Infantes: estudio iconográfico’, Boletín del Seminario de Estudios de Arte y Arqueología, 43: 6I-97

Abásolo, José Antonio. 2005. 'Lara de los Infantes, municipum a pesar de la arqueología', in Villes et territoires dans le bassin du Douro à l'époque romaine, ed. by Milagros Navarro Caballero, Juan José Palao Vicente, and M. ángeles Magallón Botaya (Bordeaux: Ausonius Éditions), pp. I25-48

Albertos Firmat, María Lourdes. I980. 'Dos estelas de la región de Lara de los Infantes', Boletín del Seminario de Estudios de Arte y Arqueología, 46: 197-20I

Alva y Astorga, Pedro de. I663. Militia Immaculatae Conceptionis Virginis Mariae, contra malitiam originalis infectionis peccati (Lovanii: typographia Immaculatae Conceptionis, sub signo Gratiae)

Álvarez Borge, Ignacio. 1993. Monarquía feudal y organización territorial: alfoces y merindades en Castilla (siglos X-XIV) (Madrid: CSIC)

[Anónimo]. 1995. 'La ermita de San Julián', El alfoz de Lara, o: I8-26

Aradra Sánchez, Rosa M. 1999. 'La traducción en la teoría retórico-literaria española (I750-I83o)', in La traducción en España (1750-183o): lengua, literatura, cultura, ed. by Francisco Lafarga (Lleida: Universitat de Lleida), pp. I67-76

Arco y Garay, Ricardo del. 1942. Catálogo monumental de España: Huesca (Madrid: Instituto Diego Velázquez, CSIC)

Arco y Garay, Ricardo del. 1954. Sepulcros de la Casa Real de Castilla (Madrid: Instituto Jerónimo Zurita, CSIC)

Arellano, Ignacio; Zafra, Rafael (ed.). 20o6. Sebastián de Covarrubias Tesoro de la lengua castellana o española (I6II) (Madrid: Iberoamericana)

Argaiz, Gregorio de. I675. La soledad laureada por San Benito y sus hijos en las Iglesias de España y teatro monástico de la provincia de Asturias y Cantabria (Madrid: Antonio de Zafra, a costa de Gabriel de León)

Aris, Marc-Aeilko (ed.). 20I5. Die digitalen Monumenta Germaniae Historica (München: Deutsches Institut für Erforschung des Mittelalters) $<$ http://www.mgh.de $>$ [accessed 22-O5-20I6]

Arrue Ugarte, Begoña. 200o. 'Apuntes sobre patronazgo y conservación del patrimonio artístico del monasterio benedictino de San Millán de la Cogolla en La Rioja', in Los monasterios de San Millán de la Cogolla [ = VIJornadas de arte y patrimonio regional. San Millán de la Cogolla, 6, 7 y 8 de noviembre de 1998], ed. by Ignacio Gil-Díez Usandizaga (Logroño: Instituto de Estudios Riojanos), pp. II7-64

Azcárate, Pilar; Escalona, Julio; Jular, Cristina; Larrañaga, Miguel. 20o6. 'Volver a nacer: Historia e identidad en los monasterios de Arlanza, San Millán y Silos (siglos XII-XIII)', Cahiers d'études 
hispaniques médiévales, 29: 359-94

Bautista, Francisco. 20Io. 'Original, versiones e influencia del Liber regum: estudio textual y propuesta de stemma', e-Spania: Revue interdisciplinaire d'études hispaniques médiévales et modernes, 9 <http://e-spania.revues.org/Ig884>

Bautista, Francisco. 20Ir. 'Cardeña, Pedro de Barcelos y la Genealogía del Cid', e-Spania: Revue

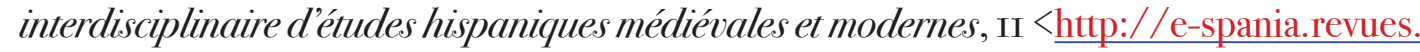
$\underline{\text { org } / 20446>}$

Barbosa Canaes de Figueiredo Castello Branco, José. I853. 'Noticia chronologica dos Condes de Castella', Memorias da Academia Real das Sciencias de Lisboa: Classe de Sciencias Moraes, Politicas e Bellas Lettras, n.s., I.I, sección 'Memorias de socios': I-33

Barrau-Dihigo, L[ouis]. I92I. 'Recherches sur l'histoire politique du royaume asturien (718-9I0)', Revue Hispanique, 52: I-36o

Barroca, Mário Jorge. 2008-9. 'De Miranda do Douro ao Sabugal: arquitectura militar e testemunhos arqueológicos medievais num espaço de frontera', Portugalia, n.s., 29-30: 193-252

Bayerische Akademie (Thesaurusbüro München) et al. (ed.). I900-. Thesaurus Linguae Latinae, IO vols to date (Leipzig: Teubner; München: Saur; Berlin: Walter de Gruyter)

Berganza, Francisco de. I7I9-I72I. Antigüedades de España, propugnadas en las noticias de sus reyes y condes de Castilla la Vieja: en la historia apologética de Rodrigo Díaz de Bivar, dicho el Cid Campeador, y en la corónica del Real Monasterio de San Pedro de Cardeña, 2 vols (Madrid: Francisco del Hierro)

Blázquez Martínez, José María. 1995. 'Arte provincial de la Hispania Romana: estelas de Lara de los Infantes (Burgos)', Latomus: Revue d'études latines, 54·4: 768-83

Bonachía Hernando, Juan Antonio. 1978. El Concejo de Burgos en la Baja Edad Media (1345-1426) (Valladolid: Universidad de Valladolid)

Bonachía Hernando, Juan Antonio. 1985. 'Las relaciones señoriales del Concejo de Burgos con la villa de Lara y su tierra: Las Ordenanzas de I459’, En la España medieval, 6: 52I-44

Burillo Mozota, Francisco. r988. 'Segeda', in Celtíberos, ed. by F. Burillo, J. A. Pérez Casas, and M. L. Sus Jiménez (Zaragoza: Diputación Provincial de Zaragoza), pp. 32-35

Burillo Mozota, Francisco. 2005. Segeda (Mara-Belmonte de Gracián): la ciudad celtibérica que cambió el calendario (Zaragoza: Fundación Segeda)

Campa, Mariano de la (ed.). 2oog. La Estoria de España de Alfonso X: Estudio y edición de la Versión Crítica desde Fruela II hasta la muerte de Fernando II (Málaga: Universidad de Málaga)

Canellas López, Ángel. r979. Diplomática Hispano-Visigoda (Zaragoza: Institución "Fernando el Católico")

Cantera Burgos, Francisco. 1952. Alvar García de Santa María y su familia de conversos: historia de la Judería de Burgos y de sus conversos más egregios (Madrid: Instituto Arias Montano, CSIC)

Cappelli, Adriano. 1979. Lexicon abbreviaturarum = Dizionario di abbreviature latine ed italiane, 6th edn (Milano: Ulrico Hoepli)

Castillo, Belén. 1997. Museo de Burgos: guía breve (Valladolid: Junta de Castilla y León)

Castor de Caunedo, Nicolás. I854. 'Alfonso el Casto', Semanario Pintoresco Español, 6 (5-02-I854): 
$4 \mathrm{I}-45$

Comisión Provincial de Monumentos. 1926-29. Boletín de la Comisión Provincial de Monumentos de Burgos, 2

Caveda y Nava, José. I879. 'Examen crítico de la restauración de la monarquía visigoda en el siglo VIII', Memorias de la Real Academia de la Historia, 9: I-IO9

CLCLT-3 = Corpus Christianorum: Cetedoc Library of Christian Latin Texts [CD-ROM]. 1996. (Turnhout: Brepols)

CODOLGA: vid. López Pereira (20I5)

CODOLCAT: vid. Quetglas (2015)

CORDE: Corpus diacrónico del español (Madrid: Real Academia Española) <http:// corpus.rae.es/

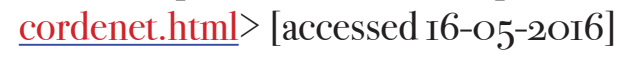

Cruz González, Aniceto de la. I795. Historia de la milagrosa imagen de Ntra. Sra. de las Viñas, Patrona de la Villa de Aranda de Duero (Madrid: Aznar)

De Ruggiero, Ettore. I895-I922. Dizionario epigrafico di antichità romane, 3 vols (Roma: Istituto Italiano per la Storia Antica; L. Pasqualucci)

Dekkers, E.; Fraipont, J. (ed.). 1956. Sancti Aurelii Augustini Enarrationes in Psalmos I-L, Corpus Christianorum Series Latina, 38 (Turnhout: Brepols)

Díaz Ibáñez, Jorge. 2005. 'La incorporación de la nobleza al alto clero en el reino de Castilla durante la Baja Edad Media', Anuario de Estudios Medievales, 35: 557-604 <http://dx.doi. org/IO.3989/aem.2005.v35.i2.I49>

Diego Santos, Francisco. 1994. Inscripciones medievales de Asturias (Oviedo: Principado de Asturias)

Diputación Provincial de Burgos. 1930. Guía ilustrada de la provincia de Burgos ([Burgos]: DPB)

Dorado, Bernardo. [i776]. Compendio histórico de la ciudad de Salamanca, su antigüedad, la de su Santa Iglesia, su fundación y grandezas que la ilustran (Salamanca: Juan Antonio de Lasanta)

Domínguez Sánchez, Santiago. 2008. 'Las fórmulas diplomáticas latinas en epigrafía', Documenta \& Instrumenta, 6: I79-200

Du Cange, Charles du Fresne Sieur, et al. I883-1887. Glossarium mediae et infimae latinitatis, éd. augm., IO vols (L. Favre : Niort)

Durán Gudiol, Antonio. 1967. 'Las inscripciones medievales de la provincia de Huesca', Estudios de Edad Media de la Corona de Aragón, 8: 45-I53

Durán Gudiol, Antonio. 1986. El Hospital de Somport entre Aragón y Bearn (siglos XII y XIII) (Zaragoza: Guara)

Escalona Monge, Julio. 1995. Transformaciones sociales y organización del espacio en el alfoz de Lara en la Alta Edad Media (unpublished tesis, Universidad Complutense de Madrid) < http:// eprints.ucm.es/2447/>

Escalona Monge, Julio. 200o. 'Épica, crónicas y genealogías: En torno a la historicidad de la Leyenda de los infantes de Lara', Cahiers de linguistique hispanique médiévale, 23: 113-76

Escalona Monge, Julio; Azcárate Aguilar-Amat, Pilar. 2OoI. 'Una fuente “casi” perdida para la 
historia de la Castilla medieval: notas en torno al Becerro de San Pedro de Arlanza', Hispania, 6I.208: 449-74 <http://dx.doi.org/IO.3989/hispania.200I.v6I.i208.293>

Escalona Monge, Julio; Azcárate Aguilar-Amat, Pilar; Larrañaga Zulueta, Miguel. 2002. 'De la crítica diplomática a la ideología política: los diplomas fundacionales de San Pedro de Arlanza y la construcción de una identidad para la Castilla medieval', in Actas del VI Congreso Internacional de Historia de la Cultura Escrita, ed. by Carlos Sáez Sánchez and Antonio Castillo Gómez (Alcalá de Henares: Calambur), II, I59-206

Estepa, Carlos. 1978. 'La vida urbana en el norte de la Península Ibérica en los siglos VIII y IX: el significado de los términos civitates y castra', Hispania 38.I39: 257-73

Esteras, José Ángel; Gonzalo, César; Lorenzo, Josemi. 20o9. 'Claustros y galerías porticadas en el Románico de Soria', in Las Edades del Hombre. Paisaje interior: Soria, concatedral de San Pedro, mayo a diciembre de 2009 (Soria: Gráficas Varona, I25-62)

Esteras Martínez, José Ángel; Lorenzo Arribas, Josemi. 2009. 'Elementos románicos repintados: planteamiento de una cuestión incómoda', Ge-conservación: Publicación digital hispano-lusa de conservación y restauración, o: $\mathrm{II}_{7}-3 \mathrm{I}<$ http://tinyurl.com/gqgzc5d $>$

Esteras, José Ángel; Lorenzo, Josemi. 20I4. 'Siete arcos, Siete Infantes: Leyendas en torno al origen de las galerías porticadas románicas', Cahiers d'études hispaniques medievales, 37: 2I5-32

Favreau, Robert. 1999. Épigraphie médiévale (Turnhout : Brepols)

Fernández Conde, Francisco Javier. 1993-94. 'Lugares de culto en Asturias durante la época de transición’, Asturiensia Medievalia, 7: 31-55

Ferreira, M. do Rosário. 2OII. 'A estratégia genealógica de D. Pedro, Conde de Barcelos, e as refundições do Livro de Linhagens', e-Spania: Revue interdisciplinaire d'études hispaniques médiévales et modernes, II $<$ http:/ / e-spania.revues.org/20273>

Fita, Fidel. I894. 'Inscripciones romanas de Lara de los Infantes', Boletín de la Sociedad Española de Excursiones, 2.II: I54-57

Fita, Fidel. I896. 'Lápidas visigóticas de Guadix, Cabra, Vejer, Bailén y Madrid’, Boletín de la Real Academia de la Historia, 28: 403-26

Fita Fidel. r9o7a, ‘De Clunia a Tricio: viaje epigráfico', Boletín de la Real Academia de la Historia, 50: $27 \mathrm{I}^{-} 3 \mathrm{IO}$

Fita Fidel. 1907b, 'Canales de la Sierra: su fuero antiguo', Boletín de la Real Academia de la Historia 50, 316-32.

Fita Fidel. r9o7c, 'Canales de la Sierra: datos inéditos', Boletín de la Real Academia de la Historia 50, 37'-95.

Fita Fidel. I9O7d, 'Un mártir verdadero, siete apócrifos y diez varones ilustres de Canales de la Sierra', Boletín de la Real Academia de la Historia, 50: 396-404

Fita Fidel. rgoze, 'Canales de la Sierra: sus mujeres y varones ilustres en los siglos XI y XII', Boletín de la Real Academia de la Historia, 50: 47 I-84

Flórez, Enrique. I77 I. El estado antiguo de las iglesias de Auca, de Valpuesta, y de Burgos, España Sagrada, 26 (Madrid: Pedro Marín)

Flórez, Enrique. I772. Las iglesias colegiales, monasterios y santos de la diócesi de Burgos, 
conventos, parroquias y hospitales de la ciudad, España Sagrada, 27 (Madrid: Antonio de Sancha) [2nd edn Madrid: José del Collado, I824]

Fort, Carlos Ramón. I879. Tratado de los obispos españoles titulares de iglesias in partibus infidelium o auxiliares en las de España, ed. by Vicente de la Fuente, España Sagrada, $5^{\mathrm{I}}$ (Madrid: José Rodríguez)

Francisco Olmos, José María de. 2004. Los usos cronológicos en la documentación epigráfica de la Europa occidental en las épocas antigua y medieval, 2nd edn (Madrid: Castellum)

García Cubero, Luis. 1992. Bibliografía heráldico-genealógico-nobiliaria de la Biblioteca Nacional (Manuscritos) (Madrid: Biblioteca Nacional)

García González, Juan José. 20o8. 'Formación, expansión y consolidación de Castilla', in Historia de Castilla: de Atapuerca a Fuensaldaña, ed. by Juan José García González (Madrid: Esfera de los Libros), pp. 2I-30O

García González, Juan José; Peterson, David; García Izquierdo, Iván; García Aragón, Lucía. 20IO. 'Introducción al conocimiento de la viaria romana de la cuenca del Duero a través de la documentación altomedieval', in Las técnicas en la ingeniería romana: V Congreso de las obras públicas romanas ([Madrid]: Fundación de la Ingeniería Técnica de Obras Públicas), pp. 135-63

García Lobo, Vicente. 1982. Las inscripciones de San Miguel de Escalada: estudio crítico (Barcelona: El Albir)

García Morilla, Alejandro. 20I2. 'La escritura visigótica publicitaria en la provincia de Burgos', Espacio, Tiempo y Forma, Serie III: Historia Medieval, 25: 199-238

García Morilla, Alejandro. 20I3. Las inscripciones medievales de la provincia de Burgos: siglos VIII-XIII (unpublished thesis, Universidad Complutense de Madrid) <http://eprints.ucm. $\underline{\mathrm{es} / 2 \mathrm{I} 465 / \mathrm{I} / \mathrm{T}_{34} 473 \cdot \mathrm{pdf}>}$

García Omedes, Antonio. 2002-I6. Románico aragonés: La guía digital del arte románico (Huesca: El Autor) http://www.romanicoaragones.com/ [accessed I5-O5-2OI6]

Gimeno, H.; Mayer, M. r993. 'Una propuesta de identificación epigráfica: Lara de los Infantes / Noua Augusta', Chiron, 23: 313-2I

Gil, Juan; Moralejo, José L.; Ruiz de la Peña, Juan I. (ed.). 1985. Crónicas Asturianas: Crónica de Alfonso III (Rotensey "A Sebastián"), Crónica Albeldense (y "Profética") (Oviedo: Universidad de Oviedo)

Glare, P.G.W. (ed.). 1996. Oxford Latin Dictionary (Oxford: Clarendon Press)

Godoy Alcántara, José. I868. Historia crítica de los falsos cronicones (Madrid: M. Rivadeneyra)

González op, Carmen. I993. Real monasterio de Santo Domingo de Caleruega: fundación de Alfonso X el Sabio, Monumenta Historica Iberoamericana de la Orden de Predicadores, I (Salamanca: Ed. San Esteban)

González Dávila, Gil. I645-50. Teatro eclesiástico de las iglesias metropolitanas y catedrales de los Reynos de las dos Castillas: Vidas de sus arzobispos, y Obispos, y cosas memorables de sus Sedes, 3 vols (Madrid: Francisco Martinez, Pedro de Horma y Villanueva, Diego Daz de la Carrera)

González Díez, Emiliano; Martínez Llorente, Félix. 1992. Fueros y cartas pueblas de Castilla y León: el derecho de un pueblo (Salamanca: Junta de Castilla y León) 
Guil, Itziar (ed.). 200I. Libro de Fernán Gonçález (Madrid: Instituto de la Lengua Española, CSIC)

Gutiérrez Álvarez, Manuel. 1997. Corpus inscriptionum Hispaniae mediaevalium, I/ı: Zamora. Colección epigráfica (Tunhout: Brepols; León: Universidad de León)

Hergueta y Marín, Domingo. 1934. Folklore burgalés (Burgos: Diputación Provincial de Burgos)

Hernando Garrido, José Luis. 2009. 'Lara de los Infantes. Iglesia de la Natividad de Nuestra Señora’, in Enciclopedia del Románico en Castilla y León: Burgos, ed. by M.Á. García Guinea, and J.M. Pérez González (Aguilar de Campoo: Fundación Santa María la Real; Centro de Estudios del Románico), IV, 2415-25

Hernando Garrido, José Luis; Martín Montes, Miguel Angel; Moreda Blanco, Francisco Javier. I995-96. 'Un tímpano con una inscripción inédita de cronología románica en Villavés (Burgos)', Acta Historica et Archaeologica Mediaevalia, I6-I7: 235-43

Hoyos OP, Manuel María de los. 1966-68. Registro historial de la provincia de España, 3 vols (Madrid: OPE)

Hübner, Ernst Willibald Emil. I87r. Inscriptiones Hispaniae Christianae (Berolini: Georgium Reimerum)

Hübner, Ernst Willibald Emil. I9oo. Inscriptionum Hispaniae Christianarum supplementum (Berolini: Georgium Reimerium)

Huidobro Serna, Luciano. 1928. 'El arte visigótico y de la Reconquista en Castilla: nuevos descubrimientos', Boletín de la Comisión Provincial de Monumentos Históricos y Artísticos de Burgos, 7.25: $365^{-6} 6$

Huidobro Serna, Luciano. I927. 'Ermita de Santa María en Quintanilla de las Viñas', Boletín de la Comisión Provincial de Monumentos Históricos y Artísticos de Burgos, 6.21: 24I

Huidobro Serna, Luciano. I928. 'Ermita de Santa María en Quintanilla de las Viñas (Continuación)', Boletín de la Comisión Provincial de Monumentos Históricos y Artísticos de Burgos, 7.22: 268

Janáriz, Damián. 1924. Historia y novena de la Virgen de las Viñas, patrona de Aranda de Duero (Aranda de Duero: Pedro Díaz Bayo)

Juez, Víctores. I796. 'Lara. Cabeza de Arciprestazgo y Vicaría', in Diccionario geográfico de España: Burgos, ed. by Tomás López (Madrid: Biblioteca Nacional de España), MSS/ 7296, ff. $234 \mathrm{r}-242 \mathrm{r}$

Justel, Pablo (ed.). 20I3-I4. Les sept infants de Lara: l'histoire face à la légende, monográfico de Cahiers d'études hispaniques medievales, 36 -37

Klopsch, Paul. 1972. Einführung in die mittellateinische Verslehre (Darmstadt: Wissenschaftliche Buchgesellschaft)

Ladero Quesada, Miguel Ángel. 2006. 'Fray Gonzalo de Arredondo, cronista de Enrique III, Juan II y Enrique IV de Castilla: texto inédito', Medievalismo, I6: 27I-88

Laureys, Marc (ed.). 1995. Ioannes Cavallinus de Cerronibus = Giovanni Cavallini dei Cerroni Polistoria de virtutibus et dotibus Romanorum (Stuttgart: Teubner)

López, Juan. I6I3. Tercera parte de la historia general de Santo Domingo y de su Orden de Predicadores, 2 t. in I vol (Valladolid: Francisco Fernández de Córdova) 
López Pereira, J. Eduardo (ed.). 20I5. Corpus Documentale Latinum Gallaeciae $<$ http://corpus. cirp.es/codolga $>$ [accessed 22-05-20I6]

Lorenzo Arribas, Josemi. 20o9. 'Canecillo de San Miguel', in Las Edades del Hombre. Paisaje interior: Soria, concatedral de San Pedro, mayo a diciembre de 2009 (Soria: Gráficas Varona), pp. $57^{6-78}$

Lorenzo Arribas, Josemi. 20II. 'Mantua Carpetanea', in Gran Enciclopedia Cervantina, ed. by Carlos Alvar (Alcalá de Henares: Centro de Estudios Cervantinos), vIII, 7537-39

Mangas, Julio; Cortina, I. 198I. 'Nueva inscripción romana de Lara de los Infantes', Memorias de Historia Antigua, 5: 269-7I

Manzanares Rodríguez, Joaquín. I95I. 'Contribución a la epigrafía asturiana', Archivum: Revista de la Facultad de Filología, ,: 95-12 I

Marín Pina, M. Carmen (ed.). 1998. Primaleón (1512) (Alcalá de Henares: Centro de Estudios Cervantinos)

Martí Bonet, José M. (ed.). 20II. Guía de los archivos de la Iglesia en España [CD-Rom] Instrumentos informáticos de consulta de los archivos de la Iglesia en España, I (Barcelona: Archivo Diocesano de Barcelona para la Asociación de Archiveros de la Iglesia en España)

Martin, Georges. 1992. Les juges de Castille: Mentalités et discours historique dans l'Espagne médiévale (Paris: Klincksieck)

Martín, J. C. 2009. 'Los Annales Castellani Antiquiores y Annales Castellani Recentiores: edicion y traduccion anotada', Territorio, Sociedad y Poder, 4: 203-26

Martín Viso, Iñaki. 20oo. Poblamiento y estructuras sociales en el norte de la Península Ibérica: siglos VI-XIII (Salamanca: Universidad de Salamanca)

Martínez Ariz-Navarreta, Gerónimo (ed.). 1934. Antonio Zapata Historia de la villa de Canales: escrita en el año 1657 (Buenos Aires: Amorrortu)

Martínez Diez, Gonzalo. I997. 'El monasterio de San Millán y sus monasterios filiales:

Documentación emilianense y diplomas apócrifos', Brocar, 2I: 7-53

Martínez Diez, Gonzalo (ed.). 1998. Colección documental del Monasterio de San Pedro de Cardeña (Burgos: Caja de Ahorros del Círculo Católico; Monasterio de San Pedro de Cardeña)

Martínez Diez, Gonzalo. 2004. 'Tres anales burgaleses medievales', Boletín de la Institución Fernán González, 229: 227-63

Martínez Diez, Gonzalo. 2005. El condado de Castilla (711-1038): La historia frente a la leyenda, 2 vols (Valladolid: Junta de Castilla y León)

Martínez Diez, Gonzalo. 20o8. 'Sepulcros y memorias funerarias en Cardeña’, Boletín de la Institución Fernán González, 87: 133-60

Martínez Diez, Gonzalo. 20I4. 'El Cantar de los siete infantes de Lara: la historia y la leyenda', Cahiers d'études hispaniques medievales, 37: I7I-89

Martínez Tejera, A. M. I996. 'Dedicaciones, consagraciones y monumenta consecrationis (ss. VIXII): testimonios epigráficos altomedievales en los antiguos reinos de Asturias y León’, Brigecio: Revista de Estudios de Benavente y sus Tierras, 6: 77-IO2

Masdeu, Juan Francisco de. I783-I805. Historia crítica de España y de la cultura española, 20 vols 
(Madrid: Antonio de Sancha)

Massaro, Matteo. 1984. 'Carmina latina epigraphica', in Enciclopedia Virgiliana, (Roma: Istituto della Enciclopedia Italiana), I, 669-7I

Mayans y Siscar, Gregorio. I757. Rhetorica, 2 vols (Valencia: Herederos de Jerónimo Conejos)

Méndez, Francisco. i78o. Noticias sobre la vida y escritos del Rmo. P. Mro. Fr. Henrique Florez (Madrid: Pedro Marín)

Menéndez Pidal, Ramón. I896. La leyenda de los infantes de Lara (Madrid: Hijos de José M. Ducazal) [3rd reprint add Madrid: Espasa-Calpe, I97I]

Menéndez Pidal, Ramón (ed.). 1955. Primera Crónica General de España, rev. edn (Madrid: Gredos)

Meyer-Lübke, Wilhelm. 1935. Romanisches etymologisches Wörterbuch, 3rd edn rev. (Heidelberg, Carl Winter)

MGH: vid. Aeilko (ed. 20I5)

Migne, Jacques-Paul (ed.). 1844-82. Patrologice cursus completus: Series Latina prior, in qua prodeunt patres, doctores scriptoresque Ecclesice Latince, 22I vols (Paris: the author; Garnier)

Ministerio de Cultura. 1982. 'Real Decreto 2026/1982, de 25 de junio por el que se declara monumento histórico-artístico, de carácter nacional, la iglesia parroquial en Lara de los Infantes (Burgos)', Boletín Oficial del Estado, 200: 22626

Ministerio de Instrucción Pública y Bellas Artes. I93I. 'Decreto [de 3 de junio de I93I]', Gaceta de Madrid, I55: II8I-85

Monsalvo Antón, José M. 2005. 'Espacios y fronteras en el discurso territorial del reino de Asturias (del Cantábrico al Duero en las Crónicas asturianas)', Studia Historica: Historia medieval, 23: $43-87$

Monsalvo Antón, José M. 2007. 'Territorialidad regia y sistemas concejiles en la zona de Montes de Oca y Rioja Alta (siglos XI al XIV): de los alfoces al realengo concejil de las villas', Brocar, 3I: $236-40$

Montaner, Alberto. 2009. 'El proyecto historiográfico del Archetypum Naiarense', e-Spania: Revue interdisciplinaire d'études hispaniques médiévales et modernes, $7<\underline{\text { http://espania.revues.org/ }}$ indexı80 $75 \cdot \mathrm{html}>$

Montaner, Alberto. 20II. 'L'intégration des emprunts arabes en latin médiévale (d'après la documentation léonaise)', in Influencias léxicas de otras lenguas en el latin medieval = Influences lexicales d'autres langues sur le latin médiéval, ed. by Maurilio Pérez González, and Estrella Pérez Rodríguez (León: Universidad de León; Valladolid: Universidad de Valladolid), pp. I37-I6o

Montaner, Alberto. 20I4. 'Historicidad medieval y protomoderna: lo auténtico sobre lo verídico', e-Spania: Revue interdisciplinaire d'études hispaniques médiévales et modernes, I9 $<$ http:/ / spania.revues.org/24054>

Montaner, Alberto. 2015. 'Épica, historia, historificación', in El Poema de mio Cid y la épica medieval castellana: Nuevas aproximaciones críticas, ed. by Juan-Carlos Conde \& Amaranta Saguar, (London: Queen Mary University of London), pp. I7-53

[Noguera Ramon, Vicente]. I787. 'Ensayo cronológico de los reynados de los soberanos que dominaron en España desde la invasión de los Árabes hasta D. Fernando I', in Historia general 
de España que escribió el padre Juan de Mariana, ilustrada en nesta nueva impresión de tablas cronológicas, notas y observaciones crtíticas (Valencia: Benito Monfort), III, 393-5I3

Núñez Hernández, Sarah; Curchin, Leonard A. 2005. 'Corpus des Villes', in Villes et territoires dans le bassin du Douro à l'époque romaine, ed. by Milagros Navarro Caballero, Juan José Palao Vicente, and M. Ángeles Magallón Botaya (Bordeaux : Ausonius Éditions), pp. 432-6I2

Oliver, José Manuel. 1995. 'Los matrimonios de José Pellicer: noticias de su vida familiar y descendencia’, Criticón, 63: 47-88

Oroz Reta, José; Marcos Casquero, Manuel Antonio (ed.). 1993-94. Isidoro de Sevilla Etimologías, 2nd edn, 2 vols (Madrid: Biblioteca de Autores Cristianos)

Ortiz y Sanz, José. I795-I803. Compendio cronológico de la historia de España desde los tiempos más antiguos hasta nuestros días, 7 vols (Madrid: Imprenta Real)

Ortiz y Sanz, José. I04I-42. Compendio cronológico de la historia de España desde los tiempos más antiguos hasta nuestros días, 2nd edn with appendix up to I843, 9 vols (Madrid: Fuentenebro)

Palomero, Félix. 2004. 'El lenguaje románico en la Sierra de la Demanda', in Arte medieval en La Rioja. Prerrománico y románico [= VIII Jornadas de Arte y Patrimonio Regional, Logroño, 29 y зo de noviembre de 2002], ed. by Ignacio Gil-Díez Usandizaga (Logroño: Instituto de Estudios Riojanos), pp. Io9-2IO

Palomero Aragón, Félix; Reyes Téllez, Francisco; Escalona Monge, Julio. 1996-97. 'El monasterio de San Millán de Lara (Burgos): notas para el replanteamiento de su trayectoria evolutiva en los siglos X-XII', Annals de l'Institut d'Estudis Gironins, 30: I36I-82

Pascual Barea, Joaquín (ed.). 20oo. Rodrigo Caro Poesía castellana y latina e inscripciones originales (Sevilla: Diputación de Sevilla)

Pellicer de Ossau y Tovar, José. I68I. Annales de la Monarquía de España después de su pérdida, ed. by Miguel Pellicer de Ossau y Tovar (Madrid: Francisco Sanz)

Peña Pérez, F. Javier. 2008. 'A orillas del Duero hace mil años: leyendas de frontera', Biblioteca. Estudio e Investigación, 23: 345-56

Pérez de Urbel, Justo. 1925. 'Epigrafía burgalesa', Boletín de la Real Academia de la Historia, 87: $87-95$

Pérez de Urbel, Justo. 1945. Historia del Condado de Castilla, 3 vols (Madrid: Escuela de Estudios Medievales, CSIC)

Pérez de Urbel, Justo (ed.). 1952. Sampiro, su crónica y la monarquía leonesa en el siglo X (Madrid: Escuela de Estudios Medievales, CSIC)

Pérez-Prendes, José Manuel. I984. Curso de historia del derecho español: Volumen primero, parte general (Madrid: Universidad Complutense)

Pérez González, Maurilio. 20o8. 'El latín medieval diplomático’, Bulletin du Cange = Archivum Latinitatis Medii Aevi, 66: 47-IOI

Pérez González, Maurilio (ed.). 20Io. Lexicon Latinitatis Medï Aevi Regni Legionis (s. VIII-123o) Imperfectum (Turnhout: Brepols)

PL: vid. Migne (ed. I844-82)

Quetglas Nicolau, Pere J. (ed.). 20I5. Corpus Documentale Latinum Cataloniae, version 4.0 


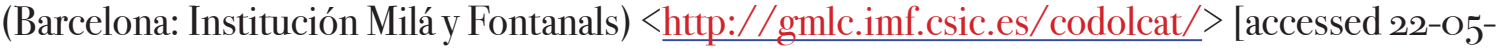
2OI6]

Real Academia Española. I726-39. Diccionario [de Autoridades] de la Lengua Castellana, 6 vols (Madrid: Francisco del Hierro)

Redondo Veintemillas, Guillermo; Morte García, Carmen (ed.). 1996. Jerónimo de Blancas - Martín Carrillo - Diego José Dormer Inscripciones latinas a los retratos de los reyes de Sobrarbe, Condes antiguos, y Reyes de Aragon, puestos en la Sala Real de la Diputación de la Ciudad de Zaragoça (Zaragoza: Cortes de Aragón) [ist edn i68o]

Reichert, Bendictus Maria (ed.). I9oo. Acta Capitulorum generalium Ordinis Praedicatorum vol. III ab anno 1380 usque ad annum 1498, Monumenta Ordinis Fratrum Praedicatorum Historica, 8 (Romae: In Domo Generalia, ex Typographia Polyglotta S. C. de Propaganda Fide; StuttgardiaeVindobonae: Jos. Roth)

Rey, Alfonso. 2003. 'Notas a la edición de la poesía moral de Quevedo (I)', La Perinola, 7ः 439-45

Rico, Francisco. 1984. Alfonso el Sabio y la "General estoria", 2nd edn (Barcelona: Ariel)

Rico Damps, Daniel. 2009. 'Arquitectura y epigrafía en la Antigüedad Tardía: testimonios hispanos', Pyrenae: Revista de Prehistòria i Antiguitat de la Mediterrània Occidental, 40.I: 7-53

Risco, Manuel. I786. Memorias de la Santa Iglesia esenta de León, concernientes a los siglos XI, XII y XIII, España Sagrada, 35 (Madrid: Pedro Marín)

Rodríguez Montañés, José Manuel. 2009. 'San Millán de Lara’, in Enciclopedia del Románico en Castilla y León: Burgos, ed. by M. Á. García Guinea, J. M. Pérez González (Aguilar de Campoo: Fundación Santa María la Real; Centro de Estudios del Románico), IV, 25I7-30

Rodríguez Suárez, M. del Pilar; Vaquero Bertomeu, Mercedes. 2005. 'De epigrafía medieval lucense: la colección del Museo Provincial', Boletín do Museo Provincial de Lugo, I2: Io9-22

Rodríguez Villa, Antonio. 2005. Catálogo general de manuscritos de la Real Academia de la Historia (1910 - 1912), digital ed. by Juan Manuel Abascal (Madrid: RAH) <http://tinyurl.com/ jkzoxf3> [accessed 23-05-20I6]

Salazar y Castro, Luis de. I696-I697. Historia Genealógica de la Casa de Lara justificada con instrumentos, y escritores de inviolable fe, 3 vols (Madrid: Imprenta Real por Mateo de Llanos y Guzmán)

Sánchez Ameijeiras, Rocío. 2005. 'The Eventful Life of the Royal Tombs of San Isidoro in León', Church, State, Vellum, and Stone: Essays on Medieval Spain in Honor of John Williams, ed. by Thérèse Martin, and Julie A. Harris (Leiden: Brill), pp. 479-520

Sandoval, Prudencio de. I6I5. Historias de Idacio Obispo, que escrivio poco antes que España se perdiese. De Isidoro Obispo de Badajoz [...]. De Sebastiano Obispo de Salamanca [...]. De Sampiro Obispo de Astorga [...]. De Pelagio Obispo de Ouiedo [...]. Nunca hasta agora impressas, con otras notas tocantes a estas historias y reyes dellas (Pamplona: Nicolas de Assiayn) [2nd edn Zaragoza: a costa de Pedro Escuer, I634]

Santiago Fernández, Javier de. 2002. 'Las inscripciones medievales: Documentos al servicio del poder político y religioso', in IJornadas sobre Documentación jurídico-administrativa, económico-financiera y judicial del reino castellano-leonés (siglos X-XIII), ed. by Ángel Riesco Terrero (Madrid: Dpto. de Ciencias y Técnicas Historiográficas, Universidad Complutense), pp. 
93-II8

Santiago Fernández, Javier de. 2008. 'El hábito epigráfico en la Hispania visigoda', in VIII Jornadas Científicas sobre Documentación de la Hispania altomedieval (siglos VI-X), ed. by Juan Carlos Galende Díaz, and Javier de Santiago Fernández (Madrid: Universidad Complutense), pp. 29I-344

Scalia, G. (ed.). 1998-99. Salimbene de Adam = Salimbene degli Adami Chronica, Corpus Christianorum Continuatio Mediaevalis, I25 \& I25A, 2 vols (Turnhout: Brepols)

Seel, Otto (ed.). I985. M. Iuniani Iustini epitoma Historiarum Philippicarum Pompei Trogi, Bibliotheca Scriptorum Graecorum et Romanorum Teubneriana (Stuttgart: Teubner)

Senra Gabriel y Galán, José Luis. 1999. 'La escultura románica y sus problemas de interpretación: el llamado sepulcro "de Mudarra" procedente del Monasterio de San Pedro de Arlanza', Archivo Español de Arte, 72.285: 25-38 <http://dx.doi.org/IO.3989/aearte.I999.v72.i285.734>

Senra Gabriel y Galán, José Luis. 2006. 'Mutatis mutandis: creaciones apócrifas en el monasterio de San Pedro de Arlanza (Burgos)', Cahiers d'études hispaniques médiévales, 29: 23-43

Senra Gabriel y Galán, José Luis. 20I2. 'Entre la santidad y la epopeya: rastreando el desaparecido claustro románico del monasterio de San Salvador de Oña', in Oña, un Milenio: Actas del Congreso Internacional sobre el monasterio de Oña (1011-2011), ed. by Rafael Sánchez Domingo (Oña: Fundación Milenario San Salvador de Oña), pp. 398-42I

Sepúlveda González, M. de los Ángeles. I986. 'Los anagramas y el programa iconográfico de Quintanilla de las Viñas: una hipótesis de interpretación’, En la España Medieval, 5: 12I7-48

Serrano, Luciano (ed.). 1925. Cartulario de San Pedro de Arlanza, antiguo monasterio benedictino (Madrid: Centro de Estudios Históricos)

Serrano, Luciano (ed.). I93o. Cartulario de San Millán de la Cogolla (Madrid: Centro de Estudios Históricos)

Serrano, Luciano. 1935. El obispado de Burgos y Castilla primitiva desde el siglo V al XIII, 3 vols (Madrid: Instituto de Valencia de Don Juan)

Smith, Colin. 1982. 'Leyendas de Cardeña', Boletín de la Real Academia de la Historia, I79: 485-523

Sota, Francisco. I68I. Chronica de los principes de Asturias, y Cantabria (Madrid: Juan García Infanzón)

Suárez González, Ana. 2003. ‘Del pergamino a la piedra? ¿de la piedra al pergamino? (entre diplomas, obituarios y epitafios medievales)', Anuario de Estudios Medievales, 33.I: 365-4I5 $<$ http://dx.doi.org/IO.3989/aem.2O03.v33.iI.205>

TLL: vid. Bayerische Akademie (ed. I9oo-)

Vaquero, Mercedes (ed.). 1987. Vida rimada de Fernán González (Exeter: University of Exeter)

Vossius, Johann Gerhard. I647. Rhetorices contractae sive partitiones oratoriarum libri quinque, 4th edn (Brusnvigae: Chistophorum Fridericum Zilligerum)

Yusta, José Francisco; Diestro, Francisca; Gonzalo, César; Esteras, José Ángel; Lorenzo, Josemi. 2010. 'Estrategia de actuación ante una ruina románica: la ermita de la Virgen del Vallejo en Alcozar (Soria)', in VI Congreso Internacional 'Restaurar la memoria': La gestión del Patrimonio hacia un planteamiento sostenible [= AR\&PA, 31 octubre-2 noviembre de 2008, Valladolid], ed. by 
J. J. Rivera Blanco (Salamanca: Junta de Castilla y León), II, 45-50

Zabalza Duque, Manuel. 1998. Colección diplomática de los Condes de Castilla: edición y comentario de los documentos de los condes Fernán González, García Fernández, Sancho García y García Sánchez (Salamanca: Junta de Castilla y León)

Zaragoza i Pascual, Ernest. 1998. 'La fundación del monasterio benedictino de Ntra. Sra. de la Misericordia de Frómista (I437)’, Publicaciones de la Institución Tello Téllez de Meneses, 69: 87$\mathrm{I} 2 \mathrm{O}$ 